\title{
Steroid Transport, Local Synthesis, and Signaling within the Brain: Roles in Neurogenesis, Neuroprotection, and Sexual Behaviors
}

\author{
Nicolas Diotel ${ }^{1 *}$, Thierry D. Charlier ${ }^{2}$, Christian Lefebvre d'Hellencourt ${ }^{1}$, David Couret ${ }^{1,3}$, \\ Vance L. Trudeau ${ }^{4}$, Joel C. Nicolau ${ }^{2}$, Olivier Meilhac ${ }^{1,3}$, Olivier Kah ${ }^{2}$ and \\ Elisabeth Pellegrini ${ }^{2 *}$ \\ 1 Université de La Réunion, Institut National de la Santé et de la Recherche Médicale, UMR 1188, Diabète athérothrombose \\ Thérapies Réunion Océan Indien, Saint-Denis de La Réunion, France, ${ }^{2}$ Univ Rennes, Inserm, EHESP, Irset (Institut de \\ recherche en santé, environnement et travail) - UMR_S 1085, Rennes, France, ${ }^{3} \mathrm{CHU}$ de La Réunion, Saint-Denis, France, \\ ${ }^{4}$ Department of Biology, University of Ottawa, Ottawa, ON, Canada
}

\section{OPEN ACCESS}

Edited by:

Julie A. Chowen,

Hospital Infantil Universitario Niño Jesús, Spain

Reviewed by: Christina Dalla,

National and Kapodistrian University

of Athens, Greece

Tatsushi Onaka,

Jichi Medical University, Japan

*Correspondence:

Nicolas Diotel

nicolas.diote/@univ-reunion.fr

Elisabeth Pellegrini

elisabeth.pellegrini@univ-rennes1.fr

Specialty section:

This article was submitted to

Neuroendocrine Science,

a section of the journal

Frontiers in Neuroscience

Received: 01 December 2017

Accepted: 02 February 2018

Published: 20 February 2018

Citation:

Diotel N, Charlier TD, Lefebvre d'Hellencourt $C$, Couret $D$,

Trudeau VL, Nicolau JC, Meilhac O, Kah $O$ and Pellegrini E (2018) Steroid

Transport, Local Synthesis, and

Signaling within the Brain: Roles in

Neurogenesis, Neuroprotection, and

Sexual Behaviors.

Front. Neurosci. 12:84.

doi: 10.3389/fnins.2018.00084
Sex steroid hormones are synthesized from cholesterol and exert pleiotropic effects notably in the central nervous system. Pioneering studies from Baulieu and colleagues have suggested that steroids are also locally-synthesized in the brain. Such steroids, called neurosteroids, can rapidly modulate neuronal excitability and functions, brain plasticity, and behavior. Accumulating data obtained on a wide variety of species demonstrate that neurosteroidogenesis is an evolutionary conserved feature across fish, birds, and mammals. In this review, we will first document neurosteroidogenesis and steroid signaling for estrogens, progestagens, and androgens in the brain of teleost fish, birds, and mammals. We will next consider the effects of sex steroids in homeostatic and regenerative neurogenesis, in neuroprotection, and in sexual behaviors. In a last part, we will discuss the transport of steroids and lipoproteins from the periphery within the brain (and vice-versa) and document their effects on the blood-brain barrier (BBB) permeability and on neuroprotection. We will emphasize the potential interaction between lipoproteins and sex steroids, addressing the beneficial effects of steroids and lipoproteins, particularly HDL-cholesterol, against the breakdown of the BBB reported to occur during brain ischemic stroke. We will consequently highlight the potential anti-inflammatory, anti-oxidant, and neuroprotective properties of sex steroid and lipoproteins, these latest improving cholesterol and steroid ester transport within the brain after insults.

Keywords: aromatase, cholesterol, blood-brain barrier, estrogens, HDL, lipoproteins, stroke, progestins

\section{INTRODUCTION}

Steroid hormones display important physiological functions and exert pleiotropic effects on many target organs including among others the gonads, the liver, and the nervous system. Neurosteroids are produced in the central nervous system (CNS), either via de novo synthesis from cholesterol or from local metabolism of steroid intermediate produced in the periphery. The shift from systemic to local synthesis and regulation of steroid action within target tissues, such as the brain, was referred to "Balkanization" of the endocrine system, and could allow the 
tissue to autonomously synthesize and modulate local steroid signaling (Schmidt et al., 2008). Neurosteroids and peripherally produced steroids have pleiotropic effects and can modulate both brain homeostasis and cerebral functions. The aim of the present review is to summarize the current knowledge regarding the activity and the expression of the steroidogenic enzymes and the targets of steroids, produced in the periphery as well as locally in the brain. We will further consider the roles of androgens, estrogens, and progestagens on physiology and behavior, focusing our discussion on constitutive and regenerative neurogenesis, notably in stroke conditions, as well as the impact of these locally-produced sex steroids on sexual behavior. These points will be discussed from studies performed in fish, birds, and mammals from a comparative point of view. Furthermore, we will discuss the transport of peripheral steroids through the blood-brain barrier (BBB) and their effects on its permeability. We will emphasize the role of this transport by lipoproteins in the functioning of the $\mathrm{BBB}$ and during CNS insults, raising the question of the potential roles of cholesterol/steroid transport in neuroprotection and reactive neurogenesis.

\section{NEUROSTEROIDOGENESIS IN THE BRAIN: AN OVERVIEW IN FISH, BIRDS, AND MAMMALS}

\section{Steroidogenesis}

Steroidogenesis is the enzymatic process by which cholesterol is converted to biologically active steroid hormones. The steroidogenic acute regulatory protein (StAR), and translocator protein (TSPO), in a complex with various proteins including VDAC and ATAD3A, are involved in the transport of cholesterol to the inner membrane of the mitochondria. The first and rate-limiting enzymatic step of the steroidogenic process is the conversion of cholesterol into pregnenolone by $\mathrm{P} 450$ side chain cleavage $\left(\mathrm{P} 450_{\text {scc }} ; \mathrm{CYP} 11 \mathrm{~A} 1\right)$. As shown in the steroidogenic pathway illustrated in Figure 1, pregnenolone can subsequently be converted into progesterone $(\mathrm{P})$ by 3-beta-hydroxysteroid

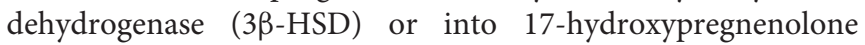
by 17-alpha-hydroxylase/17,20 lyase (CYP17). Then, CYP17 can convert progesterone into 17-hydroxyprogesterone, while $3 \beta$-HSD can convert 17-hydroxypregnenolone into 17 hydroxyprogesterone. In a next step, 17-hydroxypregnenolone and 17-hydroxyprogesterone can be converted by CYP17 into dehydroepiandrosterone (DHEA) and androstenedione, respectively. In turn, the activity of different $17 \beta-\mathrm{HSD}$ enzymes catalyzes the synthesis of androstenediol from DHEA and testosterone $(\mathrm{T})$ from androstenedione. Aromatase converts androstenedione and testosterone into estrone (E1) and estradiol (E2), respectively, while $5 \alpha$-reductase converts testosterone into $5 \alpha$-dihydrotestosterone (DHT). Considering glucocorticoids, the synthesis of 11-deoxycortisol and 11-deoxycorticosterone from 17-hydroxyprogesterone and progesterone, respectively, are catalyzed by 21-hydroxylase (CYP21A2), followed by the P450C11 (Cyp11, cytochrome P450 11 $\beta$-hydroxylase B1 and/or B2) activity leading to the synthesis of cortisol and corticosterone. Cortisone can also be converted into cortisol by $11 \beta$-HSD.

\section{Steroidogenic Activities in the Brains of Fish}

In the 80s, pioneering studies performed in the goldfish (Carassius auratus) and the toadfish (Opsanus tau) documented very high brain aromatase and $5 \alpha$-reductase activities (Pasmanik and Callard, 1985, 1988). High aromatase expression and activity in the brain is a common feature of teleost fish (Kah et al., 2009; Diotel et al., 2010), as reported in the African catfish (Clarias gariepinus) (Timmers and Lambert, 1987), the Atlantic Salmon (Salmo salar) (Andersson et al., 1988), the three-spined stickleback (Gasterosteus aculeatus) (Borg et al., 1989), the European sea bass (Dicentrarchus labrax) (Gonzalez and Piferrer, 2003), and the zebrafish (Danio rerio) (Goto-Kazeto et al., 2004; Diotel et al., 2011b). The high aromatase activity in the brain of fish is due to the sustained expression of the cyp 19a1b gene coding for the Cyp19a1b/Aromatase B protein (AroB), while the cyp19a1a isoform coding for Cyp19a1a/Aromatase A protein is mainly expressed in gonads. These two isoforms likely resulted from a third round of genomic duplication event occurring 320-350 million years ago in fish (Ravi and Venkatesh, 2008).

Biochemical studies using RP-HPLC analysis showed that the brains of adult zebrafish is able to convert $\left[{ }^{3} \mathrm{H}\right]$-pregnenolone into $\left[{ }^{3} \mathrm{H}\right]$-progesterone, documenting subsequently $3 \beta-\mathrm{HSD}$ activity in the brain of this teleost. These data were reinforced by the absence of progesterone synthesis following treatment with trilostane, a specific inhibitor of $3 \beta$-HSD (Sakamoto et al., 2001a). Ten years later, using similar methods, it was shown that the adult zebrafish brain can convert $\left[{ }^{3} \mathrm{H}\right]$-pregnenolone into a wide variety of radiolabeled steroids including $17 \mathrm{OH}$-pregnenolone, progesterone $(\mathrm{P})$, and tetrahydro-P, DHEA, androstenedione, testosterone $(\mathrm{T})$, dihydrotestosterone (DHT), 17 $\beta$-estradiol (17 $\beta$ E2), and also estrone (E1) (Diotel et al., 2011b). Expression and activity studies in the brain of adult zebrafish were documented for $3 \alpha-H s d, 3 \beta-H s d, 17 \beta-H s d$, Cyp17, AroB, and $5 \alpha$-reductase (Diotel et al., 2011b). The recent reanalysis of the RP-HPLC profiles previously reported by Diotel et al. (2011a) indicated that $\left[{ }^{3} \mathrm{H}\right]$-pregnenolone can also be converted into cortisol and tetrahydrodeoxycorticosterone (THDOC), further highlighting Cyp21A2 and Cyp11C1 activities within the brain of adult zebrafish (Weger et al., accepted).

Taken together, these data demonstrate that the brain of adult fish is able to de novo synthesize a wide variety of steroids from pregnenolone, suggesting that the substrates available for steroidogenesis can originate from local synthesis within the brain, and also from the conversion of peripherally produced precursors.

\section{Steroidogenic Enzyme Expression in the Brains of Fish}

The first attempts to localize aromatase-expressing cells in the brain of fish were performed in goldfish using antibodies raised against human placental aromatase (Gelinas and Callard, 


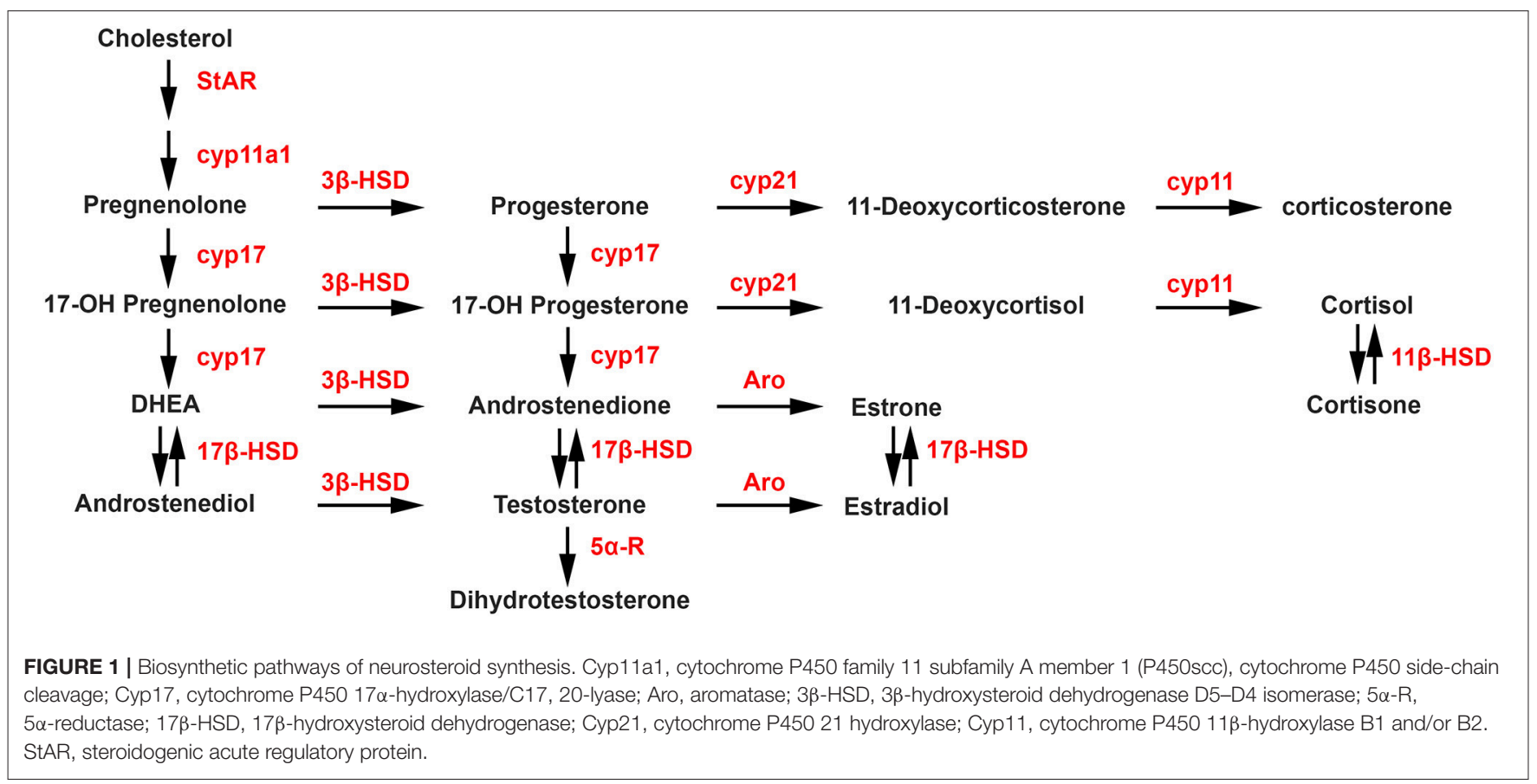

1997). In this work, neuron-like cells were labeled in the olfactory bulb, the telencephalon, the preoptic area, and the hypothalamus. However, cyp19a1b in situ hybridization and double immunohistochemistry using specific AroB antibodies and glial (GFAP, S100 $\beta$, and BLBP) or neuronal markers (HuC/D or NeuN) clearly demonstrated the exclusive glial nature of $\mathrm{AroB}^{+}$cells in others teleost species (Forlano et al., 2001; Goto-Kazeto et al., 2004; Forlano and Bass, 2005; StroblMazzulla et al., 2005; Pellegrini et al., 2007; Mouriec et al., 2008; Tong et al., 2009; März et al., 2010; Coumailleau et al., 2015; Diotel et al., 2016). These data were further reinforced by the development of a cyp19a1b-GFP transgenic zebrafish line, showing the exclusive GFP co-expression with glial markers (Tong et al., 2009). Interestingly, $\mathrm{AroB}^{+}$cells correspond to radial glial cells (RGCs), a particular type of cells with a characteristic morphology. Radial glial cells display a soma localized in the vicinity of the ventricular layer and exhibit two cytoplasmic processes, a short one extending to the ventricle and a longer one running through the brain parenchyma toward the pial surface. In mammals, RGCs behave as neural stem cells (NSCs) during embryonic development and transform into astrocytes at the perinatal stage (Noctor et al., 2001; Weissman et al., 2003; Kriegstein and AlvarezBuylla, 2009). In fish, they persist during adulthood and maintain neural progenitor properties (Adolf et al., 2006; Pellegrini et al., 2007, 2013, 2015; Tong et al., 2009; März et al., 2010; Rothenaigner et al., 2011; Kizil et al., 2012; Diotel et al., 2016).

Other studies performed in zebrafish documented the expression of $3 \beta-\mathrm{Hsd}$ in neuronal soma and fibers throughout the brain (i.e., dorsal telencephalon, thalamus, preoptic area, paraventricular organ), the cerebellum and the spinal cord
(Sakamoto et al., 2001a). In the African lungfish (Protopterus annectens), $3 \beta$-Hsd was also shown to be expressed in neurons while $5 \alpha$-reductase was detected in both glia and neurons (Mathieu et al., 2001). Furthermore, numerous experiments documented the expression of the steroidogenic enzymes (P450scc, 3 $\beta$-hsd, cyp17, and cyp19a1b) in the brains of fish including the Tongue sole (Cynoglossus semilaevis) and the Black porgy (Acanthopagrus schlegeli) (Tomy et al., 2007; Chen et al., 2010b). In adult zebrafish, in situ hybridization experiments indicate that there is a wide and overlapping distribution of $P 450 s c c, 3 \beta$-hsd, cyp17, and $c y p 19 a 1 b$ throughout the brain particularly in the telencephalon, the preoptic area, the hypothalamus, and the cerebellum (Diotel et al., 2011b). The distributions of $P 450 s c c, 3 \beta$-hsd, and cyp 17 suggest a potential expression in neurons as well as in neural progenitors, as shown by co-expression with AroB, a RGC marker. From 2011 until now, new isoforms for these steroidogenic enzymes have been identified: 3- $\beta$ hsd1, 3- $\beta$ hsd2, cyp11a1, cyp11a2, cyp17a1, and cyp17a2. Recent work confirmed the sites of expression of these steroidogenic enzymes in the brain of adult zebrafish and further described the distribution of their respective isoforms (Weger et al., accepted). It appears that all these steroidogenic enzymes display overlapping distributions. In addition, expression of cyp21a2, cyp11c1, and $f d x 1 / f d x 1 b$ (co-factors of glucocorticoid synthesis) was recently described in adult zebrafish brain (Weger et al., accepted), and patterns appeared similar to other steroidogenic enzymes. Furthermore, isolation and culture of goldfish RGCs was performed (Xing et al., 2014), and deep RNA sequencing of these RGCs indicates expression of steroidogenic acute regulatory protein (star), cyp11a1, cyp17a1, fdx1, hsd17b10 in addition to cyp19a1b and $5 \alpha$-reductase (Da Fonte et al., 2017). Proteomic 
analyses also revealed the production of $20 \beta$-Hsd (Xing et al., 2016).

Altogether, these studies suggest that the brains of adult fish widely express the biologically active steroidogenic enzymes leading to sex steroid synthesis. They also suggest that RGCs in fish may be capable of de novo steroid production from cholesterol and could be consequently envisioned as true steroidogenic cells (Figure 2A).

\section{Steroidogenic Enzyme Activities and Expression in the Brains of Birds}

Birds are excellent models for understanding the impact of peripherally and locally produced steroids on brain functions, including behavior. Pioneering studies from the groups of Tsutsui and Schlinger have shown that the brains of the quail (Coturnix japonica) and zebra finch (Taeniopygia guttata) are capable of de novo steroidogenesis. They showed that the avian brain expresses the active P450scc, 3 $\beta$-HSD, CYP17, 17 $\beta$-HSD, and aromatase enzymes, leading to the production of a wide variety of neurosteroids including pregnenolone, progesterone, androstenedione, testosterone, and estradiol from cholesterol (Tsutsui and Yamazaki, 1995; Tsutsui et al., 1999, 2006, 2009; Matsunaga et al., 2001; London et al., 2006, 2009; London and Schlinger, 2007; Tsutsui, 2011; Schlinger and Remage-Healey, 2012). Western-Blot and immunohistochemistry experiments allow the detection of P450scc immunoreactive neurons through the preoptic area, the thalamus, the hypothalamus, and the

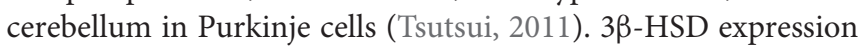
was highlighted based on enzymatic activity in the brain of the adult quail, with a strong presence in the telencephalon and the diencephalon and a lower one in the mesencephalon (Ukena et al., 1999). In quail, Cyp17 gene expression is detected in the preoptic area, the thalamus, the hypothalamus, and the optic tectum as well as in Purkinje cells (Matsunaga et al., 2001).

Aromatase expression was thoroughly studied in several brain regions particularly, in the hypothalamus and the preoptic area in quail (Balthazart and Foidart, 1993; Balthazart et al., 1996; Balthazart and Ball, 1998; Tsutsui, 2011) and in the telencephalon in zebra finches (Schlinger, 1997). Interestingly, data showed overlapping distribution of StAR, CYP11A1, $3 \beta$ $H S D$, and CYP17 mRNA in the ventricular proliferative zone of the avian brain during support (London and Schlinger, 2007), suggesting potential roles of neurosteroids in neurogenesis and CNS development. It should be noted that $3 \beta-\mathrm{HSD}$ is also present throughout the telencephalon in adult song birds (Soma et al., 2004; Schlinger et al., 2008). Furthermore, aromatase expression was also studied throughout the avian brain during support and de novo expression was documented in RGCs following brain injury in adult birds (Peterson et al., 2004). These data surface a potential role of aromatase and estrogen synthesis in neuroprotection and brain repair mechanisms.

These different studies highlight the capacity of the avian brain to synthesize its own steroids and suggest key roles of neurosteroids in reproductive behavior and neurogenesis.

\section{Steroidogenic Enzyme Activities and Expression in the Brains of Mammals}

$P 450_{s c c}$ gene expression was detected in numerous brain regions of the rodent (i.e., cerebral cortex) and human brain (i.e., cerebral cortex, olfactory bulbs, hippocampus, cerebellum) (Pelletier, 2010). Cells immunoreactive for P450 scc were observed in the white matter, the pyramidal and granular neurons of the developing and adult hippocampus (a brain region known for maintaining active neurogenesis during adulthood), and also in Purkinje cells from the cerebellum (Le Goascogne et al., 1987; Tsutsui and Ukena, 1999; Kimoto et al., 2001).

In the $80 \mathrm{~s}, 3 \beta-\mathrm{HSD}$ activity was reported in rat brain homogenates through the conversion of pregnenolone into

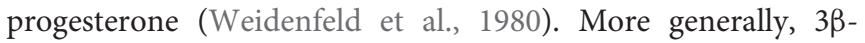
HSD gene and protein expressions were documented in primary cultures of rodent oligodendrocytes and neurons, and distributed especially in the olfactory bulbs, the thalamus, the cerebral cortex, the hypothalamus, and the cerebellum (Dupont et al., 1994; Guennoun et al., 1995; Meffre et al., 2007; Pelletier, 2010). In humans, $3 \beta-H S D$ gene expression was detected in neuronal, astroglial, and oligodendrocyte cell lines (Brown et al., 2000) and had a similar distribution compared to rodents, notably in the thalamus, the hippocampus, and the cerebellum (Yu et al., 2002).

The presence of Cyp17 in the mammalian central nervous system (CNS) is currently not clear. Indeed, some work suggested the absence of Cyp17 gene expression while other studies reported Cyp17 gene expression in the cerebellum and the brainstem of rat, and showed Cyp17 immuno-positive cells in the hippocampus, the hypothalamus, and in the Purkinje cells (Mellon and Deschepper, 1993; Strömstedt and Waterman, 1995; Hojo et al., 2004; Pelletier, 2010). During development, the expression of Cyp17 in the rat brain is present but decreases postnatally (Compagnone and Mellon, 2000). Hence, the question of Cyp17 expression and activity in the mammalian brain remains open.

In rodents, aromatase expression (mRNA and protein) and activity were documented in numerous brain regions including the cerebral cortex, the preoptic nucleus, the hypothalamus as well as the hippocampus; in humans, it was also detected in the pons, the thalamus, the hypothalamus, and the hippocampus (Lephart et al., 1992; Lephart, 1996; Sasano et al., 1998; GarciaSegura et al., 2003; Hojo et al., 2004; Yague et al., 2006; Pelletier, 2010). In rodents, aromatase expression was mainly detected in neurons and not in glial cells, except following brain injury that results in a de novo aromatase expression by astrocytes, suggesting a role of estrogens in neuroprotection (Garcia-Segura et al., 1999; Azcoitia et al., 2001; Garcia-Segura, 2008). In contrast to rodents, in some primates including humans, the estrogensynthesizing enzyme expression was also reported in some subpopulations of astrocytes in addition to neurons (Yague et al., 2006; Roselli, 2007). As reviewed by Pelletier (2010), numerous studies demonstrate aromatase activity in the brain of mammals including primates.

Consequently, de novo steroid synthesis occurs in the brains of mammals (Figure 2B). Neurosteroidogenesis is active in 

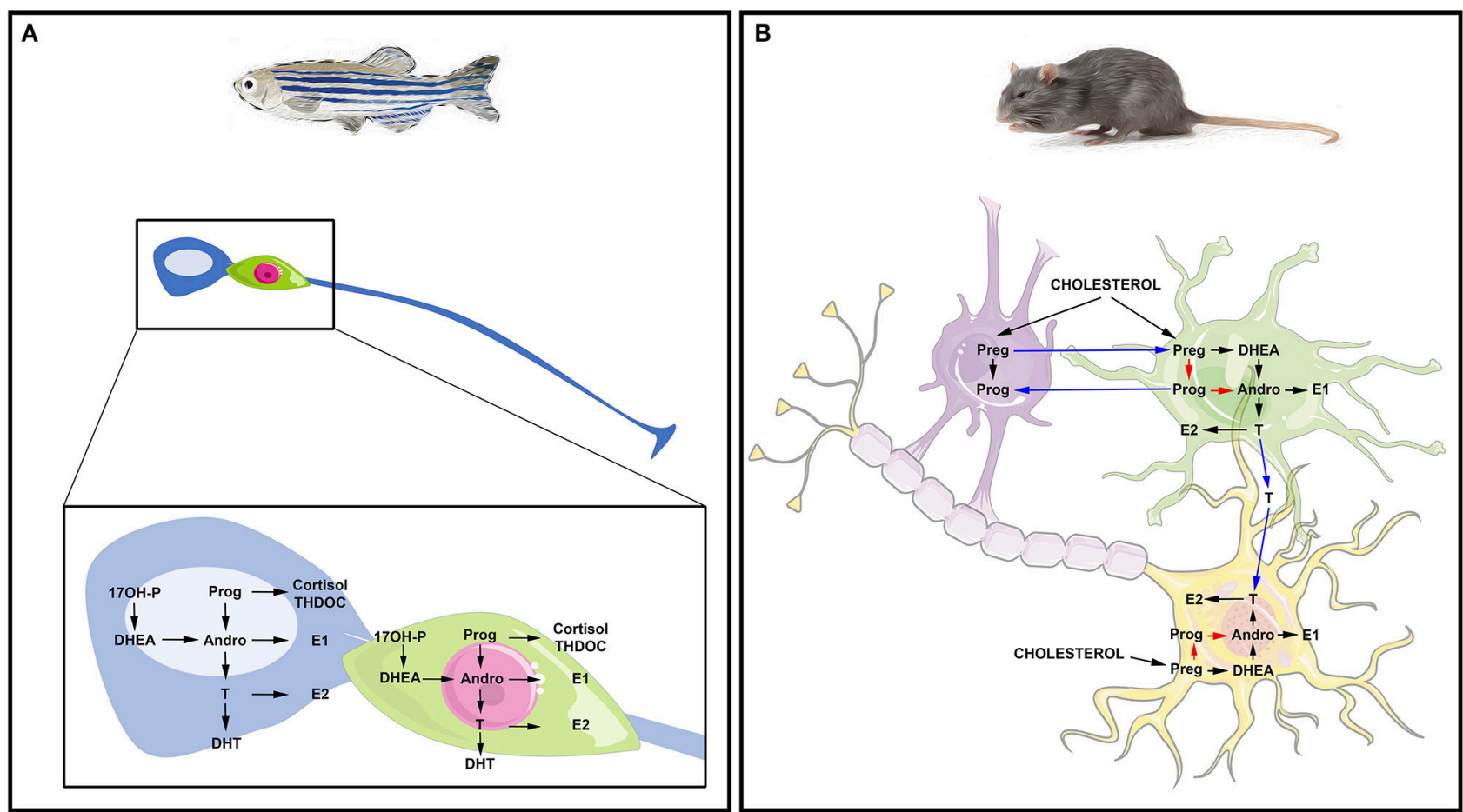

FIGURE 2 | Steroidogenesis in the brain of fish and mammals. (A) Steroidogenesis in the brain of adult fish. The blue cell corresponds to a radial glia cell acting as neural stem cell, while the green cell corresponds to a neuron. Data obtained by in situ hybridization, RNA sequencing and/or proteomics show neuronal and radial glial expression of steroidogenic enzymes involved in the synthesis of $17 \mathrm{OH}$-Pregnenolone (17OH-P), Progesterone (P), dehydroepiandrosterone (DHEA), Androstenedione (Andro), Estrone (E1), 17 $\beta$-estradiol (17 $\beta$-E2, called here E2), testosterone (T) and dihydro-testosterone (DHT), cortisol and THDOC (tetrahydrodeoxycorticosterone). (B) Steroidogenesis in the brain of rat. The purple cell corresponds to an oligodendrocyte that participates in the myelin sheath genesis of axons; the green cell is an astrocyte and the yellow one is a neuron whose axon is myelinated by the oligodendrocyte. This schematic view adapted from Zwain and Yen (1999) highlights potential interaction of oligodendrocytes, astrocytes, and neurons in neurosteroidogenesis. The main steroidogenic pathway is shown by black arrows, the minor ones by red arrows and the suggested ones by blue arrows referring to the work of Zwain and Yen (1999). Note that arrows do not necessarily document the direct conversion of the one steroid into another, but can include several enzymatic processes.

numerous regions including the hippocampus, known for maintaining an intense neurogenic activity during adulthood. Interestingly, this region was shown to synthesize $17 \beta$-E2 from pregnenolone (Hojo et al., 2004), reinforcing the idea that steroids could impact neurogenesis.

In conclusion, neurosteroidogenesis appears to be a conserved process well-documented in fish, birds and mammals (Figure 2). It occurs in numerous evolutionary conserved regions such as the telencephalon, the diencephalon (i.e., preoptic area and hypothalamus), and also the cerebellum. This sustained synthesis of steroids may regulate several brain functions and participate to brain homeostasis, neurotransmission, neurogenesis, and brain plasticity by targeting different cell types.

\section{STEROID SIGNALING IN THE BRAIN: FOCUS ON THE BRAINS OF FISH, BIRDS, AND MAMMALS}

Peripherally and locally produced steroids can target different brain regions and cell-types expressing their respective and specific receptors. Here, we will describe the main sites of expression of steroid receptors, with a special focus on estrogen, progesterone, and androgen receptors. We will first discuss receptor distributions in the brain of fish and birds before highlighting the situation in mammals.

\section{Expression of Nuclear and Membrane-Associated Steroid Receptors in the Brains of Fish Nuclear Estrogen Receptors (ER)}

Unique among vertebrates, fish have three nuclear estrogen receptors resulting from an ancient genome duplication: one $\operatorname{ER} \alpha$ and two $\operatorname{ER} \beta$. The $\operatorname{ER} \alpha$ and $\operatorname{ER} \beta$ probably arose from a first duplication event prior the emergence of ray-finned species. A second duplication led to the emergence of two $E R \beta$ and $E R \alpha$ genes but the second copy of the $E R \alpha$ probably disappeared (Thornton, 2001; Bardet et al., 2002; Nagler et al., 2007).

Nuclear estrogen receptors genes [ER $\alpha$ (esr1), ER $\beta 1$ (esr $2 b)$, and $E R \beta 2(e s r 2 a)$ ] were identified in many teleost species, including the rainbow trout (Oncorhynchus mykiss), tilapia (Oreochromis niloticus), medaka (Oryzias latipes), goldfish, and zebrafish among others (Pakdel et al., 1990; Tan et al., 1995; 
Muñoz-Cueto et al., 1999; Tchoudakova et al., 1999; Xia et al., 1999; Hawkins et al., 2000; Kawahara et al., 2000; Ma et al., 2000; Socorro et al., 2000; Bardet et al., 2002; Lassiter et al., 2002; Menuet et al., 2002; Andreassen et al., 2003; Choi and Habibi, 2003; Halm et al., 2004; Sabo-Attwood et al., 2004; Filby and Tyler, 2005; Forlano et al., 2005; Nagler et al., 2007; StroblMazzulla et al., 2008; Chakraborty et al., 2011; Zhang et al., 2012; Katsu et al., 2013).

Most studies carried out so far reported the presence of esr transcripts in the brain of adult fish. In situ hybridization and immunohistochemistry experiments used to localize ERexpressing cells in the brain revealed distinct but partly overlapping patterns of expression in many fish species including medaka, Atlantic croaker (Micropogonias undulatus), pejerrey (Odontesthes argentinensis), trout and zebrafish (Salbert et al., 1991; Anglade et al., 1994; Hawkins et al., 2000, 2005; Menuet et al., 2002; Pellegrini et al., 2005; Nagler et al., 2007; Strobl-Mazzulla et al., 2008; Zempo et al., 2013; Coumailleau et al., 2015). In general, transcripts for ERs have a broad distribution and were detected in many brain regions known to regulate sexual, reproductive, social behaviors, and sensorymotor activities such as the telencephalon, the preoptic area, the hypothalamus, and the cerebellum. Additionally, ER transcripts have been reported in cells lining the ventricles, where RGCs are localized, and also in cells localized more deeply in the brain parenchyma. Interestingly, there are clear evidences that $\mathrm{ER} \alpha$ is expressed in dopaminergic, GABAergic, kisspeptin- and neuropeptide B-positive neurons in several species (Linard et al., 1996; Anglade et al., 1999; Mitani et al., 2010; Escobar et al., 2013; Zempo et al., 2013; Hiraki et al., 2014). Similarly to rodents, ERs were not reported in neurons expressing gonadotrophinreleasing hormone (Navas et al., 1995).

In midshipman (Porichthys notatus), pejerrey, and zebrafish, the pattern of expression of the nuclear estrogen receptors and AroB (Cyp19a1b) are closely related (Forlano et al., 2005; StroblMazzulla et al., 2008; Diotel et al., 2011a). Careful examination of adjacent sections hybridized with cyp19a1b and esr 1 riboprobes in trout and zebrafish failed to evidence any co-localization (Menuet et al., 2003, 2005). However, esr2b was recently shown to be expressed in AroB-expressing RGCs (Pellegrini et al., 2015), and RT-PCR analysis performed in glial cells enriched cultures from adult trout or goldfish suggested that a weak expression of ER $\alpha$ could not be excluded (Menuet et al., 2003; Xing et al., 2015). A recent study designed to characterize the transcriptome of cultured goldfish RGCs and reported esr 1 , esr $2 b$, and esr $2 a$ expression in these neural progenitors (Da Fonte et al., 2017).

Knowledge about estrogen signaling during early development in fish is very limited and the zebrafish is the only species in which expression of the three ERs during embryogenesis was monitored. Quantitative-PCR experiments established that esr 1 , esr $2 a$, and especially esr $2 b$ mRNA were maternally inherited and expressed in eggs before dropping down to $24 \mathrm{~h}$ post-fertilization (hpf) (Bardet et al., 2002; Lassiter et al., 2002; Mouriec et al., 2009; Bondesson et al., 2015). Nuclear estrogen receptor expression then started to increase at $24 \mathrm{~h}$, when the onset of zygotic transcription is activated (Bardet et al., 2002; Lassiter et al., 2002; Mouriec et al., 2009). Whole mount in situ hybridization showed that esr $2 a$ and esr $2 b$ mRNA were detectable at $48 \mathrm{hpf}$ in the ventral telencephalon and in the presumptive preoptic area as well as in the hypothalamus, in line with what was described in the adult brain (Mouriec et al., 2009). A clear expression for esr 1 is described in these regions but at later stages, between 14 days post-fertilization (dpf) and 21 dpf (Kallivretaki et al., 2007; Mouriec et al., 2009). Using cyp19a1b-GFP zebrafish embryos, GFP expression was shown to be inducible in RGCs at $24 \mathrm{~h}$ after $17 \beta$-E2 treatment, an effect blocked by the ER antagonist ICI 182,780, indicating that ERs were fully functional in the brain early during development (Mouriec et al., 2009). A morpholino approach confirmed the specific role of esr $2 b$ in the induction of the cyp $19 a 1 b$ gene (Griffin et al., 2013). Temporary disruption of esr $2 a$ expression in zebrafish with the same technological approach was associated with a developmental defect of sensory hair cells (Froehlicher et al., 2009). Knockdown of both maternally inherited and zygotic esr2a was associated with an increase in apoptotic cells particularly in the brain leading to severe brain defects (Celeghin et al., 2011).

\section{Membrane-Associated Estrogen Receptors (mER)}

Membrane receptors responding to $17 \beta-\mathrm{E} 2$ stimulation via rapid non-genomic signaling have been characterized in fish. G protein-coupled estrogen receptor 1 (GPER or GPR30) is a member of this receptor family. A partial or full-length gper was cloned, characterized, and detected in the brain of adult zebrafish, Atlantic croaker, and goldfish (Pang et al., 2008; Liu et al., 2009; Pang and Thomas, 2009; Mangiamele et al., 2017). In zebrafish, gper in situ hybridization on adult brain sections showed a specific pattern of expression in the olfactory bulbs, the telencephalon, the hypothalamus, the optic tectum, the cerebellum, and the medulla oblongata (Liu et al., 2009). In goldfish, gper was also expressed in the forebrain and the suprachiasmatic nucleus, the preoptic area, and the optic tectum (Mangiamele et al., 2017). Originally, it was proposed that goldfish RGCs did not express the G-protein coupled estrogen receptor because attempts to amplify a specific cDNA from cultured cells failed (Xing et al., 2015). However, whole RNA sequencing of separate primary cultures of these cells revealed expression of gper1, suggesting that some subpopulations of RGCs express the membrane ER (Da Fonte et al., 2017).

The spatiotemporal distribution of gper was investigated in zebrafish using PCR. Its expression was observed in the anterior diencephalon, the midbrain and the hindbrain (Jayasinghe and Volz, 2012; Shi et al., 2013). Both gper and esr2b mRNA are expressed in neuromasts, suggesting a role of estrogens and a close interaction between these receptors in the developmental regulation of this mecanoreceptive organ (Froehlicher et al., 2009). Knock-down of gper resulted in morphological defects in the zebrafish brain at $24 \mathrm{hpf}$ (Shi et al., 2013). At $30 \mathrm{hpf}$, these morphants displayed an increased number of apoptotic cells, and a decreased brain cell proliferation (Shi et al., 2013). A slight reduction in otx2 gene expression, which is required for sensory organs development and brain function, was also observed in gper knock-down zebrafish. Taken together, these data show the 
potential involvement of both nuclear and membrane-associated estrogen receptors in brain development and functions.

\section{Nuclear Progestin Receptors (PR)}

Nuclear progestin receptor (PR) genes have been characterized in a few fish species (Ikeuchi et al., 2002; Morini et al., 2017). In European eel (Anguilla Anguilla), two PR genes, pgr1 and pgr2, were differentially expressed in the brain (olfactory bulb, telencephalon, diencephalon, cerebellum) and in the pituitary of immatures males and females (Morini et al., 2017). Two genes were also identified in the Japanese eel (Anguilla japonica) but only pgr2 mRNA was detected in the brain (Ikeuchi et al., 2002). In zebrafish, a single locus encoding PR (Pgr) was identified (Chen et al., 2010a; Hanna et al., 2010). Ontogenic expression analysis determined by PCR during early embryogenesis showed that $p g r$ mRNA was not maternally inherited and became detectable in embryos at $8 \mathrm{hpf}$ (Chen et al., 2010a). Immunohistochemistry and in situ hybridization revealed a widespread distribution of zebrafish Pgr receptor (protein and mRNA) in the brain especially neuroendocrine regions (olfactory bulbs, preoptic area, telencephalon, thalamus, hypothalamus, optic tectum, torus longitudinalis, valvula cerebelli) (Hanna et al., 2010; Diotel et al., 2011c). It should be noted that Pgr-positive cells were observed along the ventricular cavities and also more deeply in the brain parenchyma. In this work, it was shown that periventricular Pgr-positive cells displayed a stronger staining compared to Pgr-positive cells located deeply in the parenchyma (Hanna et al., 2010; Diotel et al., 2011c). By performing double immunostainings, it was shown that a large portion of Pgrpositive cells located in the cerebral parenchyma correspond to acetylated-tubulin positive neurons (Diotel et al., 2011c). In contrast, immunohistochemistry on cyp19a1b-GFP transgenic zebrafish clearly showed Pgr-expressing cells along the ventricle correspond to $\mathrm{AroB}^{+}$RGCs (Diotel et al., 2011c). These data were confirmed by a transcriptomic analysis showing pgr mRNA expression in cultured goldfish RGCs (Da Fonte et al., 2017). Pgr expression is consequently high in the estrogen-synthesizing RGCs. This suggests a relationship between locally-produced estrogens and Pgr expression. Indeed, treatments with the aromatase inhibitor ATD or with $17 \beta$-E2 respectively decrease or increase $p r g$ expression in the brains of adult zebrafish and also in larvae (Diotel et al., 2011c).

Gene knockout using the TALENs strategy allowed to generate zebrafish lines with null Pgr expression to assess the in vivo function of this receptor. Unfortunately, all studies performed with these models have focused at the gonadal levels and none of them looked at the effect of Pgr expression disruption in the brain (Zhu et al., 2015; Tang et al., 2016; Wang et al., 2016).

\section{Membrane-Associated Progestin Receptors (mPR)}

In mammals, many progestins exert non-genomic effects through rapid activation of intracellular signaling pathways mediated by two groups of membrane progestin receptors: mPRs (belonging to the PARQ family) and PGRMC1 and PGRMC2 (Petersen et al., 2013). However, there are only scarce data on membraneassociated progestin receptors existence and sites of expression in the brain and the pituitary of fish (Thomas, 2008).
The $m P R \alpha$ was identified and detected in the brain of adult spotted seatrout (Cynoscion nebulosus) (Zhu et al., 2003). It was also recently cloned in medaka but no data about its brain expression are available (Roy et al., 2017). In goldfish, $m P R \alpha$, $m P R \beta, m P R \gamma 1$, and $m P R \gamma 2$ were also detected in the brain (Tokumoto et al., 2006, 2012). Other studies documented the expression of different mPRs and/or PGMRCs in the brain and the pituitary of the European eel (Anguilla anguilla), the channel catfish (Ictalurus punctatus) and also the rainbow trout (Kazeto et al., 2005; Mourot et al., 2006; Morini et al., 2017). To date, $\operatorname{mPR} \alpha$ and $\operatorname{mPR} \beta$ were the only form to be identified in zebrafish (Zhu et al., 2003). Using specific antibodies for zebrafish $\operatorname{mPR} \alpha$ and $\operatorname{mPR} \beta$, Hanna and Zhu demonstrated their expression in brain samples (Hanna and Zhu, 2009). Currently, the distributions and functions of mPR in the brain of fish, if any, are completely unknown.

\section{Nuclear Androgen Receptors (AR)}

Two ar genes (ar1 and ar2) were isolated and characterized in several fish species including the Japanese eel (Anguilla japonica), the rainbow trout, the kelp bass (Paralabrax clathratus), the Atlantic croaker, and cichlids (Ikeuchi et al., 1999; Sperry and Thomas, 1999a,b; Takeo and Yamashita, 1999, 2000; Harbott et al., 2007). More recently, only one ar isoform was described in the stickleback (Olsson et al., 2005), the wrasse (Halichoeres trimaculatus) (Kim et al., 2002), the zebrafish (Jorgensen et al., 2007; de Waal et al., 2008; Gorelick et al., 2008; Hossain et al., 2008), and in the plainfish midshipman (Forlano et al., 2010).

The first immunohistochemistry studies carried out on the brains of adult goldfish with an heterologous antibody revealed AR-positive cells with neuronal appearance in neuroendocrine regions such as the preoptic area and the hypothalamus, as well as in the olfactory bulbs, the telencephalon and the optic tectum (Gelinas and Callard, 1997). More detailed results were obtained in the brain of the plainfin midshipman, a fish that express mating behavior triggered by auditory signal. These data showed mRNA expression in auditory-related nuclei of the telencephalon, hypothalamus, midbrain, and in the vocal prepacemaker and vocal motor nuclei (Forlano et al., 2010). Numerous studies showed AR expression in the brain of fish including among others wrasse and zebrafish (Kim et al., 2002; Harbott et al., 2007; Hossain et al., 2008; Pouso et al., 2010).

In adult zebrafish, ar is strongly expressed along the ventricle and within the brain parenchyma of the telencephalon, the preoptic area, and the hypothalamus (Gorelick et al., 2008). In embryos, ar trancripts are maternally deposited and expression levels start to increase substantially at $24 \mathrm{hpf}$ (Hossain et al., 2008). The ar gene expression is detected at $24 \mathrm{hpf}$ in the olfactory placodes and in the midbrain, at $48 \mathrm{hpf}$ in the medial diencephalon and at $3 \mathrm{dpf}$ in the pineal organ (Gorelick et al., 2008). All neuroanatomical studies undertaken to date show that ARs are expressed in ventricular margins, where RGC are located (Harbott et al., 2007; Gorelick et al., 2008; Forlano et al., 2010; Pouso et al., 2010). Recently, transcriptomic analysis showed the expression of ar in goldfish RGCs (Da Fonte et al., 2017).

As mentioned above, it was shown that goldfish RGCs express progesterone receptor (Pgr), androgen receptor (ar), estrogen 
receptor $\alpha$ (esr 1$)$, estrogen receptor $\beta 1$ (esr $2 b)$, and estrogen receptor $\beta 2$ (esr2a) (Da Fonte et al., 2017). This data supports other reports in zebrafish showing that RGCs express Pgr protein (Diotel et al., 2011c) and observations for the expression of $a r$, esr 1 , esr $2 a$, and esr $2 b$ mRNAs within neurons and/or $\mathrm{AroB}^{+}$ RGCs (Diotel et al., 2011a; Pellegrini et al., 2015). All this suggests that RGCs are both a source and a target of neurosteroids (Diotel et al., 2011a; Pellegrini et al., 2015; Xing et al., 2016), arguing for key roles of steroids in RGC activity.

\section{Expression of Nuclear and Membrane-Associated Steroid Receptors in the Brains of Birds Nuclear and Membrane-Associated Estrogen Receptors}

Early data on the distribution of sex hormone receptors in the brain of birds was extensively reviewed (Gahr, 2001). Similar to mammals, there are two different avian genes coding for ER $\alpha$ and ER $\beta$ (Bernard et al., 1999; Jacobs et al., 1999). In birds, $\mathrm{ER} \alpha$ is expressed in the brain of all the species studies so far, including members of Apodiformes, Passeriformes, Galliformes, Columbiformes, and Psittaciformes. These ERs are distributed in various brain territories including the telencephalon, the diencephalon, and the rhombencephalon, with more noticeable expression in the preoptic area and the hippocampus (Gahr, 2001). For instance, in the brain of zebra finch, ER $\alpha$ mRNAs was observed in the nidopallium, the arcopallium, the hippocampus, the diencephalon, the midbrain and within the vocal control circuitry (Jacobs et al., 1999). Interestingly, $\mathrm{ER} \alpha$ mRNAs expression overlap with that of aromatase (Jacobs et al., 1999). $\operatorname{ER} \beta$ was first described in the brain of the Japanese quail, the European starling (Sturnus vulgaris), and the canary (Bernard et al., 1999; Foidart et al., 1999; Gahr, 2001). In general, ER $\beta$ was reported in the preoptic area, the hypothalamus, the thalamus and different midbrain nuclei. In the European starling, in situ hybridization experiments allowed the detection of ER $\beta$ mRNA in the nidopallium and the preoptic area in a pattern reminiscent of aromatase (Bernard et al., 1999; Axelsson et al., 2007). Consequently, ER $\alpha, \mathrm{ER} \beta$ and aromatase distributions strongly overlap. As reported in oscine birds, ER labeling was detected in different forebrain regions while it was not found in nonoscine ones, highlighting discrete differences in ER expression in songbird species and families (Gahr, 2001). It should be noted that, while histological studies have focused on the distribution of the nuclear isoforms, numerous functional studies suggest that estrogen receptors act at the level of the membrane, probably via interaction with other receptors such as glutamate receptors (Pawlisch and Remage-Healey, 2015; Seredynski et al., 2015).

\section{Nuclear and Membrane-Associated Progesterone Receptors}

Concerning PR expression, most studies in birds have focused on the hypothalamic region, because of the potential role of PR signaling in reproductive and egg-laying behaviors. Similarly to ER and AR, PR expression was investigated and documented by in situ hybridization and immunohistochemistry in the preoptic area, the hypothalamus, the thalamus, the hippocampus of the zebra finch, and the hen (Sterling et al., 1987; Lubischer and Arnold, 1990).

\section{Androgen Receptors}

The first studies documenting AR distribution in the brain of birds were performed by in vivo autoradiography with radiolabeled steroids (Arnold, 1980; Gahr, 2001). In zebra finch, these autoradiographic studies demonstrated the binding of tritiated testosterone in the HVC (used as the proper term, but previously known as hyperstriatum ventrale pars caudalis or and high vocal center), the magnocellular nucleus of the anterior nidopallium, the robust nucleus of the arcoplallium, the nucleus intercollicularis of the midbrain, and the periventricular magnocellular nucleus of the anterior hypothalamus (Arnold, 1980). In the golden-collared manakins (Manacus vitellinus), in situ hybridization for AR revealed expression in the forebrain, in the nucleus taeniae of the amygdala and in the arcopallium (Fusani et al., 2014). In general, ARs are detected in the hypothalamus, the preoptic area, the midbrain, and hindbrain in all species studied to date.

Taken together, it appears that ER, AR, and PR display almost similar distribution in the avian brain, with higher expression in the preoptic area, hypothalamus, thalamus, and hippocampus.

\section{Expression of Nuclear and Membrane-Associated Steroid Receptor in the Brains of Mammals}

\section{Estrogen Receptors}

Data concerning ERs mRNA and protein expression mostly originate from rat studies showing a strong expression of $\mathrm{ER} \alpha$ and ER $\beta$ throughout the brain (Li et al., 1997; Shughrue et al., 1997). In situ hybridization and immunohistochemistry experiments revealed that $\mathrm{ER} \alpha$ and $\mathrm{ER} \beta$ are expressed in neurons and glia from many CNS regions including the olfactory bulbs, the preoptic area, the hypothalamus, the zona incerta, the ventral tegmentum as well as the cerebellum in Purkinje cells (Li et al., 1997; Shughrue et al., 1997; Mitra et al., 2003; Frick et al., 2015). Both ERs were also detected in the cerebral cortex and in the hippocampus, with higher ER $\beta$ expression compared to $\mathrm{ER} \alpha$ (Shughrue et al., 1997). In the brain of mouse, immunohistochemistry against $\operatorname{ER} \beta$ allows the detection of immunoreactive cells in regions similar to the rat. However, $\mathrm{ER} \alpha$ expression appears stronger in the hippocampus and the hypothalamus, and lower in the cerebral cortex and cerebellum (Mitra et al., 2003), suggesting some differences in ER signaling between rat and mouse. Importantly, ERs are widely and strongly expressed in the brain of mouse at postnatal day 7, but their respective expression declines the two following days with different kinetics (Sugiyama et al., 2009). In humans, $\mathrm{ER} \alpha$ is detected in the cortex at 9 gestational weeks in proliferating zones and in the cortical plate. Its expression subsequently decreases until birth before increasing gain during adulthood. At 15 gestational weeks, ER $\beta$ was also detected in proliferating zones and in the cortical plate with expression persisting in the adult cortex (González et al., 2007). Interestingly, from 15 
gestational weeks to adulthood, $\operatorname{ER} \alpha$ and $\operatorname{ER} \beta$ are detected in the hippocampus including the dentate gyrus, known to be a neurogenic region (González et al., 2007). In the same line, ERs have been detected in embryonic/adult NSCs in rodents and humans, suggesting a roles of estrogen signaling in NSC activity (Brännvall et al., 2002; Kishi et al., 2005; Hajszan et al., 2007; Suzuki et al., 2007; Okada et al., 2010). The spatiotemporally regulated expression of ERs in the embryonic brain of mouse and human, notably in the cerebral cortex and the hippocampus, argue in favor of different roles of estradiol during development (González et al., 2007; Sugiyama et al., 2009). Furthermore, a plasma membrane-associated ER (ER-X, GPER, GPR30, GPER1) was identified in the brain, mediating estrogen activation of MAPK/ERK (Toran-Allerand, 2005). This receptor is functionally distinct from $\mathrm{ER} \alpha$ and $\mathrm{ER} \beta$ and is up-regulated in the adult brain after ischemic stroke (Toran-Allerand et al., 2002). Its expression in the hippocampus is likely to play a role in synaptic plasticity (Waters et al., 2015).

\section{Progesterone Receptors}

In mammals, progesterone receptors include the classic nuclear PRA and PRB receptors, splice variants, and membraneassociated receptors $\mathrm{mPR}(\mathrm{mPR} \alpha, \mathrm{mPR} \beta$, and $\mathrm{mPR} \gamma)$ (Brinton et al., 2008). Nuclear PRs are expressed through the brain in neurons and glial cells of the hippocampus, the cortex and the hypothalamus (Hagihara et al., 1992a,b; Brinton et al., 2008), and their expression is up-regulated by estrogens in a region specific manner (Guerra-Araiza et al., 2003). Among the three mPR subtypes described, $m P R \alpha$ is the best characterized pharmacologically. In situ hybridization and immunohistochemistry experiments have shown a wide $\mathrm{mPR} \alpha$ neuronal expression in the olfactory bulbs, the cortex, the hypothalamus, the hippocampus, and the cerebellum (Meffre et al., 2013). Very interestingly, after traumatic brain injury, $\mathrm{mPR} \alpha$ is de novo expressed in microglia, astrocytes and oligodendrocytes, highlighting a potential role of this receptor in inflammation and brain repair mechanisms (Meffre et al., 2013). In rat, $\mathrm{mPR} \beta$-expressing neurons are detected in the forebrain and the midbrain (Zuloaga et al., 2012). In human, mPR mRNAs are distributed in the forebrain, the hypothalamus and also the hippocampus (Pang et al., 2013).

\section{Androgen Receptors}

In adult rodents, AR mRNA and protein are detected in neurons and glia of the medial amygdala, the preoptic area, the hypothalamus, the cerebellum, and the dentate gyrus of the hippocampus (Commins and Yahr, 1985; Sar et al., 1990; Hajszan et al., 2007; Feng et al., 2010; Pelletier, 2010; MhaoutyKodja, 2017). Interestingly, AR protein level is correlated with circulating levels of estradiol and testosterone across the estrous cycle, suggesting an estrogenic regulation of its expression (Feng et al., 2010).

To conclude, across vertebrate species, the distribution of ER, $\mathrm{PR}$, and $\mathrm{AR}$ in the brain are evolutionary conserved, especially in the hypothalamus, the preoptic area, and some striatal regions. They are also expressed in neurogenic brain regions, arguing in favor of a role sex steroids in the regulation of NSC activity, neuronal differentiation, and cell survival.

\section{ROLE OF STEROIDS IN THE BRAINS OF FISH, MAMMALS, AND BIRDS}

In this third part, we will discuss the action of estrogens, progestagens and androgens on constitutive neurogenesis and their effects on CNS following insults such as stroke and traumatic brain injury, with a focus on the impact of sex on brain injury. Then, we will discuss the impact of neurosteroids on behavior in fish, birds, and rodents, focusing only on sexual behavior.

\section{Constitutive and Regenerative Neurogenesis}

The actions of steroids in the brain are complex and depend of many factors such as the strain, the species, the timing, the concentration, and the rhythm of secretion, as well as the regions studied (Duarte-Guterman et al., 2015; Heberden, 2017). Sex steroids are well-documented for impacting neuronal plasticity including synaptogenesis/spinogenesis such as shown for estrogens (Fester et al., 2012; Brandt et al., 2013; Sellers et al., 2015; Sager et al., 2017), progesterone (Sakamoto et al., 2001b, 2002; Zhao et al., 2011), and testosterone (Manolides and Baloyannis, 1984; Devoogd et al., 1985). They have been also wellcharacterized for their role on learning/memory processes (Frye and Walf, 2008, 2010; Frye et al., 2008; Phan et al., 2012; Celec et al., 2015; Frick et al., 2015). In addition, estrogens, progestins, and androgens display neuroprotective effects through genomic and non-genomic mechanisms (López-Rodríguez et al., 2015). These neuroprotective effects involved the upregulation of antiapoptotic factors (i.e., $\mathrm{Bcl} 2$ ) and antioxidant enzymes (i.e., SOD and GPx), as well as the down-regulation of pro-inflammatory cytokines (López-Rodríguez et al., 2015). Due to limited space and to avoid redundancy with recently published reviews (Shahrokhi et al., 2012; Heberden, 2017; McEwen and Milner, 2017), we will mainly focus on the roles of these sex steroids on neurogenesis under homeostatic and regenerative conditions (i.e., stroke, traumatic brain injury).

\section{Effects of Estrogens}

In the brain, estrogens modulate synaptic plasticity, NSC proliferation, newborn neuron migration, differentiation, and survival, as well as neuroprotection (McEwen and Woolley, 1994; McEwen et al., 1995; Azcoitia et al., 2001; McCullough et al., 2003; Murashov et al., 2004; Mukai et al., 2010; Frick et al., 2015).

For instance, $17 \beta$-E2 treatment of rat embryonic NSCs increases cell proliferation and neuronal differentiation (Brännvall et al., 2002), and promotes human embryonic NSC differentiation into dopaminergic neurons (Kishi et al., 2005). In addition, ER $\beta$ knock-out mice display a thinner cortex at E18.5 due to defects in neuronal migration and increased cell-death arguing for a role of ER $\beta$ in newborn neuronal differentiation and survival during the late phase of corticogenesis (Wang et al., 2003). 
During adulthood, rat hippocampal cell genesis in female is modulated by ovarian hormone levels and is higher during pro-estrus, when 17ß-E2 concentration is elevated (Tanapat et al., 1999, 2005). In the same line of evidence, ovariectomy leads to decreased hippocampal proliferation that is restored by $17 \beta-\mathrm{E} 2$ treatments through ER dependent mechanism as demonstrated by the use of specific ER agonists (Mazzucco et al., 2006). The impact of other estrogens such as estradiolbenzoate, $17 \alpha-\mathrm{E} 2$, and estrone have been shown to also increase cell proliferation in ovariectomized rats suggesting that the positive neurogenic effects of estrogens are a general feature of female sex hormones (Frick et al., 2015). In meadow voles (Microtus pennsylvanicus), the reproductive status also influences dentate gyrus cell proliferation and/or surviving (higher in inactive females; higher in active males) (Ormerod and Galea, 2001, 2003). However, hippocampal cell proliferation in squirrels (Sciurus carolinensis) was not shown to be sexually dimorphic and to be modulated across the reproductive cycle (Lavenex et al., 2000). Furthermore, in striking contrast with most studies, an acute 17B-E2 treatment decreases cell proliferation in the subventricular zone (SVZ) and leads to a decrease in newborn cells in the olfactory bulbs (Brock et al., 2010). In addition, chronic $17 \beta$-E2 treatments in zebrafish impair NSC proliferation, cell survival, and the newborn cell migration (Diotel et al., 2013).

Estrogens also display neuroprotective properties and promote neural regeneration following traumatic brain injury and cerebral ischemia by decreasing apoptotic signaling, neuroinflammation, and oxidatative stress and by normalizing glutamate concentrations (Petrone et al., 2015). These neuroprotective effects of estrogens on brain ischemia have been well-established in ovariectomized rodents, and result in a significang decrease in the size of the lesion and in the infarct volume (Gibson et al., 2006; Petrone et al., 2015).

\section{Effects of Progesterone and Allopregnenolone}

In the brain, progesterone is known to regulate spinogenesis, synaptogenesis, neuronal survival, and dendritic growth (McEwen and Woolley, 1994; Brinton et al., 2008; Tsutsui, 2008; Zhang et al., 2010; Rossetti et al., 2016). Following cerebral ischemia in rat, progesterone promotes neurogenesis in the SVZ of the lateral ventricles and favors cell survival in the peri-infarct region several days post-stroke (Jiang et al., 2016). Interestingly, numerous studies documented estrogen and progesterone effects on learning and memory across the estrous cycle as reviewed in Duarte-Guterman et al. (2015). Allopregnanolone, a progesterone metabolite considered as one of the most important neuroactive steroid in the CNS, also plays key roles by increasing neurogenesis, neuronal cell survival, and by reducing cell-death in the hippocampus and the midbrain (Charalampopoulos et al., 2008; Zhang et al., 2015; Rossetti et al., 2016). It also exerts major neuroprotective roles in neurodegenerative diseases (Rossetti et al., 2016).

\section{Effects of Androgens}

Concerning androgens, a pioneer study in songbird suggested that testosterone could favor neurogenesis (Louissaint et al., 2002), further corroborated by mice castration studies resulting in decreased hippocampal neurogenesis (Spritzer and Galea, 2007; Heberden, 2017). In songbirds, androgens and estrogens are well-known to induce seasonal-like growth of song nuclei in the adult (Tramontin et al., 2003; Balthazart and Ball, 2016). Additional experiments in rodents document the positive effect of testosterone on SVZ cell proliferation (Tramontin et al., 2003; Farinetti et al., 2015; Balthazart and Ball, 2016), and those of testosterone and dihydrotestosterone on newborn neuron survival (Spritzer and Galea, 2007). In the same line, testosterone increases neurogenesis in wild-type males but not in androgen-insensitive ones (Hamson et al., 2013). This effect is blocked by AR antagonist (flutamide), demonstrating that androgens act through $\mathrm{AR}$ and not through $\mathrm{ER}$ after conversion into estrogens (Hamson et al., 2013). However, the reality appears more complex as treatment with nandrolone, a synthetic androgen, decreases hippocampal neurogenesis in male and female (Brännvall et al., 2005). Experiments performed in post-ischemic mice established that endogenous androgens do not alter injury-induced neurogenesis, while supra-physiological levels of testosterone and dihydrotestosterone strongly inhibits post-stroke neurogenesis in the dentate gyrus, reducing brain repair (Zhang et al., 2014).

\section{Sex Difference after Brain Injuries}

Interestingly, clinical and experimental findings are abundant and highlight important sex differences after stroke (Roof and Hall, 2000; Girijala et al., 2017). Clinical studies showed that aging women display worse outcomes following ischemic stroke than men, and higher mortality after hemorrhagic stroke (Sohrabji, 2015). In addition, ischemic stroke model in rodents document that young female have smaller infarcted area than young males (Alkayed et al., 1998), and also exhibit less severe stroke consequences during pro-estrus (high $17 \beta-\mathrm{E} 2$ concentration) than during metestrus (low 17 $\beta$-E2 concentration) (Liao et al., 2001). However, these studies only correlate between levels of $17 \beta-\mathrm{E} 2$ and stroke severity without taking into consideration other steroid hormone such as progesterone. During aging, mortality is higher in female than in male, and in the case of hemorrhagic stroke, males display greater bleeding and mortality (Sohrabji, 2015). It was also shown that estrogen treatments improve outcomes in young females and males after ischemic and hemorrhagic stroke, while their effects are controversial on aging females during ischemia (Sohrabji, 2015). Other clinical and experimental findings also document the impact of gender and of sex steroids on other CNS insults. For instance, after traumatic brain injury, men displayed greater levels of injury severity as indicated by the Glasgow Coma Scale score, but such an effect is not always found (Slewa-Younan et al., 2004; Davis et al., 2006). Taken together, these data argue in favor of an impact of sex and circulating steroids on the consequences of CNS insults.

In conclusion, sex steroids, peripherally or centrally produced, exert numerous actions on constitutive and regenerative neurogenesis, on brain plasticity, learning, and behaviors (Figure 3). For more details on sex hormone modulation of hippocampal neurogenesis, see (Galea et al., 2006; Frick et al., 2015). 


\section{Sexual Behavior}

As introduced earlier, sex steroids module in a wide array of behaviors, including aggression, parental behavior, sexual behavior, but also more cognitive aspects, including attention and visual and verbal memory. Although original studies investigated the role of gonadally-produced steroids, it is now clear that the local synthesis of these steroids directly in the central nervous system play a significant role as well. The shift from systemic to local synthesis and regulation of steroid action within target tissues, such as the brain, was called "Balkanization" of the endocrine system (Schmidt et al., 2008). This process would allow the brain to produce specific steroids required for the activation of defined behavior, while leaving other tissues unaffected. The central synthesis of estrogens in the male brain is probably the best example, as high peripheral production of these steroids would have major feminizing effects. Amongst the many behavioral effects of steroids, we chose to discuss in more detail the steroid-dependent modulation of sexual behavior. Indeed, the neuroanatomy and physiology underlying this reproductive behavior have been under study for decades, and sexual behavior provide an excellent model to further investigate the respective role of locally- vs. peripherally- produced sex steroids.

\section{Importance of Neuroestrogens}

The role for aromatase on male sexual behavior was hypothesized over 50 years ago (Clemens, 2013; Södersten, 2013) and a very large number of studies using pharmacological tools have demonstrated that testosterone action on male sexual behavior in various species requires its aromatization in the brain (Christensen and Clemens, 1975; Beyer et al., 1976; Morali et al., 1977; Balthazart and Foidart, 1993; Roselli et al., 2003). These observations were further confirmed by the use of various aromatase knock-out mice (Fisher et al., 1998; Honda et al., 1998; Matsumoto et al., 2003; Bakker et al., 2004). Furthermore, the importance of the central production of estrogens was highlighted by stereotaxic experiments affecting estrogen synthesis within the preoptic area. This region is a key brain center involved the control of male sexual behavior in most vertebrate species and, importantly, contains a very high concentration of aromatase, especially in birds (Balthazart et al., 2004; Perkins and Roselli, 2007; McCarthy, 2011). Numerous studies have shown that preoptic aromatase activity is critical for the activation of male sexual differentiation and male sexual behavior. For example, chronic inhibition of aromatase activity by specific inhibitors delivered to the preoptic area results in the complete suppression of copulatory behavior within a few days (Christensen and Clemens, 1975; Watson and AdkinsRegan, 1989a; Balthazart and Surlemont, 1990; Balthazart et al., 1990). In castrates, the male sexual behavior can be restored by the local administration of testosterone as well as estrogens (Christensen and Clemens, 1974; Watson and Adkins-Regan, 1989b). These results indicate that the expression of male sexual behavior is tied to changes in aromatase concentration and activity in the preoptic area (POA). Interestingly, these change in aromatase expression and male sexual behavior are also linked to an important local neuroplasticity (Aste et al., 1993; Panzica et al., 1998; Charlier et al., 2008). It should be noted that most of these effects were taking place after several days of steroid treatment, clearly suggesting direct genomic effects via the activation of nuclear receptors (Panzica et al., 1998; Scordalakes et al., 2002; Balthazart et al., 2004).

In addition to the long-term effects of estrogens, estrogens also display rapid effects on several aspects of male sexual behavior. For example, research in mouse and Japanese quail showed that acute modulation of estrogen concentrations rapidly affect male sexual behavior (Cornil et al., 2006; Taziaux et al., 2007; Seredynski et al., 2013, 2015). Many of these rapid effects require doses of estradiol that surpass systemic estradiol concentrations in the blood, but local estradiol levels could reach high concentrations quickly, because aromatase and other steroidogenic enzymes can be rapidly regulated in the brain (see below) and are enriched in subcellular compartments such as the presynaptic bouton (Peterson et al., 2005; Saldanha et al., 2011; Cornil et al., 2012). These rapid and local effects of steroids have led to the hypothesis that neuroestrogens act as neurotransmitters (Balthazart and Ball, 2006). Moreover, exposure to sexual stimuli will in turn affect aromatase activity in several regions. Indeed, copulation rapidly and significantly reduced aromatase activity in hypothalamic nuclei and in median preoptic nucleus or tuberal hypothalamus isolated using the Palkovits punch technique (Cornil et al., 2005; de Bournonville et al., 2013). Conversely, exposure to stress upregulates aromatase activity within $5 \mathrm{~min}$ in a sex- and brain region-dependent manner in quail (Dickens et al., 2011, 2013), but this increase was counteracted by copulation with a female (Dickens et al., 2012). The mechanisms leading to rapid changes of aromatase activity seem to rely on phosphorylation-dephosphorylation processes but the exact mechanisms are far from being understood (Balthazart et al., 2005, 2006; Charlier et al., 2011a).

It should be noted that the measurements of estrogens do not correlate with aromatase activity in most cases and future work should tackle this discrepancy (Charlier et al., 2011b; Dickens et al., 2014; de Bournonville et al., 2017b). Interestingly, central aromatase is not only important for male sexual behavior but was also shown recently to be involved in female sexual behavior in Japanese quail (de Bournonville et al., 2016, 2017a), see also recent discussion in Cornil (2017). The very high concentration of aromatase in birds make them a very suitable model to investigate its function in modulating sexual behavior but it is likely that rapid change in aromatase activity are also important in mammals and fish, as rapid effects of estrogens were demonstrated on sexual motivation in rat and Goldfish (Cross and Roselli, 1999). However, little is known about the behavioral role of aromatase in fish. As stated above, fish in general possess a very wide distribution of aromatase but the presence of high levels of aromatase, androgen, and estrogen receptors, in brain regions involved in the detection and processing of visual stimuli, suggests that visual processes related to reproduction may be influenced by sex steroids (Gelinas and Callard, 1993, 1997). Testosterone is necessary and sufficient for the enhancement of male approach responses toward a female stimulus to occur and androgen treatments in female goldfish also induce selective approach responses toward female visual stimuli (Thompson et al., 2004). Injections of $17 \beta$-E2 had the same behavioral effect 

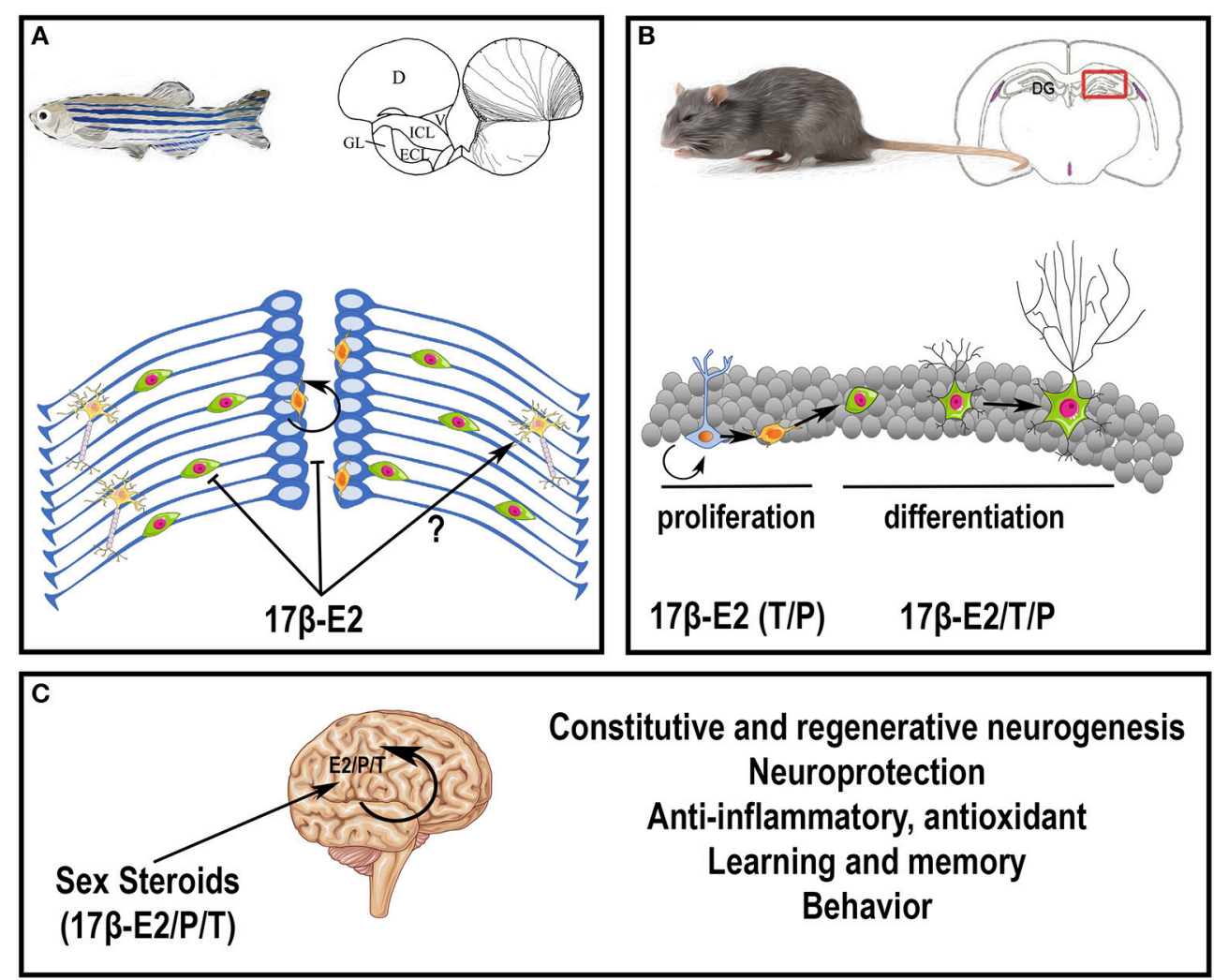

FIGURE 3 | Potential roles of steroids in the brain. (A) Effects of $17 \beta$-estradiol on neurogenesis in adult zebrafish. At the top, the scheme represents a zebrafish and a transversal brain section through the olfactory bulbs, taken from Menuet et al. (2005). The lines on the right hemisphere correspond to radial glial cells, that behave as neural stem cells. At the bottom, the scheme illustrates neurogenesis events occurring on the zebrafish brain. Radial glial cells (blue) give rise to new neurons (green) that migrate and differentiate into mature and functional neurons (yellow). The orange cells close to the ventricle vicinity are further committed progenitors. It was shown that $17 \beta$-estradiol impairs neural progenitor proliferation and new born cell migration; the data obtained for neural differentiation and survival are not clear (Diotel et al., 2013; Pellegrini et al., 2015). (B) Effects of sex steroids on neurogenesis in adult rodents. At the top, the scheme represents a rodent and a transversal brain section through the dentate gyrus (DG) of the hippocampus (framed box), where neurogenesis is maintained during adulthood. At the bottom, the scheme illustrates neurogenesis events occurring in the granular cell layer of the dentate gyrus. Radial glial cells (blue light) give rise to neural progenitors (orange) that give birth to new neurons (green with a small neuritic arborescence) that migrate and differentiate into mature and functional neurons (green with a huge neuritic arborescence). In general, $17 \beta$-estradiol (17 $\beta$-E2) favors neural stem cell/progenitor proliferation; to a lesser extent, testosterone $(T)$ and progesterone (P) also exert positive role on proliferation; 17 $\beta$-estradiol, testosterone and progesterone also promote neuronal migration and differentiation (Heberden, 2017). In addition, these three sex steroids promote new born cell survival in constitutive and regenerative neurogenesis. Note, that the effects of sex steroids on neurogenesis could be dependent of the timing, the concentration, the rhythm of exposure and the regions targeted. For instance, estradiol treatment has been shown to decrease neurogenesis in the SVZ (Brock et al., 2010). (C) Peripheral steroids and neurosteroids impact brain functions and homeostasis, by modulating neurogenesis under homeostatic and regenerative conditions, by promoting neuroprotection, learning, and memory, and by exerting anti-inflammatory and antioxidant properties. They also modulate sexual behavior.

as testosterone, and pretreatment with the aromatase inhibitor (fadrozole) 15 min prior to testosterone injections significantly reduced the male's ability to detect and/or orient toward potential mates. Local $17 \beta$-E2 synthesis in neural pathways involved in visual processing could therefore sensitize the males to some visual features of females and modulate orientation responses in the context of reproduction (Lord et al., 2009).

\section{Importance of Neuroprogestins: Neuroprogesterone}

In most species, the synchrony between ovulation and female sexual behavior is obviously fundamental for efficient reproductive output. Both processes require a sequential elevation of estradiol and progesterone (Mahesh and Brann, 1998; Stephens et al., 2015). Although preliminary observations suggested that progesterone originating from the periphery (Buckingham et al., 1978; Putnam et al., 1991; Mahesh and Brann, 1992), ovariectomized and adrenalectomized rats continue to produce a LH surge in response to estradiol priming, suggesting a role for the central production of progesterone (Ferin et al., 1969; Micevych et al., 2003). This central production of neuroprogesterone is linked to astrocytic activity as astrocytes possess transport proteins (TSPO, StAR) and steroidogenic enzymes (P450ssc, 3ßHSD, etc.) required to transform cholesterol into progesterone. Importantly, the synthesis of progesterone in female hypothalamic astrocytes is regulated by estradiol. This estradiol, from gonadal origin will likely affect the transcription and/or activity of multiple transporters and enzymes, including StAR, TSPO, P450ssc, 
and $3 \beta$-HSD, as observed in vitro and in vivo (Sinchak et al., 2003; Soma et al., 2005; Micevych et al., 2007; Micevych and Sinchak, 2008a; Kuo et al., 2010; Chen et al., 2014). To our knowledge, the role of neuroprogesterone on the display of sexual behavior is currently not known, although the very fast effect of progesterone receptor antisense oligonucleotides on lordosis behavior could suggest a local synthesis of progesterone (Mani et al., 1994). Although the role of neuroprogesterone on female sexual behavior has not been extensively studied, the function of its metabolite allopregnanolone has been investigated in more detail (Frye, 2011).

\section{Importance of Neuroprogestins: Allopregnanolone}

Allopregnanolone, also known as $3 \alpha$-hydroxy-5 $\alpha$-pregnan-20one $(3 \alpha, 5 \alpha-\mathrm{THP})$, is a neurosteroid produced in several regions of the central nervous system by local conversion of progesterone via $5 \alpha$-reductase. After paced mating $3 \alpha, 5 \alpha$-THP rapidly increases in the midbrain ventral tegmental area (VTA), a dopaminergic region involved in reproductive behaviors of female rodents. The rapidity of the rise in midbrain $3 \alpha, 5 \alpha-$ THP levels, and independence of ovaries and/or adrenals as sources of steroids, suggest that biosynthesis underlies matinginduced increases (Frye and Vongher, 1999). Paced mating also increases $3 \alpha, 5 \alpha$-THP concentrations in other structures of the mesocorticolimbic circuit, such as hippocampus, and cortex (Frye et al., 2013). Central infusions with an inhibitor of TSPO (PK-11195), or with an inhibitor of $3 \alpha-\mathrm{HSD}$ within the midbrain VTA significantly attenuated $3 \alpha, 5 \alpha$-THP levels of pro-estrus rats and led to a significant reduction in sexual behavior (Frye and Paris, 2011). In order to assess whether central $3 \alpha, 5 \alpha-$ THP is necessary and sufficient for these effects, pro-estrus rats were infused with $3 \alpha, 5 \alpha$-THP subsequent to inhibitor infusions and results indicated a reinstatement of sexual behavior (Frye and Paris, 2011). In hamsters, infusions of a TSPO agonist, to the VTA increased sexual responsiveness and lordosis of cycling, estradiol and progesterone-primed hamsters, compared to vehicle. In contrast, and similarly to what was observed in rat, the TSPO antagonist (PK-11195) injection to the VTA attenuated sexual responsiveness of naturally receptive or estradiol benzoate (EB) + progesterone -primed hamsters compared to vehicle. In parallel, these treatments respectively led to increased and decreased midbrain levels of allopregnenolone (Petralia and Frye, 2005). Future work should define in more detail the precise relationship between localized allopregnanolone synthesis and specific sexual behaviors.

Neurosteroid synthesis is pronounced during early development. Numerous steroidogenic enzymes are expressed at very high levels in the developing avian brain (Goodson et al., 2005; Tsutsui et al., 2006; London and Schlinger, 2007). In rodent brain, most steroidogenic enzymes are typically expressed at much lower levels compared to fish and birds and thus more difficult to quantify but the developmental expression pattern was described for a few steroidogenic enzymes. For example, in rats, brain expression of $\mathrm{P} 450 \mathrm{c} 17$, the enzyme responsible for the transformation of pregnenolone to DHEA, is elevated in the embryo and decreases postnatally (Compagnone and Mellon, 2000). Brain 3 $\beta$-HSD mRNA in rodents is highest during early development (Ibanez et al., 2003). Although steroids from gonadal origin are known to be a significant parameter in sex differentiation in bird, neurosteroids may regulate sexual differentiation in songbird species. In nestling European starlings, neural metabolism of DHEA and 17 $\beta$-E2 can be greater in males than females at specific ages (Chin et al., 2008; Shah et al., 2011). In zebra finches, 17 $\beta$-E2 synthesized de novo in cultured male brain slices triggers development of an important projection in the song control circuit (Holloway and Clayton, 2001). Female brain slices developed this projection only when co-cultured with male slices, suggesting a sex difference in neural $17 \beta$-E2 synthesis during development (Holloway and Clayton, 2001; Schlinger et al., 2001). Progesterone is also synthesized in the brain during development (Zwain and Yen, 1999; Micevych and Sinchak, 2008a,b) and promotes myelination (Koenig et al., 1995; Schumacher et al., 2007).

\section{STEROIDS AND LIPOPROTEINS: FROM PERIPHERY TO THE BRAIN \\ Transport and Actions of Steroids on the Blood-Brain Barrier}

Although neurosteroids play key roles on brain functions, peripheral steroid hormones have the main effects on the CNS, either by crossing the BBB or by targeting the BBB cells, which in turn impact the brain parenchyma by modulating inflammatory and oxidative signals. Some of these possibilities were recently discussed in a review for other hormones called adipokines (Parimisetty et al., 2016). In this part, we will first describe the structure of the BBB in fish, birds, and mammals, then document the transport of steroid through the BBB before discussing the potential roles of steroids on the BBB.

\section{Blood-Brain Barrier in Fish, Bird, and Mammals}

The BBB is a specialized layer of cells that controls molecular trafficking between blood and brain, and contributes to the regulation (homeostasis) of the brain microenvironment. In mammalian species, BBB is composed of adjacent endothelial cells bound to each other by tight junctions whose major components are transmembrane and cytoplasmic anchoring protein such as occludin, claudin, and zona occludens (ZO1). To complete the barrier, endothelial cells are wrapped by pericytes and surrounded by astrocytic cytoplasmic processes called end-feet. This cellular association is important for proper brain homeostasis, neuronal activity but also for protecting nervous tissue pathogens and harmful molecules transported by blood flow. The BBB, by separating the peripheral blood circulation from the brain parenchyma, filters the entrance of many molecules but also the removal of molecules from the brain (Banks, 2012).

Very few studies have focused on anatomical and functional organization of the BBB in birds and fish. Electron microscopy performed in adult and embryonic brains of quail and chicken showed that cerebral endothelial cells of both species are bound by tight junctions and that BBB is probably functional very early during embryonic development (Wakai and Hirokawa, 1978; 
Stewart and Wiley, 1981; Roncali et al., 1986). In embryonic chick, aquaporin 4, a molecular water channels identified in mammalian BBB, was described in astroglia (Nico et al., 2001). In zebrafish, anatomical analysis and transmission electron microscopy revealed that adult endothelial cells display physical barrier properties and express Claudin-5 and ZO-1 proteins (Jeong et al., 2008; Eliceiri et al., 2011; Li et al., 2017). Complete maturation of the zebrafish BBB occurs between 3 and 10 days when expression of Claudin-5 and ZO-1 proteins are detected in cerebral endothelial vascular cells (Jeong et al., 2008; Eliceiri et al., 2011; Fleming et al., 2013; Li et al., 2017). Although some studies have highlighted the presence of stellate astrocytes in some fish (Kawai et al., 2001; Alunni et al., 2005; StroblMazzulla et al., 2010), immunohistochemistry against GFAP or $S 100 \beta$ protein has generally failed to demonstrate the presence of star-shaped cells resembling mammalian astrocytes in brain of many fish, including trout, carp, and zebrafish (Arochena et al., 2004; Pellegrini et al., 2005; Grupp et al., 2010; März et al., 2010). These findings raise the possibility that specialized functions of mammalian astrocytes could be supported by the GFAP, BLBP, and S100 $\beta$-positive RGCs that remains numerous in adults. RNA sequencing analysis performed on goldfish RGC revealed the presence of many receptors and signaling molecules known to be expressed by astrocytes in mammals, a finding that strongly suggests that RGCs share functional similarities with mammalian astrocytes (Grupp et al., 2010; Fleming et al., 2013; Da Fonte et al., 2017). Very interestingly, in the zebrafish brain, blood vessels are wrapped by $\mathrm{AroB}^{+}$processes, in a way similar to astrocytic endfeet in mammals, further reinforcing the idea that RGCs in fish perform some, if not all, functions of astrocytes (Figures 4A,B).

\section{Steroid Transport through the Blood-Brain Barrier}

Steroid hormones are lipophilic and thus may cross the BBB by simple diffusion (Witt and Sandoval, 2014). Hormones can also enter the brain via specific transporters (Banks, 2012). In mammals, the transporters that help the passage from the blood circulation to the brain parenchyma are named influx transporters and include organic anion transporting polypeptides (OATPs), proton-coupled monocarboxylate transporters (MCTs), and peptide transporter. In the case of simple diffusion through the BBB, steroid concentrations will tend to equilibrate between the plasma and the brain. However, most steroid hormones are transported in the blood by albumin, sex hormone-binding globulin, or by corticosteroid-binding globulin, changing their availability and the possibility of passive diffusion through the $\mathrm{BBB}$, as shown in most vertebrates, including fish, birds, and mammals (Hammond, 2011, 2016; Rosner, 2015). In rats, radiolabeled steroids (i.e., progesterone, testosterone, estradiol and corticosterone, and cortisol), intravenously injected have been shown to diffuse through the $\mathrm{BBB}$, but this diffusion was significantly slowed down by the presence of binding globulin (Pardridge and Mietus, 1979).In addition, one must take into account that the concentration of carrier proteins may be different in the peripheral circulation vs. the cerebrospinal fluid (CSF). For example, the albumin concentration is one hundred time less important in the CSF
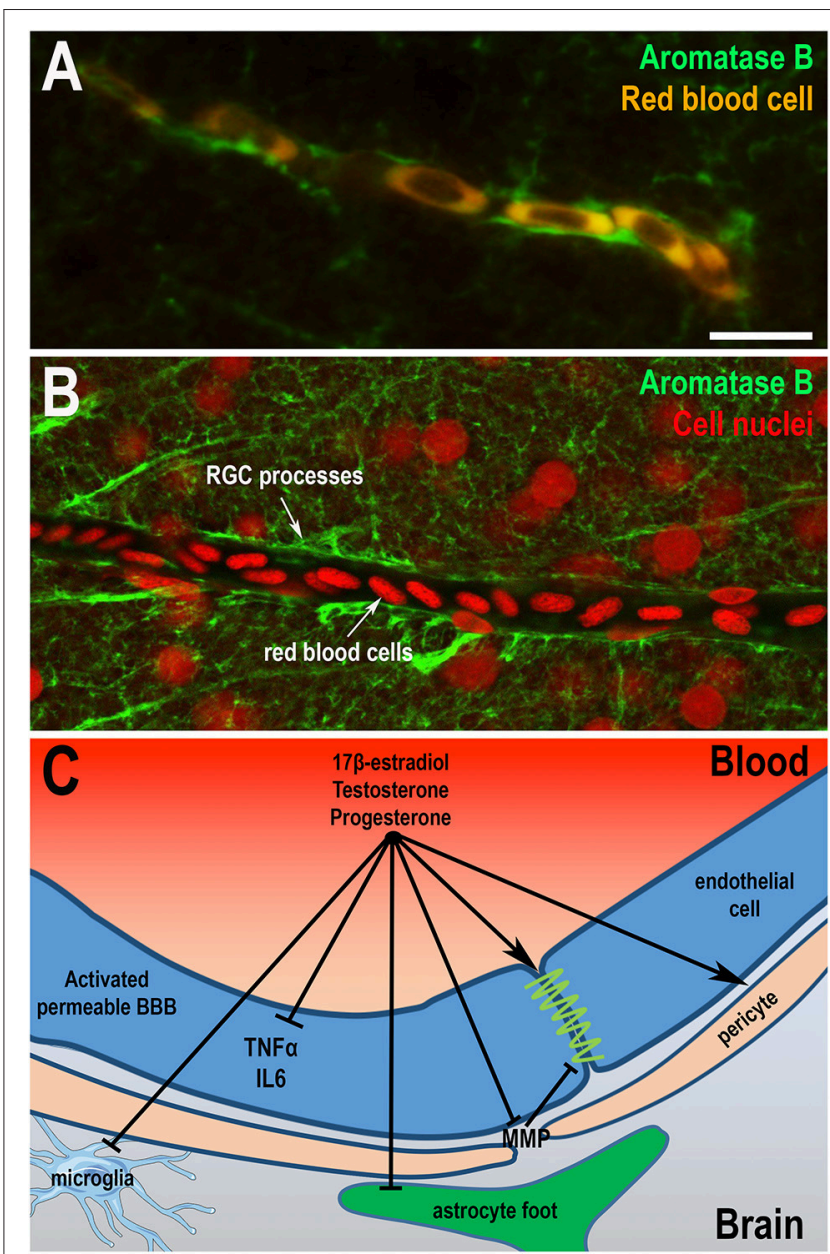

FIGURE 4 | Sex hormones restore blood-brain barrier physiology and integrity. (A,B) Aromatase B immunohistochemistry (green) on zebrafish brain highlights that radial glial processes envelop blood vessels as shown by the auto-fluorescence of red blood cells (A) or by nuclear staining (B). These data suggest that radial glial cells could endorse the role of astrocytes in the establishment of the BBB, given the absence of astrocytic cell-type in the brain of fish. It also raises the question of the potential role of locally-produced estrogens on the BBB physiology. Scale bar: $7 \mu \mathrm{m}$. (C) Sex steroids (17 $\beta$-E2, progesterone, and testosterone) display direct and indirect effects on the BBB through the restauration of thigh junctions, the inhibition of inflammatory cytokine expression and metalloproteinases production, the regulation of pericytes contraction, and consequently the modulation of cerebral blood flow. They also limit reactive gliosis through the inhibition of glial activation under pathological conditions (astrocytes and microglia). Sex steroids participate in the maintenance of a functional BBB, reducing neuroinflammation and promoting neuroprotection.

than in the plasma in humans (Alafuzoff et al., 1983), potentially modulating availability and stability of the steroids.

In addition, hormones may be transported back into the blood circulation by efflux transporters. In mammals, these transporters, belonging to the ABC (ATP Binding Cassette) family, play a key role in brain homeostasis and mediate active efflux of many potential toxicants including lipophilic compounds. They include the P-glycoprotein, also known as 
MDR1, ABCB1), multidrug resistance-associated protein, and breast cancer-related protein (Witt and Sandoval, 2014). Organic ion transporting polypeptides (OATPs) and the organic ion transporters, which belong to the solute-linked carrier (SLC) class, could be involved in uptake and/or efflux (Kusuhara and Sugiyama, 2005). For example, metabolites of estrogens can be transported back in the blood circulation from the brain such as demonstrated in male rats (Sugiyama et al., 2001). The same was also shown in rats for the neuroactive androgenic steroid dehydroepiandrosterone sulfate (DHEAS) that is transported back through a member of the SLC class (Asaba et al., 2000). However, the role of efflux transporter in the regulation of the concentration of steroids in the brain is not well-known and remains controversial.

\section{Effects of Steroids on the Blood-Brain Barrier}

Steroids could act directly or indirectly on the BBB, notably by binding to receptors present in the cells composing the BBB. The effects of glucocorticoids on the BBB are well-described and notably include decrease in inflammation (cytokines, chemokines, metalloproteinases) and increase in protective or reparative effects on tight junctions (Witt and Sandoval, 2014). Sex steroids were also shown to exert protective effects on the $\mathrm{BBB}$, using microvessel endothelial bEnd.3 cells ( $\mathrm{Na}$ et al., 2015). Considering estrogens, treatment with $17 \beta-\mathrm{E} 2$ restores the $\mathrm{BBB}$ integrity and its permeability in a model of stroke or in a lipopolysaccharides-induced inflammation in rodents (Maggioli et al., 2016; Xiao et al., 2017). Of interest, the BBB permeability is increased when circulating estrogens decrease with aging (Bake and Sohrabji, 2004). With respect to androgens, when gonadal testosterone is depleted from the body, glial cells (microglia and astrocytes) are activated and BBB permeability and inflammation are increased. Testosterone treatments restore these parameters (Atallah et al., 2017). Finally, it also seems that progesterone exerts positive effects on the BBB physiology after stroke and TBI (Ishrat et al., 2010; Si et al., 2014). The effects (direct and indirect) of steroids on the BBB is described in Figure 4C.

Interestingly, it was also demonstrated that sex steroids $(17 \beta$ $\mathrm{E} 2$, testosterone, and progesterone) regulate both cerebrovascular tone, endothelial function, oxidative stress, and inflammation as well as brain functions under normal and/or pathological conditions (i.e., middle cerebral artery occlusion: MCAO) (Krause et al., 2011; Gonzales, 2013; Si et al., 2014).

\section{Lipoproteins in the Brain}

Lipid metabolism, high density lipoprotein (HDL)-, and low density lipoprotein (LDL)-cholesterol were studied in a wide variety of groups including rodents, lagomorph, birds, and fish ( $\mathrm{Liu}$ and $\mathrm{Wu}, 2004)$. Lipoprotein metabolism, HDL-, and LDL-cholesterol in zebrafish appear similar to humans, making zebrafish an appropriate model for studying lipoproteins, given that zebrafish express the main set of lipid transporters, apolipoproteins, and enzymes involved in lipoprotein metabolism (Fang et al., 2014). However, to our knowledge, except in rodents, not much is known concerning the effects of HDL-cholesterol in the transport of steroids, in the maintenance of the $\mathrm{BBB}$ integrity and in neuroprotection. We consequently emphasize these points in this last part.

The brain is a cholesterol-rich organ, accounting for about $25 \%$ of the total amount present in humans. In the CNS, cholesterol is mainly synthesized by astrocytes, oligodendrocytes, microglia and to a lesser extent by neurons, where it is essentially present in its unesterified form (Björkhem and Meaney, 2004; Dietschy and Turley, 2004; Zhang and Liu, 2015). Brain cholesterol is involved in myelin sheath genesis, in synaptogenesis, and neurotransmission as well as in neurosteroidogenesis (Mauch et al., 2001; Do Rego et al., 2009; Linetti et al., 2010; Liu et al., 2010; Zhang and Liu, 2015). In adults, sterols are excreted from the brain to the plasma, and cholesterol is converted into $24 \mathrm{~S}$-hydroxycholesterol, which is more soluble and may diffuse across the BBB to reach the plasma where it is metabolized to bile acids after being picked up by circulating lipoproteins (Quan et al., 2003; Mahley, 2016). Almost no cholesterol enters the brain from the peripheral circulation. However, small high density lipoprotein (HDL) particles may cross the $\mathrm{BBB}$ and transport cholesterol within the brain (Ladu et al., 2000; Koch et al., 2001).

Spherical lipoproteins similar to HDLs have been isolated from the CSF. They are composed of ApoE and ApoJ for the largest ones whereas smaller particles contain ApoAI and ApoAII. Astrocytes are the main producers of both ApoE (with microglial cells) and ApoJ (with neurons and ependymal cells) (Vance and Hayashi, 2010). Different isoforms of ApoE have been described in brain HDL particles (ApoE2, ApoE3, and ApoE4). ApoE is the main cholesterol carrier in the brain and is associated with Alzheimer's disease and other neurodegenerative disorders (Liu et al., 2013). Interestingly, cultured neurons and astrocytes expressing the ApoE4 isoforms display a reduced secretion of cholesterol and phospholipids, as well as a blunted lipid-binding capacity (Mahley, 2016). In addition, estrogens were shown to promote ApoE expression in microglia and astrocytes (Stone et al., 1997). Other brain apolipoproteins (i.e., ApoA-I, Apo$\mathrm{J}$, and Apo-D) may participate in cholesterol distribution via different receptors including LDL receptor, ABC (ATP-binding cassette receptor) -A1 and -A2 transporters, LDL Receptorrelated protein), VLDL receptor, ApoE receptor 2, and megalin (Herz and Bock, 2002; Björkhem and Meaney, 2004).

In pathological conditions that lead to $\mathrm{BBB}$ loss of integrity, such as ischemic stroke, exogenous lipoproteins may enter the cerebral parenchyma and produce different effects. Functional HDL particles (HDLs displaying anti-inflammatory and antioxidant properties, see Figure 5A) are taken up by endothelial cells of the BBB in a thrombo-embolic stroke model of rat. Injection of fluorescent lipoproteins post-stroke are taken up by endothelial cells and astrocytes, but not by neurons (Lapergue et al., 2010). In this model and in the MCAO (middle-cerebral artery occlusion), one intravenous injection of HDLs isolated from healthy subjects reduced the mortality, the infarct volume and the hemorrhagic transformation associated with rtPA (recombinant tissue plasminogen activator) treatment (Lapergue et al., 2013). It is not known whether the cholesterol or steroids contained within these HDL particles are involved in the protective effects. It is indeed possible that either ester of steroids 
or cholesterol delivery for local steroid synthesis could participate in neurogenesis and post-stroke remodeling. In this line, there is no study showing any beneficial effect of reconstituted HDL particles in CNS disorders. Noteworthy, these HDLs are composed of ApoA-I and phospholipids, but are devoid of cholesterol (Darabi et al., 2016). Ortiz-Munoz et al. recently demonstrated that at the acute phase of stroke, HDL particles are dysfunctional (HDLs displaying defective anti-inflammatory and antioxidant properties) and larger than in controls (OrtizMuñoz et al., 2016). These qualitative abnormalities blunted their ability to protect the $\mathrm{BBB}$ during acute brain injury. In fact, in addition to their action on reverse transport of cholesterol, HDLs also display anti-oxidant, anti-inflammatory, and anti-protease activities (Tran-Dinh et al., 2013). These pleiotropic effects could be due to different proteins associated with HDL particles such as paraoxonase-1 (PON-1), but also to the lipids that they transport, and to steroids. In type 2 diabetes mellitus conditions (T2DM), HDL anti-inflammatory capacity is impaired due to decreased PON-1 activity (Ebtehaj et al., 2017). Another study investigated the association between plasma cholesterol/lipoproteins and BBB permeability in a condition of CNS inflammation such as multiple sclerosis (Fellows et al., 2015). HDL-Cholesterol was associated with lower levels of BBB injury and low CSF total protein concentration. The authors suggest that the $\mathrm{BBB}$ structural integrity is associated with plasma membrane subdomains involved in cholesterol homeostasis. HDL particles are larger in stroke patients than in controls and they display a reduced protective effect for the BBB (OrtizMuñoz et al., 2016). Small HDL particles enter the CNS via SRB1-mediated uptake and transcytosis (Balazs et al., 2004; Vitali et al., 2014). Morphological abnormality of HDLs in brain injury condition like stroke could be responsible for their reduced capacity to cross the blood-cerebrospinal fluid barrier. HDL supplementation could represent an interesting and innovative protective therapy for brain injury.

Interestingly, Leszczynski and Schafer (1991) demonstrated the interaction between lipoproteins and steroid hormones (androstenediol, 17 $\beta$-E2, DHEA, DHT, pregnenolone, and progesterone), highlighting a new pathway in steroid hormone processing in plasma and/or steroid hormone delivery to cells (Leszczynski and Schafer, 1991). Other reports also suggest that $17 \beta-E 2$ could be incorporated into HDL particles by lecithin:cholesterol acyltransferase under the form of $17 \beta-\mathrm{E} 2$ ester, that could be in turn transferred into LDL particles by cholesteryl ester transfer protein LDL particles as reviewed in Tikkanen et al. (2002) and Höckerstedt et al. (2004). The Figure 5B illustrates such a transport of 17 $\beta$-E2 ester in HDLs and LDLs. These data would argue in favor of potential antioxidant, anti-inflammatory, and neuroprotective effects of HDLs implying cholesterol and other steroids (or their esterified forms) associated to lipoprotein particles. Indeed, estrogen derivatives with an unsubstituted A-ring phenolic hydroxyl group confers stronger antioxidant protection to LDL and HDL (Badeau et al., 2005). Such data could suggest a potential therapeutic use of HDL particles in order to improve their neuroprotective properties through their enrichment with steroids.

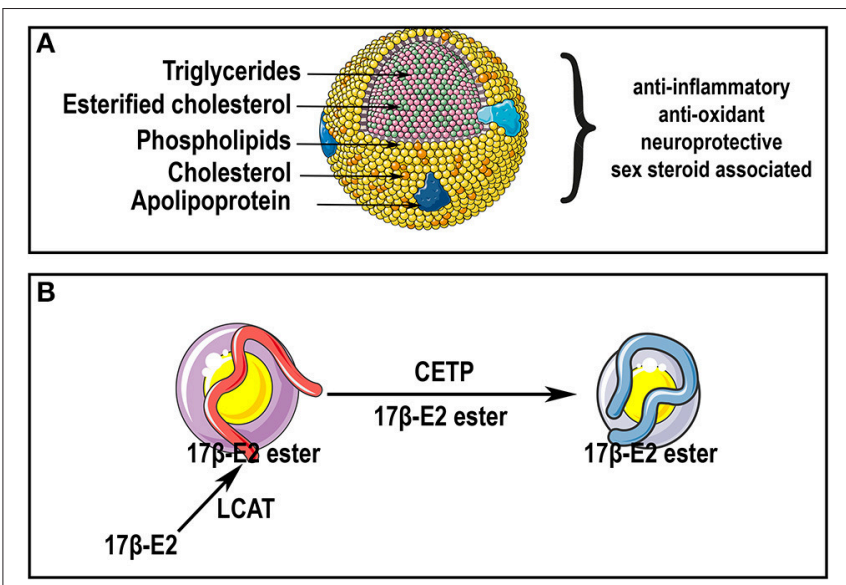

FIGURE 5 | HDL particles and sex steroids. (A) Lipoprotein particles display a central core containing cholesterol, cholesterol esters and triglycerides, that is enveloped by free cholesterol, phospholipids, and apolipoproteins. HDL particles display pleiotropic effects partly supported by their anti-inflammatory, anti-oxidant and neuroprotective properties. HDLs have been shown to display metabolic interaction with sex steroids (i.e., androstenediol, estradiol, DHEA, dihydrotestosterone, pregnenolone, and progesterone). (B) As suggested by Tikkanen et al. (2002), 17 $\beta$-E2 could be esterified with fatty acids by lecithin:cholesterol acyltransferase (LCAT) in HDL. Esterified 17 $\beta$-E2 could be subsequently transferred from HDLs to LDLs by cholesteryl ester transfer protein (CETP). Thus, HDL particles could be a source of cholesterol and steroids in the brain notably after CNS insults, and could be used as a carrier for improving steroids delivery in therapeutically approaches.

\section{CONCLUSION}

In this review, we reported that the brains of fish, birds, and mammals are able to de novo synthesize a wide variety of sex steroids demonstrating that neurosteroidogenesis is an evolutionary conserved feature shared by common ancestors. We also emphasize that neurogenic regions are closely related to neurosteroid production. In particular, RGCs, acting as neural progenitors in the brain of adult fish, strongly express Aromatase $B$ and some other steroidogenic enzymes, suggesting that RGCs are true steroidogenic cells. Such an expression of aromatase in RGCs is not restricted to fish as it was also observed in mammals during embryonic development (Martínez-Cerdeño et al., 2006) and in birds after mechanical lesion of the brain (Peterson et al., 2001).

Peripheral, we also highlighted the fact that the brains of fish, birds, and mammals are targeted by peripheral and locally-produced steroids namely estrogens, progestins, and androgens. It appears that nuclear and membrane-associated sex steroid receptors are widely expressed in the brains of vertebrates particularly in neuroendocrine regions (i.e., preoptic area and hypothalamus) as well as in neurogenic niches and neural progenitors, suggesting key roles of steroids in sexual behaviors and neurogenesis. Indeed, we notably depicted the roles of estrogens, progestins and androgens in constitutive and regenerative neurogenesis and in sexual behaviors. Due to their anti-inflammatory, antioxidant, and anti-apoptotic properties, sex steroids also exert neuroprotective properties in the brain, particularly after CNS insults such as stroke and traumatic brain 
injury. However, the effects of steroids are not trivial to study and understand given that their actions are largely dependent on numerous variables (i.e., the timing, the concentration, the rhythm of exposure,...).

Peripheral steroids may diffuse or cross the BBB through transporters, raising the question of the respective roles of peripherally vs. centrally-produced steroids in brain homeostasis and functions. Peripheral sex steroid and neurosteroids can also act on the $\mathrm{BBB}$ permeability by modulating inflammatory and oxidative signals and consequently regulate brain homeostasis.

Of interest, in this review, we also discussed the potential hypothesis that the protective effects of HDL particles on stroke could be partly attributed to their interactions with sex-steroids. Thus, we raised the question of the contribution of cholesterol and sex-steroids transported by lipoproteins in the neuroprotection at the acute phase of stroke. Steroids are considered as good therapeutic candidates for CNS insults (i.e., stroke, traumatic brain injury), aging, and neurodegenerative

\section{REFERENCES}

Adolf, B., Chapouton, P., Lam, C. S., Topp, S., Tannhäuser, B., Strähle, U., et al. (2006). Conserved and acquired features of adult neurogenesis in the zebrafish telencephalon. Dev. Biol. 295, 278-293. doi: 10.1016/j.ydbio.2006.03.023

Alafuzoff, I., Adolfsson, R., Bucht, G., and Winblad, B. (1983). Albumin and immunoglobulin in plasma and cerebrospinal fluid, and bloodcerebrospinal fluid barrier function in patients with dementia of Alzheimer type and multi-infarct dementia. J. Neurol. Sci. 60, 465-472. doi: 10.1016/0022-510X(83)90157-0

Alkayed, N. J., Harukuni, I., Kimes, A. S., London, E. D., Traystman, R. J., and Hurn, P. D. (1998). Gender-linked brain injury in experimental stroke. Stroke 29, 159-165: discussion 166

Alunni, A., Vaccari, S., Torcia, S., Meomartini, M. E., Nicotra, A., and Alfei, L. (2005). Characterization of glial fibrillary acidic protein and astroglial architecture in the brain of a continuously growing fish, the rainbow trout. Eur. J. Histochem. 49, 157-166.

Andersson, E., Borg, B., and Lambert, J. G. (1988). Aromatase activity in brain and pituitary of immature and mature Atlantic salmon (Salmo salar L.) parr. Gen. Comp. Endocrinol. 72, 394-401. doi: 10.1016/0016-6480(88) 90161-X

Andreassen, T. K., Skjoedt, K., Anglade, I., Kah, O., and Korsgaard, B. (2003). Molecular cloning, characterisation, and tissue distribution of oestrogen receptor alpha in eelpout (Zoarces viviparus). Gen. Comp. Endocrinol. 132, 356-368. doi: 10.1016/S0016-6480(03)00101-1

Anglade, I., Mazurais, D., Douard, V., Le Jossic-Corcos, C., Mañanos, E. L., Michel, D., et al. (1999). Distribution of glutamic acid decarboxylase mRNA in the forebrain of the rainbow trout as studied by in situ hybridization. J. Comp. Neurol. 410, 277-289. doi: 10.1002/(SICI)10969861(19990726)410:2<277::AID-CNE9>3.0.CO;2-V

Anglade, I., Pakdel, F., Bailhache, T., Petit, F., Salbert, G., Jego, P., et al. (1994). Distribution of estrogen receptor-immunoreactive cells in the brain of the rainbow trout (Oncorhynchus mykiss). J. Neuroendocrinol. 6, 573-583. doi: 10.1111/j.1365-2826.1994.tb00621.x

Arnold, A. P. (1980). Quantitative analysis of sex differences in hormone accumulation in the zebra finch brain: methodological and theoretical issues. J. Comp. Neurol. 189, 421-436. doi: 10.1002/cne.901890302

Arochena, M., Anadón, R., and Diaz-Regueira, S. M. (2004). Development of vimentin and glial fibrillary acidic protein immunoreactivities in the brain of gray mullet (Chelon labrosus), an advanced teleost. J. Comp. Neurol. 469, 413-436. doi: 10.1002/cne.11021 diseases. It opens a door for therapeutic research through the use of steroids alone, in cocktail, or transported to the injured site by HDLs.

\section{AUTHOR CONTRIBUTIONS}

$\mathrm{ND}$ and EP designed the manuscript and supervised the work. ND, EP, TC, OM, CL, DC, VT, JN, and OK participated in the writing of the review. ND and CL made the figures.

\section{FUNDING}

This work was supported by grants from La Réunion University (Bonus Qualité Recherche, Dispositifs incitatifs), Conseil Régional de La Réunion, European Union (CPER/FEDER), Philancia association and Fondation de France (for UMR1188 DéTROI), as well as by grants from the Region Bretagne (SAD) and Rennes Metropole (awarded to TC).

Asaba, H., Hosoya, K., Takanaga, H., Ohtsuki, S., Tamura, E., Takizawa T., et al. (2000). Blood-brain barrier is involved in the efflux transport of a neuroactive steroid, dehydroepiandrosterone sulfate, via organic anion transporting polypeptide 2. J. Neurochem. 75, 1907-1916. doi: 10.1046/j.1471-4159.2000.0751907.x

Aste, N., Panzica, G. C., Aimar, P., Viglietti-Panzica, C., Foidart, A., and Balthazart, J. (1993). Implication of testosterone metabolism in the control of the sexually dimorphic nucleus of the quail preoptic area. Brain Res. Bull. 31, 601-611. doi: 10.1016/0361-9230(93)90129-Y

Atallah, A., Mhaouty-Kodja, S., and Grange-Messent, V. (2017). Chronic depletion of gonadal testosterone leads to blood-brain barrier dysfunction and inflammation in male mice. J. Cereb. Blood Flow Metab. 37, 3161-3175. doi: 10.1177/0271678X16683961

Axelsson, J., Mattsson, A., Brunström, B., and Halldin, K. (2007). Expression of estrogen receptor-alpha and -beta mRNA in the brain of Japanese quail embryos. Dev. Neurobiol. 67, 1742-1750. doi: 10.1002/dneu.20544

Azcoitia, I., Sierra, A., Veiga, S., Honda, S., Harada, N., and Garcia-Segura, L. M. (2001). Brain aromatase is neuroprotective. J. Neurobiol. 47, 318-329. doi: $10.1002 /$ neu. 1038

Badeau, M., Adlercreutz, H., Kaihovaara, P., and Tikkanen, M. J. (2005). Estrogen A-ring structure and antioxidative effect on lipoproteins. J. Steroid Biochem. Mol. Biol. 96, 271-278. doi: 10.1016/j.jsbmb.2005.04.034

Bake, S., and Sohrabji, F. (2004). 17beta-estradiol differentially regulates bloodbrain barrier permeability in young and aging female rats. Endocrinology 145, 5471-5475. doi: 10.1210/en.2004-0984

Bakker, J., Honda, S., Harada, N., and Balthazart, J. (2004). Restoration of male sexual behavior by adult exogenous estrogens in male aromatase knockout mice. Horm. Behav. 46, 1-10. doi: 10.1016/j.yhbeh.2004.02.003

Balazs, Z., Panzenboeck, U., Hammer, A., Sovic, A., Quehenberger, O., Malle, E., et al. (2004). Uptake and transport of high-density lipoprotein (HDL) and HDL-associated alpha-tocopherol by an in vitro blood-brain barrier model. J. Neurochem. 89, 939-950. doi: 10.1111/j.1471-4159.2004.02373.x

Balthazart, J., Absil, P., Foidart, A., Houbart, M., Harada, N., and Ball, G. F. (1996). Distribution of aromatase-immunoreactive cells in the forebrain of zebra finches (Taeniopygia guttata): implications for the neural action of steroids and nuclear definition in the avian hypothalamus. J. Neurobiol. 31, 129-148. doi: 10.1002/(SICI)1097-4695(199610)31:2>129::AID-NEU1>3.0. CO;2-D

Balthazart, J., and Ball, G. F. (1998). New insights into the regulation and function of brain estrogen synthase (aromatase). Trends Neurosci. 21, 243-249. doi: 10.1016/S0166-2236(97)01221-6 
Balthazart, J., and Ball, G. F. (2006). Is brain estradiol a hormone or a neurotransmitter? Trends Neurosci. 29, 241-249. doi: $10.1016 /$ j.tins.2006.03.004

Balthazart, J., and Ball, G. F. (2016). Endocrine and social regulation of adult neurogenesis in songbirds. Front. Neuroendocrinol. 41, 3-22. doi: 10.1016/j.yfrne.2016.03.003

Balthazart, J., and Foidart, A. (1993). Brain aromatase and the control of male sexual behavior. J. Steroid Biochem. Mol. Biol. 44, 521-540. doi: 10.1016/0960-0760(93)90256-V

Balthazart, J., and Surlemont, C. (1990). Androgen and estrogen action in the preoptic area and activation of copulatory behavior in quail. Physiol. Behav. 48, 599-609. doi: 10.1016/0031-9384(90)90198-D

Balthazart, J., Baillien, M., and Ball, G. F. (2005). Interactions between kinases and phosphatases in the rapid control of brain aromatase. J. Neuroendocrinol. 17, 553-559. doi: 10.1111/j.1365-2826.2005.01344.x

Balthazart, J., Baillien, M., and Ball, G. F. (2006). Rapid control of brain aromatase activity by glutamatergic inputs. Endocrinology 147, 359-366. doi: 10.1210/en.2005-0845

Balthazart, J., Baillien, M., Cornil, C. A., and Ball, G. F. (2004). Preoptic aromatase modulates male sexual behavior: slow and fast mechanisms of action. Physiol. Behav. 83, 247-270. doi: 10.1016/j.physbeh.2004.08.025

Balthazart, J., Evrard, L., and Surlemont, C. (1990). Effects of the nonsteroidal inhibitor R76713 on testosterone-induced sexual behavior in the Japanese quail (Coturnix coturnix japonica). Horm. Behav. 24, 510-531. doi: 10.1016/0018-506X(90)90039-Z

Banks, W. A. (2012). Brain meets body: the blood-brain barrier as an endocrine interface. Endocrinology 153, 4111-4119. doi: 10.1210/en.2012-1435

Bardet, P. L., Horard, B., Robinson-Rechavi, M., Laudet, V., and Vanacker, J. M. (2002). Characterization of oestrogen receptors in zebrafish (Danio rerio). J. Mol. Endocrinol. 28, 153-163. doi: 10.1677/jme.0.0280153

Bernard, D. J., Bentley, G. E., Balthazart, J., Turek, F. W., and Ball, G. F. (1999). Androgen receptor, estrogen receptor alpha, and estrogen receptor beta show distinct patterns of expression in forebrain song control nuclei of European starlings. Endocrinology 140, 4633-4643. doi: 10.1210/endo.140.10.7024

Beyer, C., Moralí, G., Naftolin, F., Larsson, K., and Pérez-Palacios, G. (1976). Effect of some antiestrogens and aromatase inhibitors on androgen induced sexual behavior in castrated male rats. Horm. Behav. 7, 353-363. doi: 10.1016/0018-506X(76)90040-4

Björkhem, I., and Meaney, S. (2004). Brain cholesterol: long secret life behind a barrier. Arterioscler. Thromb. Vasc. Biol. 24, 806-815. doi: 10.1161/01.ATV.0000120374.59826.1b

Bondesson, M., Hao, R., Lin, C. Y., Williams, C., and Gustafsson, J. Å. (2015). Estrogen receptor signaling during vertebrate development. Biochim. Biophys. Acta 1849, 142-151. doi: 10.1016/j.bbagrm.2014.06.005

Borg, B., Andersson, E., Mayer, I., and Lambert, J. G. (1989). Aromatase activity in the brain of the three-spined stickleback, Gasterosteus aculeatus. III. Effects of castration under different conditions and of replacement with different androgens. Exp. Biol. 48, 149-152.

Brandt, N., Vierk, R., and Rune, G. M. (2013). Sexual dimorphism in estrogeninduced synaptogenesis in the adult hippocampus. Int. J. Dev. Biol. 57, 351-356. doi: $10.1387 /$ ijdb.120217gr

Brännvall, K., Bogdanovic, N., Korhonen, L., and Lindholm, D. (2005). 19-Nortestosterone influences neural stem cell proliferation and neurogenesis in the rat brain. Eur. J. Neurosci. 21, 871-878. doi: 10.1111/j.1460-9568.2005.03942.x

Brännvall, K., Korhonen, L., and Lindholm, D. (2002). Estrogen-receptordependent regulation of neural stem cell proliferation and differentiation. Mol. Cell. Neurosci. 21, 512-520. doi: 10.1006/mcne.2002.1194

Brinton, R. D., Thompson, R. F., Foy, M. R., Baudry, M., Wang, J., Finch, C. E., et al. (2008). Progesterone receptors: form and function in brain. Front. Neuroendocrinol. 29, 313-339. doi: 10.1016/.jyfrne.2008.02.001

Brock, O., Keller, M., Veyrac, A., Douhard, Q., and Bakker, J. (2010). Short term treatment with estradiol decreases the rate of newly generated cells in the subventricular zone and main olfactory bulb of adult female mice. Neuroscience 166, 368-376. doi: 10.1016/j.neuroscience.2009.12.050

Brown, R. C., Cascio, C., and Papadopoulos, V. (2000). Pathways of neurosteroid biosynthesis in cell lines from human brain: regulation of dehydroepiandrosterone formation by oxidative stress and beta-amyloid peptide. J. Neurochem. $\quad 74, \quad 847-859 . \quad$ doi: $\quad$ 10.1046/j.1471-4159.2000. 740847.x

Buckingham, J. C., Döhler, K. D., and Wilson, C. A. (1978). Activity of the pituitary-adrenocortical system and thyroid gland during the oestrous cycle of the rat. J. Endocrinol. 78, 359-366. doi: 10.1677/joe.0.0780359

Celec, P., Ostatníková, D., and Hodosy, J. (2015). On the effects of testosterone on brain behavioral functions. Front. Neurosci. 9:12. doi: 10.3389/fnins.2015.00012

Celeghin, A., Benato, F., Pikulkaew, S., Rabbane, M. G., Colombo, L., and Dalla Valle, L. (2011). The knockdown of the maternal estrogen receptor 2a (esr2a) mRNA affects embryo transcript contents and larval development in zebrafish. Gen. Comp. Endocrinol. 172, 120-129. doi: 10.1016/j.ygcen.2010.12.020

Chakraborty, T., Shibata, Y., Zhou, L. Y., Katsu, Y., Iguchi, T., and Nagahama, Y. (2011). Differential expression of three estrogen receptor subtype mRNAs in gonads and liver from embryos to adults of the medaka, Oryzias latipes. Mol. Cell. Endocrinol. 333, 47-54. doi: 10.1016/j.mce.2010.12.002

Charalampopoulos, I., Remboutsika, E., Margioris, A. N., and Gravanis, A. (2008). Neurosteroids as modulators of neurogenesis and neuronal survival. Trends Endocrinol. Metab. 19, 300-307. doi: 10.1016/j.tem.2008.07.004.

Charlier, T. D., Ball, G. F., and Balthazart, J. (2008). Rapid action on neuroplasticity precedes behavioral activation by testosterone. Horm. Behav. 54, 488-495. doi: 10.1016/j.yhbeh.2008.03.001

Charlier, T. D., Harada, N., Balthazart, J., and Cornil, C. A. (2011a). Human and quail aromatase activity is rapidly and reversibly inhibited by phosphorylating conditions. Endocrinology 152, 4199-4210. doi: 10.1210/en.2011-0119

Charlier, T. D., Newman, A. E., Heimovics, S. A., Po, K. W., Saldanha, C. J., and Soma, K. K. (2011b). Rapid effects of aggressive interactions on aromatase activity and oestradiol in discrete brain regions of wild male white-crowned sparrows. J. Neuroendocrinol. 23, 742-753. doi: 10.1111/j.1365-2826.2011.02170.x

Chen, C. F., Wen, H. S., Wang, Z. P., He, F., Zhang, J. R., Chen, X. Y., et al. (2010b). Cloning and expression of P450c17-I (17alpha-hydroxylase/17,20lyase) in brain and ovary during gonad development in Cynoglossus semilaevis. Fish Physiol. Biochem. 36, 1001-1012. doi: 10.1007/s10695-009-9378-7

Chen, C., Kuo, J., Wong, A., and Micevych, P. (2014). Estradiol modulates translocator protein (TSPO) and steroid acute regulatory protein (StAR) via protein kinase A (PKA) signaling in hypothalamic astrocytes. Endocrinology 155, 2976-2985. doi: 10.1210/en.2013-1844

Chen, S. X., Bogerd, J., García-López, A., de Jonge, H., de Waal, P. P., Hong, W. S., et al. (2010a). Molecular cloning and functional characterization of a zebrafish nuclear progesterone receptor. Biol. Reprod. 82, 171-181. doi: 10.1095/biolreprod.109.077644

Chin, E. H., Shah, A. H., Schmidt, K. L., Sheldon, L. D., Love, O. P., and Soma, K. K. (2008). Sex differences in DHEA and estradiol during development in a wild songbird: Jugular versus brachial plasma. Horm. Behav. 54, 194-202. doi: 10.1016/j.yhbeh.2008.02.014

Choi, C. Y., and Habibi, H. R. (2003). Molecular cloning of estrogen receptor alpha and expression pattern of estrogen receptor subtypes in male and female goldfish. Mol. Cell. Endocrinol. 204, 169-177. doi: 10.1016/S0303-7207(02)00182-X

Christensen, L. W., and Clemens, L. G. (1974). Intrahypothalamic implants of testosterone or estradiol and resumption of masculine sexual behavior in long-term castrated male rats. Endocrinology 95, 984-990. doi: 10.1210/endo-95-4-984

Christensen, L. W., and Clemens, L. G. (1975). Blockade of testosterone-induced mounting behavior in the male rat with intracranial application of the aromatization inhibitor, androst-1,4,6,-triene-3,17-dione. Endocrinology 97, 1545-1551. doi: 10.1210/endo-97-6-1545

Clemens, L. G. (2013). “The aromatization hypothesis, 1970-1990," in Brain Aromatase, Estrogens, and Behavior, eds J. Balthazart and G. F. Ball (New York, NY; Oxford UP), 155-168.

Commins, D., and Yahr, P. (1985). Autoradiographic localization of estrogen and androgen receptors in the sexually dimorphic area and other regions of the gerbil brain. J. Comp. Neurol. 231, 473-489. doi: 10.1002/cne.902310406

Compagnone, N. A., and Mellon, S. H. (2000). Neurosteroids: biosynthesis and function of these novel neuromodulators. Front. Neuroendocrinol. 21, 1-56. doi: $10.1006 /$ frne.1999.0188

Cornil, C. A.(2017). On the role of brain aromatase in females: why are estrogens produced locally when they are available systemically? $J$. 
Comp. Physiol. A Neuroethol. Sens. Neural Behav. Physiol. 204, 31-49. doi: 10.1007/s00359-017-1224-2

Cornil, C. A., Dalla, C., Papadopoulou-Daifoti, Z., Baillien, M., Dejace, C., Ball, G. F., et al. (2005). Rapid decreases in preoptic aromatase activity and brain monoamine concentrations after engaging in male sexual behavior. Endocrinology 146, 3809-3820. doi: 10.1210/en.2005-0441

Cornil, C. A., Leung, C. H., Pletcher, E. R., Naranjo, K. C., Blauman, S. J., and Saldanha, C. J. (2012). Acute and specific modulation of presynaptic aromatization in the vertebrate brain. Endocrinology 153, 2562-2567. doi: 10.1210/en.2011-2159

Cornil, C. A., Taziaux, M., Baillien, M., Ball, G. F., and Balthazart, J. (2006). Rapid effects of aromatase inhibition on male reproductive behaviors in Japanese quail. Horm. Behav. 49, 45-67. doi: 10.1016/j.yhbeh.2005.05.003

Coumailleau, P., Pellegrini, E., Adrio, F., Diotel, N., Cano-Nicolau, J., Nasri, A., et al. (2015). Aromatase, estrogen receptors and brain development in fish and amphibians. Biochim. Biophys. Acta 1849, 152-162. doi: 10.1016/j.bbagrm.2014.07.002

Cross, E., and Roselli, C. E. (1999). 17beta-estradiol rapidly facilitates chemoinvestigation and mounting in castrated male rats. Am. J. Physiol. 276, R1346-R1350.

Da Fonte, D. F., Martyniuk, C. J., Xing, L., Pelin, A., Corradi, N., Hu, W., et al. (2017). Secretoneurin A regulates neurogenic and inflammatory transcriptional networks in goldfish (Carassius auratus) radial glia. Sci. Rep. 7:14930. doi: 10.1038/s41598-017-14930-8

Darabi, M., Guillas-Baudouin, I., Le Goff, W., Chapman, M. J., and Kontush, A. (2016). Therapeutic applications of reconstituted HDL: when structure meets function. Pharmacol. Ther. 157, 28-42. doi: 10.1016/j.pharmthera.2015.10.010

Davis, D. P., Douglas, D. J., Smith, W., Sise, M. J., Vilke, G. M., Holbrook, T. L., et al. (2006). Traumatic brain injury outcomes in pre- and postmenopausal females versus age-matched males. J. Neurotrauma 23, 140-148. doi: 10.1089/neu.2006.23.140

de Bournonville, C., Ball, G. F., Balthazart, J., and Cornil, C. A. (2017a). Rapid changes in brain aromatase activity in the female quail brain following expression of sexual behavior. J. Neuroendocrinol. 29:e12542. doi: 10.1111 /jne. 12542

de Bournonville, C., Balthazart, J., Ball, G. F., and Cornil, C. A. (2016). Non-ovarian aromatization is required to activate female sexual motivation in testosterone-treated ovariectomized quail. Horm. Behav. 83, 45-59. doi: 10.1016/j.yhbeh.2016.05.011

de Bournonville, C., Dickens, M. J., Ball, G. F., Balthazart, J., and Cornil, C. A. (2013). Dynamic changes in brain aromatase activity following sexual interactions in males: where, when and why? Psychoneuroendocrinology 38, 789-799. doi: 10.1016/j.psyneuen.2012.09.001

de Bournonville, C., Smolders, I., Van Eeckhaut, A., Ball, G. F., Balthazart, J., and Cornil, C. A. (2017b). Glutamate released in the preoptic area during sexual behavior controls local estrogen synthesis in male quail. Psychoneuroendocrinology 79, 49-58. doi: 10.1016/j.psyneuen.2017.02.002

de Waal, P. P., Wang, D. S., Nijenhuis, W. A., Schulz, R. W., and Bogerd, J. (2008). Functional characterization and expression analysis of the androgen receptor in zebrafish (Danio rerio) testis. Reproduction 136, 225-234. doi: 10.1530/REP-08-0055

Devoogd, T. J., Nixdorf, B., and Nottebohm, F. (1985). Synaptogenesis and changes in synaptic morphology related to acquisition of a new behavior. Brain Res. 329, 304-308. doi: 10.1016/0006-8993(85)90539-6

Dickens, M. J., Balthazart, J., and Cornil, C. A. (2012). Brain aromatase and circulating corticosterone are rapidly regulated by combined acute stress and sexual interaction in a sex-specific manner. J. Neuroendocrinol. 24, 1322-1334. doi: 10.1111/j.1365-2826.2012.02340.x

Dickens, M. J., Cornil, C. A., and Balthazart, J. (2011). Acute stress differentially affects aromatase activity in specific brain nuclei of adult male and female quail. Endocrinology 152, 4242-4251. doi: 10.1210/en.2011-1341

Dickens, M. J., Cornil, C. A., and Balthazart, J. (2013). Neurochemical control of rapid stress-induced changes in brain aromatase activity. J. Neuroendocrinol. 25, 329-339. doi: 10.1111/jne.12012

Dickens, M. J., de Bournonville, C., Balthazart, J., and Cornil, C. A. (2014). Relationships between rapid changes in local aromatase activity and estradiol concentrations in male and female quail brain. Horm. Behav. 65, 154-164. doi: 10.1016/j.yhbeh.2013.12.011
Dietschy, J. M., and Turley, S. D. (2004). Thematic review series: brain Lipids. Cholesterol Metabolism in the central nervous system during early development and in the mature animal. J. Lipid Res. 45, 1375-1397. doi: 10.1194/jlr.R400004-JLR200

Diotel, N., Do Rego, J. L., Anglade, I., Vaillant, C., Pellegrini, E., Gueguen, M. M., et al. (2011b). Activity and expression of steroidogenic enzymes in the brain of adult zebrafish. Eur. J. Neurosci. 34, 45-56. doi: 10.1111/j.1460-9568.2011.07731.x

Diotel, N., Do Rego, J. L., Anglade, I., Vaillant, C., Pellegrini, E., Vaudry, H., et al. (2011a). The brain of teleost fish, a source, and a target of sexual steroids. Front. Neurosci. 5:137. doi: 10.3389/fnins.2011.00137

Diotel, N., Le Page, Y., Mouriec, K., Tong, S. K., Pellegrini, E., Vaillant, C., et al. (2010). Aromatase in the brain of teleost fish: expression, regulation and putative functions. Front. Neuroendocrinol. 31, 172-192. doi: 10.1016/j.yfrne.2010.01.003

Diotel, N., Servili, A., Gueguen, M. M., Mironov, S., Pellegrini, E., Vaillant, C., et al. (2011c). Nuclear progesterone receptors are up-regulated by estrogens in neurons and radial glial progenitors in the brain of zebrafish. PLOS ONE 6:e28375. doi: 10.1371/journal.pone.0028375

Diotel, N., Vaillant, C., Gabbero, C., Mironov, S., Fostier, A., Gueguen, M. M., et al (2013). Effects of estradiol in adult neurogenesis and brain repair in zebrafish. Horm. Behav. 63, 193-207. doi: 10.1016/j.yhbeh.2012.04.003

Diotel, N., Vaillant, C., Kah, O., and Pellegrini, E. (2016). Mapping of brain lipid binding protein (Blbp) in the brain of adult zebrafish, co-expression with aromatase B and links with proliferation. Gene Expr. Patterns 20, 42-54. doi: 10.1016/j.gep.2015.11.003

Do Rego, J. L., Seong, J. Y., Burel, D., Leprince, J., Luu-The, V., Tsutsui, K., et al. (2009). Neurosteroid biosynthesis: enzymatic pathways and neuroendocrine regulation by neurotransmitters and neuropeptides. Front. Neuroendocrinol. 30, 259-301. doi: 10.1016/j.yfrne.2009.05.006

Duarte-Guterman, P., Yagi, S., Chow, C., and Galea, L. A. (2015). Hippocampal learning, memory, and neurogenesis: effects of sex and estrogens across the lifespan in adults. Horm. Behav. 74, 37-52. doi: 10.1016/j.yhbeh.2015.05.024

Dupont, E., Simard, J., Luu-The, V., Labrie, F., and Pelletier, G. (1994). Localization of 3 beta-hydroxysteroid dehydrogenase in rat brain as studied by in situ hybridization. Mol. Cell. Neurosci. 5, 119-123. doi: 10.1006/mcne.1994.1014

Ebtehaj, S., Gruppen, E. G., Parvizi, M. U., Tietge, U. J. F., and Dullaart, R. P. F. (2017). The anti-inflammatory function of HDL is impaired in type 2 diabetes: role of hyperglycemia, paraoxonase- 1 and low grade inflammation. Cardiovasc. Diabetol. 16, 132. doi: 10.1186/s12933-017-0613-8

Eliceiri, B. P., Gonzalez, A. M., and Baird, A. (2011). Zebrafish model of the bloodbrain barrier: morphological and permeability studies. Methods Mol. Biol. 686, 371-378. doi: 10.1007/978-1-60761-938-3_18

Escobar, S., Felip, A., Gueguen, M. M., Zanuy, S., Carrillo, M., Kah, O., et al. (2013). Expression of kisspeptins in the brain and pituitary of the European sea bass (Dicentrarchus labrax). J. Comp. Neurol. 521, 933-948. doi: 10.1002/cne. 23211

Fang, L., Liu, C., and Miller, Y. I. (2014). Zebrafish models of dyslipidemia: relevance to atherosclerosis and angiogenesis. Trans. Res. 163, 99-108. doi: 10.1016/j.trsl.2013.09.004

Farinetti, A., Tomasi, S., Foglio, B., Ferraris, A., Ponti, G., Gotti, S., et al. (2015). Testosterone and estradiol differentially affect cell proliferation in the subventricular zone of young adult gonadectomized male and female rats. Neuroscience 286, 162-170. doi: 10.1016/j.neuroscience.2014.11.050

Fellows, K., Uher, T., Browne, R. W., Weinstock-Guttman, B., Horakova, D., Posova, H., et al. (2015). Protective associations of HDL with blood-brain barrier injury in multiple sclerosis patients. J. Lipid Res. 56, 2010-2018. doi: 10.1194/jlr.M060970

Feng, Y., Weijdegård, B., Wang, T., Egecioglu, E., Fernandez-Rodriguez, J., Huhtaniemi, I., et al. (2010). Spatiotemporal expression of androgen receptors in the female rat brain during the oestrous cycle and the impact of exogenous androgen administration: a comparison with gonadally intact males. Mol. Cell. Endocrinol. 321, 161-174. doi: 10.1016/j.mce.2010.02.029

Ferin, M., Tempone, A., Zimmering, P. E., and Van de Wiele, R.L. (1969). Effect of antibodies to 17beta-estradiol and progesterone on the estrous cycle of the rat. Endocrinology 85, 1070-1078. doi: 10.1210/endo-85-6-1070

Fester, L., Prange-Kiel, J., Zhou, L., Blittersdorf, B. V., Bohm, J., Jarry, H., et al. (2012). Estrogen-regulated synaptogenesis in the hippocampus: sexual 
dimorphism in vivo but not in vitro. J. Steroid Biochem. Mol. Biol. 131, 24-29. doi: 10.1016/j.jsbmb.2011.11.010

Filby, A. L., and Tyler, C. R. (2005). Molecular characterization of estrogen receptors $1,2 \mathrm{a}$, and $2 \mathrm{~b}$ and their tissue and ontogenic expression profiles in fathead minnow (Pimephales promelas). Biol. Reprod. 73, 648-662. doi: 10.1095/biolreprod.105.039701

Fisher, C. R., Graves, K. H., Parlow, A. F., and Simpson, E. R. (1998). Characterization of mice deficient in aromatase (ArKO) because of targeted disruption of the cyp19 gene. Proc. Natl. Acad. Sci. U.S.A. 95, 6965-6970. doi: $10.1073 /$ pnas.95.12.6965

Fleming, A., Diekmann, H., and Goldsmith, P. (2013). Functional characterisation of the maturation of the blood-brain barrier in larval zebrafish. PLoS ONE 8:e77548. doi: 10.1371/journal.pone.0077548

Foidart, A., Lakaye, B., Grisar, T., Ball, G. F., and Balthazart, J. (1999). Estrogen receptor-beta in quail: cloning, tissue expression and neuroanatomical distribution. J. Neurobiol. 40, 327-342. doi: 10.1002/(SICI)1097-4695(19990905)40:3<327::AID-NEU5>3.0.CO;2-L

Forlano, P. M., and Bass, A. H. (2005). Seasonal plasticity of brain aromatase mRNA expression in glia: divergence across sex and vocal phenotypes. $J$. Neurobiol. 65, 37-49. doi: 10.1002/neu.20179

Forlano, P. M., Deitcher, D. L., and Bass, A. H. (2005). Distribution of estrogen receptor alpha mRNA in the brain and inner ear of a vocal fish with comparisons to sites of aromatase expression. J. Comp. Neurol. 483, 91-113. doi: $10.1002 /$ cne.20397

Forlano, P. M., Deitcher, D. L., Myers, D. A., and Bass, A. H. (2001). Anatomical distribution and cellular basis for high levels of aromatase activity in the brain of teleost fish: aromatase enzyme and mRNA expression identify glia as source. J. Neurosci. 21, 8943-8955.

Forlano, P. M., Marchaterre, M., Deitcher, D. L., and Bass, A. H. (2010). Distribution of androgen receptor mRNA expression in vocal, auditory, and neuroendocrine circuits in a teleost fish. J. Comp. Neurol. 518, 493-512. doi: $10.1002 /$ cne.22233

Frick, K. M., Kim, J., Tuscher, J. J., and Fortress, A. M. (2015). Sex steroid hormones matter for learning and memory: estrogenic regulation of hippocampal function in male and female rodents. Learn. Mem. 22, 472-493. doi: 10.1101/lm.037267.114

Froehlicher, M., Liedtke, A., Groh, K., López-Schier, H., Neuhauss, S. C., Segner, H., et al. (2009). Estrogen receptor subtype beta2 is involved in neuromast development in zebrafish (Danio rerio) larvae. Dev. Biol. 330, 32-43. doi: 10.1016/j.ydbio.2009.03.005

Frye, C. A. (2011). Novel substrates for, and sources of, progestogens for reproduction. J. Neuroendocrinol. 23, 961-973. doi: 10.1111/j.1365-2826.2011.02180.x

Frye, C. A., and Paris, J. J. (2011). Progesterone turnover to its 5alpha-reduced metabolites in the ventral tegmental area of the midbrain is essential for initiating social and affective behavior and progesterone metabolism in female rats. J. Endocrinol. Invest. 34, e188-e199. doi: 10.3275/7334

Frye, C. A., and Vongher, J. M. (1999). 3alpha,5alpha-THP in the midbrain ventral tegmental area of rats and hamsters is increased in exogenous hormonal states associated with estrous cyclicity and sexual receptivity. J. Endocrinol. Invest. 22, 455-464. doi: 10.1007/BF03343590

Frye, C. A., and Walf, A. A. (2008). Progesterone enhances performance of aged mice in cortical or hippocampal tasks. Neurosci. Lett. 437, 116-120. doi: 10.1016/j.neulet.2008.04.004

Frye, C. A., and Walf, A. A. (2010). Progesterone enhances learning and memory of aged wildtype and progestin receptor knockout mice. Neurosci. Lett. 472, 38-42. doi: 10.1016/j.neulet.2010.01.051

Frye, C. A., Edinger, K., and Sumida, K. (2008). Androgen administration to aged male mice increases anti-anxiety behavior and enhances cognitive performance. Neuropsychopharmacology 33, 1049-1061. doi: 10.1038/sj.npp.1301498

Frye, C. A., Koonce, C. J., Walf, A. A., and Rusconi, J. C. (2013). Motivated behaviors and levels of 3alpha,5alpha-THP in the midbrain are attenuated by knocking down expression of pregnane xenobiotic receptor in the midbrain ventral tegmental area of proestrous rats. J. Sex. Med. 10, 1692-1706. doi: $10.1111 /$ jsm. 12173

Fusani, L., Donaldson, Z., London, S. E., Fuxjager, M. J., and Schlinger, B. A. (2014). Expression of androgen receptor in the brain of a sub-oscine bird with an elaborate courtship display. Neurosci. Lett. 578, 61-65. doi: 10.1016/j.neulet.2014.06.028

Gahr, M. (2001). Distribution of sex steroid hormone receptors in the avian brain: functional implications for neural sex differences and sexual behaviors. Microsc. Res. Tech. 55, 1-11. doi: 10.1002/jemt.1151

Galea, L. A., Spritzer, M. D., Barker, J. M., and Pawluski, J. L. (2006). Gonadal hormone modulation of hippocampal neurogenesis in the adult. Hippocampus 16, 225-232. doi: 10.1002/hipo.20154

Garcia-Segura, L. M. (2008). Aromatase in the brain: not just for reproduction anymore. J. Neuroendocrinol. 20, 705-712. doi: 10.1111/j.1365-2826.2008.01713.x

Garcia-Segura, L. M., Veiga, S., Sierra, A., Melcangi, R. C., and Azcoitia, I. (2003). Aromatase: a neuroprotective enzyme. Prog. Neurobiol. 71, 31-41. doi: 10.1016/j.pneurobio.2003.09.005

Garcia-Segura, L. M., Wozniak, A., Azcoitia, I., Rodriguez, J. R., Hutchison, R. E. and Hutchison, J. B. (1999). Aromatase expression by astrocytes after brain injury: implications for local estrogen formation in brain repair. Neuroscience 89, 567-578. doi: 10.1016/S0306-4522(98)00340-6

Gelinas, D., and Callard, G. V. (1993). Immunocytochemical and biochemical evidence for aromatase in neurons of the retina, optic tectum and retinotectal pathways in goldfish. J. Neuroendocrinol. 5, 635-641. doi: 10.1111/j.1365-2826.1993.tb00533.x

Gelinas, D., and Callard, G. V. (1997). Immunolocalization of aromataseand androgen receptor-positive neurons in the goldfish brain. Gen. Comp. Endocrinol. 106, 155-168. doi: 10.1006/gcen.1997.6891

Gibson, C. L., Gray, L. J., Murphy, S. P., and Bath, P. M. (2006). Estrogens and experimental ischemic stroke: a systematic review. J. Cereb. Blood Flow Metab. 26, 1103-1113. doi: 10.1038/sj.jcbfm.9600270

Girijala, R. L., Sohrabji, F., and Bush, R. L. (2017). Sex differences in stroke: review of current knowledge and evidence. Vasc. Med. 22, 135-145. doi: $10.1177 / 1358863 X 16668263$

Gonzales, R. J. (2013). Androgens and the cerebrovasculature: modulation of vascular function during normal and pathophysiological conditions. Pflugers Archiv. 465, 627-642. doi: 10.1007/s00424-013-1267-3

Gonzalez, A., and Piferrer, F. (2003). Aromatase activity in the European sea bass (Dicentrarchus labrax L.) brain. Distribution and changes in relation to age, sex, and the annual reproductive cycle. Gen. Comp. Endocrinol. 132, 223-230. doi: 10.1016/S0016-6480(03)00086-8

González, M., Cabrera-Socorro, A., Pérez-García, C. G., Fraser, J. D., López, F. J., Alonso, R., et al. (2007). Distribution patterns of estrogen receptor alpha and beta in the human cortex and hippocampus during development and adulthood. J. Comp. Neurol. 503, 790-802. doi: 10.1002/cne.21419

Goodson, J. L., Saldanha, C. J., Hahn, T. P., and Soma, K. K. (2005). Recent advances in behavioral neuroendocrinology: insights from studies on birds. Horm. Behav. 48, 461-473. doi: 10.1016/j.yhbeh.2005.04.005

Gorelick, D. A., Watson, W., and Halpern, M. E. (2008). Androgen receptor gene expression in the developing and adult zebrafish brain. Dev. Dyn. 237, 2987-2995. doi: 10.1002/dvdy.21700

Goto-Kazeto, R., Kight, K. E., Zohar, Y., Place, A. R., and Trant, J. M. (2004). Localization and expression of aromatase mRNA in adult zebrafish. Gen. Comp. Endocrinol. 139, 72-84. doi: 10.1016/j.ygcen.2004.07.003

Griffin, L. B., January, K. E., Ho, K. W., Cotter, K. A., and Callard, G. V. (2013). Morpholino-mediated knockdown of ERalpha, ERbetaa, and ERbetab mRNAs in zebrafish (Danio rerio) embryos reveals differential regulation of estrogeninducible genes. Endocrinology 154, 4158-4169. doi: 10.1210/en.2013-1446

Grupp, L., Wolburg, H., and Mack, A. F. (2010). Astroglial structures in the zebrafish brain. J. Comp. Neurol. 518, 4277-4287. doi: 10.1002/cne.22481

Guennoun, R., Fiddes, R. J., Gouézou, M., Lombès, M., and Baulieu, E. E. (1995). A key enzyme in the biosynthesis of neurosteroids, 3 beta-hydroxysteroid dehydrogenase/delta 5-delta 4-isomerase (3 beta-HSD), is expressed in rat brain. Brain Res. Mol. Brain Res. 30, 287-300. doi: 10.1016/0169-328X(95)00016-L

Guerra-Araiza, C., Villamar-Cruz, O., González-Arenas, A., Chavira, R., and Camacho-Arroyo, I. (2003). Changes in progesterone receptor isoforms content in the rat brain during the oestrous cycle and after oestradiol and progesterone treatments. J. Neuroendocrinol. 15, 984-990. doi: 10.1046/j.1365-2826.2003.01088.x 
Hagihara, K., Hirata, S., Osada, T., Hirai, M., and Kato, J. (1992a). Distribution of cells containing progesterone receptor mRNA in the female rat di- and telencephalon: an in situ hybridization study. Brain Res. Mol. Brain Res. 14, 239-249. doi: 10.1016/0169-328X(92)90179-F

Hagihara, K., Hirata, S., Osada, T., Hirai, M., and Kato, J. (1992b). Expression of progesterone receptor in the neonatal rat brain cortex: detection of its mRNA using reverse transcription-polymerase chain reaction. J. Steroid Biochem. Mol. Biol. 41, 637-640. doi: 10.1016/0960-0760(92)90396-Z

Hajszan, T., Milner, T. A., and Leranth, C. (2007). Sex steroids and the dentate gyrus. Prog. Brain Res. 163, 399-415. doi: 10.1016/S0079-6123(07)63023-4

Halm, S., Martínez-Rodríguez, G., Rodríguez, L., Prat, F., Mylonas, C. C., Carrillo, M., et al. (2004). Cloning, characterisation, and expression of three oestrogen receptors (ERalpha, ERbeta1 and ERbeta2) in the European sea bass, Dicentrarchus labrax. Mol. Cell. Endocrinol. 223, 63-75. doi: 10.1016/j.mce.2004.05.009

Hammond, G. L. (2011). Diverse roles for sex hormone-binding globulin in reproduction. Biol. Reprod. 85, 431-441. doi: 10.1095/biolreprod.111.092593

Hammond, G. L. (2016). Plasma steroid-binding proteins: primary gatekeepers of steroid hormone action. J. Endocrinol. 230, R13-R25. doi: 10.1530/JOE-16-0070

Hamson, D. K., Wainwright, S. R., Taylor, J. R., Jones, B. A., Watson, N. V., and Galea, L. A. (2013). Androgens increase survival of adult-born neurons in the dentate gyrus by an androgen receptor-dependent mechanism in male rats. Endocrinology 154, 3294-3304. doi: 10.1210/en.2013-1129

Hanna, R. N., and Zhu, Y. (2009). Expression of membrane progestin receptors in zebrafish (Danio rerio) oocytes, testis and pituitary. Gen. Comp. Endocrinol. 161, 153-157. doi: 10.1016/j.ygcen.2008.10.006

Hanna, R. N., Daly, S. C., Pang, Y., Anglade, I., Kah, O., Thomas, P., et al. (2010). Characterization and expression of the nuclear progestin receptor in zebrafish gonads and brain. Biol. Reprod. 82, 112-122. doi: 10.1095/biolreprod.109.078527

Harbott, L. K., Burmeister, S. S., White, R. B., Vagell, M., and Fernald, R. D. (2007). Androgen receptors in a cichlid fish, Astatotilapia burtoni: structure, localization, and expression levels. J. Comp. Neurol. 504, 57-73. doi: $10.1002 / \mathrm{cne} .21435$

Hawkins, M. B., Godwin, J., Crews, D., and Thomas, P. (2005). The distributions of the duplicate oestrogen receptors ER-beta a and ER-beta $b$ in the forebrain of the Atlantic croaker (Micropogonias undulatus): evidence for subfunctionalization after gene duplication. Proc. Biol. Sci. 272, 633-641. doi: $10.1098 / \mathrm{rspb} .2004 .3008$

Hawkins, M. B., Thornton, J. W., Crews, D., Skipper, J. K., Dotte, A., and Thomas, P. (2000). Identification of a third distinct estrogen receptor and reclassification of estrogen receptors in teleosts. Proc. Natl. Acad. Sci. U.S.A. 97, 10751-10756. doi: 10.1073/pnas.97.20.10751

Heberden, C. (2017). Sex steroids and neurogenesis. Biochem. Pharmacol. 141, 56-62. doi: 10.1016/j.bcp.2017.05.019

Herz, J., and Bock, H. H. (2002). Lipoprotein receptors in the nervous system. Annu. Rev. Biochem. 71, 405-434. doi: 10.1146/annurev.biochem.71.110601.135342

Hiraki, T., Nakasone, K., Hosono, K., Kawabata, Y., Nagahama, Y., and Okubo, K. (2014). Neuropeptide B is female-specifically expressed in the telencephalic and preoptic nuclei of the medaka brain. Endocrinology 155, 1021-1032. doi: 10.1210/en.2013-1806

Höckerstedt, A., Jauhiainen, M., and Tikkanen, M. J. (2004). Lecithin/cholesterol acyltransferase induces estradiol esterification in high-density lipoprotein, increasing its antioxidant potential. J. Clin. Endocrinol. Metab. 89, 5088-5093. doi: $10.1210 /$ jc.2004-0141

Hojo, Y., Hattori, T. A., Enami, T., Furukawa, A., Suzuki, K., Ishii, H. T., et al. (2004). Adult male rat hippocampus synthesizes estradiol from pregnenolone by cytochromes P45017alpha and P450 aromatase localized in neurons. Proc. Natl. Acad. Sci. U.S.A. 101, 865-870. doi: 10.1073/pnas. 2630225100

Holloway, C. C., and Clayton, D. F. (2001). Estrogen synthesis in the male brain triggers development of the avian song control pathway in vitro. Nat. Neurosci. 4, 170-175. doi: 10.1038/84001

Honda, S., Harada, N., Ito, S., Takagi, Y., and Maeda, S. (1998). Disruption of sexual behavior in male aromatase-deficient mice lacking exons 1 and 2 of the cyp19 gene. Biochem. Biophys. Res. Commun. 252, 445-449. doi: $10.1006 /$ bbrc. 1998.9672
Hossain, M. S., Larsson, A., Scherbak, N., Olsson, P. E., and Orban, L. (2008). Zebrafish androgen receptor: isolation, molecular, and biochemical characterization. Biol. Reprod. 78, 361-369. doi: 10.1095/biolreprod.107.062018

Ibanez, C., Guennoun, R., Liere, P., Eychenne, B., Pianos, A., El-Etr, M., et al. (2003). Developmental expression of genes involved in neurosteroidogenesis: 3beta-hydroxysteroid dehydrogenase/delta5-delta4 isomerase in the rat brain. Endocrinology 144, 2902-2911. doi: 10.1210/en.2002 $-0073$

Ikeuchi, T., Todo, T., Kobayashi, T., and Nagahama, Y. (1999). cDNA cloning of a novel androgen receptor subtype. J. Biol. Chem. 274, 25205-25209. doi: $10.1074 /$ jbc.274.36.25205

Ikeuchi, T., Todo, T., Kobayashi, T., and Nagahama, Y. (2002). A novel progestogen receptor subtype in the Japanese eel, Anguilla japonica. FEBS Lett. 510, 77-82. doi: 10.1016/S0014-5793(01)03220-3

Ishrat, T., Sayeed, I., Atif, F., Hua, F., and Stein, D. G. (2010). Progesterone and allopregnanolone attenuate blood-brain barrier dysfunction following permanent focal ischemia by regulating the expression of matrix metalloproteinases. Exp. Neurol. 226, 183-190. doi: 10.1016/j.expneurol.2010.08.023

Jacobs, E. C., Arnold, A. P., and Campagnoni, A. T. (1999). Developmental regulation of the distribution of aromatase- and estrogen-receptor- mRNAexpressing cells in the zebra finch brain. Dev. Neurosci. 21, 453-472. doi: $10.1159 / 000017413$

Jayasinghe, B. S., and Volz, D. C. (2012). Aberrant ligand-induced activation of G protein-coupled estrogen receptor 1 (GPER) results in developmental malformations during vertebrate embryogenesis. Toxicol. Sci. 125, 262-273. doi: 10.1093/toxsci/kfr269

Jeong, J. Y., Kwon, H. B., Ahn, J. C., Kang, D., Kwon, S. H., Park, J. A., et al. (2008). Functional and developmental analysis of the blood-brain barrier in zebrafish. Brain Res. Bull. 75, 619-628. doi: 10.1016/j.brainresbull.2007.10.043

Jiang, C., Zuo, F., Wang, Y., Lu, H., Yang, Q., and Wang, J. (2016). Progesterone changes VEGF and BDNF expression and promotes neurogenesis after ischemic stroke. Mol. Neurobiol. 54, 571-581. doi: 10.1007/s12035-015-9651-y

Jorgensen, A., Andersen, O., Bjerregaard, P., and Rasmussen, L. J. (2007). Identification and characterisation of an androgen receptor from zebrafish Danio rerio. Comp. Biochem. Physiol. C. Toxicol. Pharmacol. 146, 561-568. doi: 10.1016/j.cbpc.2007.07.002

Kah, O., Pellegrini, E., Mouriec, K., Diotel, N., Anglade, I., Vaillant, C., et al. (2009). [Oestrogens and neurogenesis: new functions for an old hormone. Lessons from the zebrafish.]. J. Soc. Biol, 203, 29-38. doi: 10.1051/jbio:2009007

Kallivretaki, E., Eggen, R. I., Neuhauss, S. C., Kah, O., and Segner, H. (2007). The zebrafish, brain-specific, aromatase cyp19a2 is neither expressed nor distributed in a sexually dimorphic manner during sexual differentiation. Dev. Dyn. 236, 3155-3166. doi: 10.1002/dvdy.21344

Katsu, Y., Lange, A., Miyagawa, S., Urushitani, H., Tatarazako, N., Kawashima, Y., et al. (2013). Cloning, expression and functional characterization of carp, Cyprinus carpio, estrogen receptors and their differential activations by estrogens. J. Appl. Toxicol. 33, 41-49. doi: 10.1002/jat.170

Kawahara, T., Okada, H., and Yamashita, I. (2000). Cloning and expression of genomic and complementary DNAs Encoding an estrogen receptor in the medaka fish, Oryzias latipes. Zool. Sci. 17, 643-649. doi: 10.2108/zsj.17.643

Kawai, H., Arata, N., and Nakayasu, H. (2001). Three-dimensional distribution of astrocytes in zebrafish spinal cord. Glia 36, 406-413. doi: 10.1002/glia.1126

Kazeto, Y., Goto-Kazeto, R., Thomas, P., and Trant, J. M. (2005). Molecular characterization of three forms of putative membrane-bound progestin receptors and their tissue-distribution in channel catfish, Ictalurus punctatus. J. Mol. Endocrinol. 34, 781-791. doi: 10.1677/jme.1.01721

Kim, S. J., Ogasawara, K., Park, J. G., Takemura, A., and Nakamura, M. (2002). Sequence and expression of androgen receptor and estrogen receptor gene in the sex types of protogynous wrasse, Halichoeres trimaculatus. Gen. Comp. Endocrinol. 127, 165-173. doi: 10.1016/S0016-6480(02)00020-5

Kimoto, T., Tsurugizawa, T., Ohta, Y., Makino, J., Tamura, H., Hojo, Y., et al. (2001). Neurosteroid synthesis by cytochrome p450-containing systems localized in the rat brain hippocampal neurons: N-methyl-Daspartate and calcium-dependent synthesis. Endocrinology 142, 3578-3589. doi: 10.1210/endo.142.8.8327

Kishi, Y., Takahashi, J., Koyanagi, M., Morizane, A., Okamoto, Y., Horiguchi, S., et al. (2005). Estrogen promotes differentiation and survival of dopaminergic 
neurons derived from human neural stem cells. J. Neurosci. Res. 79, 279-286. doi: 10.1002/jnr.20362

Kizil, C., Kaslin, J., Kroehne, V., and Brand, M. (2012). Adult neurogenesis and brain regeneration in zebrafish. Dev. Neurobiol. 72, 429-461. doi: 10.1002/dneu.20918

Koch, S., Donarski, N., Goetze, K., Kreckel, M., Stuerenburg, H. J., Buhmann, C., et al. (2001). Characterization of four lipoprotein classes in human cerebrospinal fluid. J. Lipid Res. 42 1143-1151.

Koenig, H. L., Schumacher, M., Ferzaz, B., Thi, A. N., Ressouches, A., Guennoun, R., et al. (1995). Progesterone synthesis and myelin formation by Schwann cells. Science 268, 1500-1503. doi: 10.1126/science.7770777

Krause, D. N., Duckles, S. P., and Gonzales, R. J. (2011). Local oestrogenic/androgenic balance in the cerebral vasculature. Acta Physiol. 203, 181-186. doi: 10.1111/j.1748-1716.2011.02323.x

Kriegstein, A., and Alvarez-Buylla, A. (2009). The glial nature of embryonic and adult neural stem cells. Annu. Rev. Neurosci. 32, 149-184. doi: 10.1146/annurev.neuro.051508.135600

Kuo, J., Hamid, N., Bondar, G., Prossnitz, E. R., and Micevych, P. (2010). Membrane estrogen receptors stimulate intracellular calcium release and progesterone synthesis in hypothalamic astrocytes. J. Neurosci. 30, 12950-12957. doi: 10.1523/JNEUROSCI.1158-10.2010

Kusuhara, H., and Sugiyama, Y. (2005). Active efflux across the bloodbrain barrier: role of the solute carrier family. NeuroRx 2, 73-85. doi: $10.1602 /$ neurorx.2.1.73

Ladu, M. J., Reardon, C., Van Eldik, L., Fagan, A. M., Bu, G., Holtzman, D., et al. (2000). Lipoproteins in the central nervous system. Ann. N. Y. Acad. Sci. 903, 167-175. doi: 10.1111/j.1749-6632.2000.tb06365.x

Lapergue, B., Dang, B. Q., Desilles, J. P., Ortiz-Munoz, G., Delbosc, S., Loyau, S., et al. (2013). High-density lipoprotein-based therapy reduces the hemorrhagic complications associated with tissue plasminogen activator treatment in experimental stroke. Stroke 44, 699-707. doi: 10.1161/STROKEAHA.112.667832

Lapergue, B., Moreno, J. A., Dang, B. Q., Coutard, M., Delbosc, S., Raphaeli, G., et al. (2010). Protective effect of high-density lipoproteinbased therapy in a model of embolic stroke. Stroke 41, 1536-1542. doi: 10.1161/STROKEAHA.110.581512

Lassiter, C. S., Kelley, B., and Linney, E. (2002). Genomic structure and embryonic expression of estrogen receptor beta a (ERbetaa) in zebrafish (Danio rerio). Gene 299, 141-151. doi: 10.1016/S0378-1119(02)01050-8

Lavenex, P., Steele, M. A., and Jacobs, L. F. (2000). The seasonal pattern of cell proliferation and neuron number in the dentate gyrus of wild adult eastern grey squirrels. Eur. J. Neurosci. 12, 643-648. doi: 10.1046/j.1460-9568.2000.00949.x

Le Goascogne, C., Robel, P., Gouézou, M., Sananès, N., Baulieu, E. E., and Waterman, M. (1987). Neurosteroids: cytochrome P-450scc in rat brain. Science 237, 1212-1215. doi: 10.1126/science.3306919

Lephart, E. D. (1996). A review of brain aromatase cytochrome P450. Brain Res. Brain Res. Rev. 22, 1-26. doi: 10.1016/0165-0173(96)00002-1

Lephart, E. D., Simpson, E. R., McPhaul, M. J., Kilgore, M. W., Wilson, J. D., and Ojeda, S. R. (1992). Brain aromatase cytochrome P-450 messenger RNA levels and enzyme activity during prenatal and perinatal development in the rat. Brain Res. Mol. Brain Res. 16, 187-192. doi: 10.1016/0169-328X(92)90224-Y

Leszczynski, D. E., and Schafer, R. M. (1991). Metabolic conversion of six steroid hormones by human plasma high-density lipoprotein. Biochim. Biophys. Acta 1083, 18-28. doi: 10.1016/0005-2760(91)90120-7

Li, X., Schwartz, P. E., and Rissman, E. F. (1997). Distribution of estrogen receptorbeta-like immunoreactivity in rat forebrain. Neuroendocrinology 66, 63-67. doi: 10.1159/000127221

Li, Y., Chen, T., Miao, X., Yi, X., Wang, X., Zhao, H., et al. (2017). Zebrafish: a promising in vivo model for assessing the delivery of natural products, fluorescence dyes and drugs across the blood-brain barrier. Pharmacol. Res. 125, 246-257. doi: 10.1016/j.phrs.2017.08.017

Liao, S., Chen, W., Kuo, J., and Chen, C. (2001). Association of serum estrogen level and ischemic neuroprotection in female rats. Neurosci. Lett. 297, 159-162. doi: 10.1016/S0304-3940(00)01704-3

Linard, B., Anglade, I., Corio, M., Navas, J. M., Pakdel, F., Saligaut, C., et al. (1996). Estrogen receptors are expressed in a subset of tyrosine hydroxylasepositive neurons of the anterior preoptic region in the rainbow trout. Neuroendocrinology 63, 156-165. doi: 10.1159/000126952
Linetti, A., Fratangeli, A., Taverna, E., Valnegri, P., Francolini, M., Cappello, V., et al. (2010). Cholesterol reduction impairs exocytosis of synaptic vesicles. J. Cell Sci. 123, 595-605. doi: 10.1242/jcs.060681

Liu, C. C., Liu, C. C., Kanekiyo, T., Xu, H., and Bu, G. (2013). Apolipoprotein E and Alzheimer disease: risk, mechanisms and therapy. Nature reviews. Neurology 9 , 106-118. doi: 10.1038/nrneurol.2012.263

Liu, J. P., Tang, Y., Zhou, S., Toh, B. H., McLean, C., and Li, H. (2010). Cholesterol involvement in the pathogenesis of neurodegenerative diseases. Mol. Cell. Neurosci. 43, 33-42. doi: 10.1016/j.mcn.2009.07.013

Liu, X. M., and Wu, F. H. (2004). [Comparison of animal models of hyperlipidemia]. Zhong Xi Yi Jie He Xue Bao 2, 132-134. doi: $10.3736 /$ jcim 20040217

Liu, X., Zhu, P., Sham, K. W., Yuen, J. M., Xie, C., Zhang, Y., et al. (2009). Identification of a membrane estrogen receptor in zebrafish with homology to mammalian GPER and its high expression in early germ cells of the testis. Biol. Reprod. 80, 1253-1261. doi: 10.1095/biolreprod.108.070250

London, S. E., and Schlinger, B. A. (2007). Steroidogenic enzymes along the ventricular proliferative zone in the developing songbird brain. J. Comp. Neurol. 502, 507-521. doi: 10.1002/cne.21335

London, S. E., Monks, D. A., Wade, J., and Schlinger, B. A. (2006). Widespread capacity for steroid synthesis in the avian brain and song system. Endocrinology 147, 5975-5987. doi: 10.1210/en.2006-0154

London, S. E., Remage-Healey, L., and Schlinger, B. A. (2009). Neurosteroid production in the songbird brain: a re-evaluation of core principles. Front. Neuroendocrinol. 30, 302-314. doi: 10.1016/j.yfrne.2009.05.001

López-Rodríguez, A. B., Ávila-Rodríguez, M., Vega-Vela, N. E., Capani, F., González, J., García-Segura, L. M., et al. (2015). "Neuroprotection by exogenous estrogenic compounds following traumatic brain injury," in Estrogen Effects on Traumatic Brain Injury - Mechanisms of Neuroprotection and Repair, ed A. Duncan Kelli (Amsterdam: Academic Press Elsevier), 73-90.

Lord, L. D., Bond, J., and Thompson, R. R. (2009). Rapid steroid influences on visually guided sexual behavior in male goldfish. Horm. Behav. 56, 519-526. doi: 10.1016/j.yhbeh.2009.09.002

Louissaint, A. Jr., Rao, S., Leventhal, C., and Goldman, S. A. (2002). Coordinated interaction of neurogenesis and angiogenesis in the adult songbird brain. Neuron 34, 945-960. doi: 10.1016/S0896-6273(02)00722-5

Lubischer, J. L., and Arnold, A. P. (1990). Autoradiographic localization of progestin-concentrating cells in the brain of the zebra finch. J. Comp. Neurol. 291, 450-456. doi: 10.1002/cne.902910310

Ma, C. H., Dong, K. W., and Yu, K. L. (2000). cDNA cloning and expression of a novel estrogen receptor beta-subtype in goldfish (Carassius auratus). Biochim. Biophys. Acta 1490, 145-152. doi: 10.1016/S0167-4781(99)00235-3

Maggioli, E., McArthur, S., Mauro, C., Kieswich, J., Kusters, D. H., Reutelingsperger, C. P., et al. (2016). Estrogen protects the blood-brain barrier from inflammation-induced disruption and increased lymphocyte trafficking. Brain Behav. Immun. 51, 212-222. doi: 10.1016/j.bbi.2015.08.020

Mahesh, V. B., and Brann, D. W. (1992). Interaction between ovarian and adrenal steroids in the regulation of gonadotropin secretion. J. Steroid Biochem. Mol. Biol. 41, 495-513. doi: 10.1016/0960-0760(92)90375-S

Mahesh, V. B., and Brann, D. W. (1998). Regulation of the preovulatory gonadotropin surge by endogenous steroids. Steroids 63, 616-629. doi: 10.1016/S0039-128X(98)00075-0

Mahley, R. W. (2016). Central nervous system lipoproteins: ApoE and regulation of cholesterol metabolism. Arterioscler. Thromb. Vasc. Biol. 36, 1305-1315. doi: 10.1161/ATVBAHA.116.307023

Mangiamele, L. A., Gomez, J. R., Curtis, N. J., and Thompson, R. R. (2017). GPER/GPR30, a membrane estrogen receptor, is expressed in the brain and retina of a social fish (Carassius auratus) and colocalizes with isotocin. J. Comp. Neurol. 525, 252-270. doi: 10.1002/cne.24056

Mani, S. K., Blaustein, J. D., Allen, J. M., Law, S. W., O’Malley, B. W., and Clark, J. H. (1994). Inhibition of rat sexual behavior by antisense oligonucleotides to the progesterone receptor. Endocrinology 135, 1409-1414. doi: 10.1210/endo.135.4.7925102

Manolides, L. S., and Baloyannis, S. J. (1984). Influence of hydrocortisone, progesterone and testosterone on dendritic growth in vitro. Acta Otolaryngol. 97, 509-522. doi: 10.3109/00016488409132929

Martínez-Cerdeño, V., Noctor, S. C., and Kriegstein, A. R. (2006). Estradiol stimulates progenitor cell division in the ventricular and subventricular 
zones of the embryonic neocortex. Eur. J. Neurosci. 24, 3475-3488. doi: 10.1111/j.1460-9568.2006.05239.x

März, M., Chapouton, P., Diotel, N., Vaillant, C., Hesl, B., Takamiya, M., et al. (2010). Heterogeneity in progenitor cell subtypes in the ventricular zone of the zebrafish adult telencephalon. Glia 58, 870-888. doi: 10.1002/glia.20971

Mathieu, M., Mensah-Nyagan, A. G., Vallarino, M., Do-Régo, J. L., Beaujean, D., Vaudry, D., et al. (2001). Immunohistochemical localization of 3 betahydroxysteroid dehydrogenase and 5 alpha-reductase in the brain of the African lungfish Protopterus annectens. J. Comp. Neurol. 438, 123-135. doi: $10.1002 /$ cne. 1304

Matsumoto, T., Honda, S., and Harada, N. (2003). Alteration in sex-specific behaviors in male mice lacking the aromatase gene. Neuroendocrinology 77, 416-424. doi: 10.1159/000071313

Matsunaga, M., Ukena, K., and Tsutsui, K. (2001). Expression and localization of cytochrome P450 17 alpha-hydroxylase/c17,20-lyase in the avian brain. Brain Res. 899, 112-122. doi: 10.1016/S0006-8993(01)02217-X

Mauch, D. H., Nägler, K., Schumacher, S., Göritz, C., Müller, E. C., Otto, A., et al. (2001). CNS synaptogenesis promoted by glia-derived cholesterol. Science 294, 1354-1357. doi: 10.1126/science.294.5545.1354

Mazzucco, C. A., Lieblich, S. E., Bingham, B. I., Williamson, M. A., Viau, V., and Galea, L. A. (2006). Both estrogen receptor alpha and estrogen receptor beta agonists enhance cell proliferation in the dentate gyrus of adult female rats. Neuroscience 141, 1793-1800. doi: 10.1016/j.neuroscience.2006.05.032

McCarthy, M. M. (2011). A lumpers versus splitters approach to sexual differentiation of the brain. Front. Neuroendocrinol. 32, 114-123. doi: 10.1016/j.yfrne.2011.01.004

McCullough, L. D., Blizzard, K., Simpson, E. R., Oz, O. K., and Hurn, P. D. (2003). Aromatase cytochrome $\mathrm{P} 450$ and extragonadal estrogen play a role in ischemic neuroprotection. J. Neurosci. 23, 8701-8705.

McEwen, B. S., and Milner, T. A. (2017). Understanding the broad influence of sex hormones and sex differences in the brain. J. Neurosci. Res. 95, 24-39. doi: 10.1002/jnr.23809

McEwen, B. S., and Woolley, C. S. (1994). Estradiol and progesterone regulate neuronal structure and synaptic connectivity in adult as well as developing brain. Exp. Gerontol. 29, 431-436. doi: 10.1016/0531-5565(94)90022-1

McEwen, B. S., Gould, E., Orchinik, M., Weiland, N. G., and Woolley, C. S. (1995). Oestrogens and the structural and functional plasticity of neurons: implications for memory, ageing and neurodegenerative processes. Ciba Found Symp, 191, 52-66: discussion 66-73.

Meffre, D., Delespierre, B., Gouézou, M., Schumacher, M., Stein, D. G., and Guennoun, R. (2007). 3beta-Hydroxysteroid dehydrogenase/5-ene-4ene isomerase mRNA expression in rat brain: effect of pseudopregnancy and traumatic brain injury. J. Steroid Biochem. Mol. Biol. 104, 293-300. doi: 10.1016/j.jsbmb.2007.03.003

Meffre, D., Labombarda, F., Delespierre, B., Chastre, A., De Nicola, A. F., Stein, D. G., et al. (2013). Distribution of membrane progesterone receptor alpha in the male mouse and rat brain and its regulation after traumatic brain injury. Neuroscience 231, 111-124. doi: 10.1016/j.neuroscience.2012.11.039

Mellon, S. H., and Deschepper, C. F. (1993). Neurosteroid biosynthesis: genes for adrenal steroidogenic enzymes are expressed in the brain. Brain Res. 629, 283-292. doi: 10.1016/0006-8993(93)91332-M

Menuet, A., Anglade, I., Le Guevel, R., Pellegrini, E., Pakdel, F., and Kah, O. (2003). Distribution of aromatase mRNA and protein in the brain and pituitary of female rainbow trout: comparison with estrogen receptor alpha. J. Comp. Neurol. 462, 180-193. doi: 10.1002/cne.10726

Menuet, A., Pellegrini, E., Anglade, I., Blaise, O., Laudet, V., Kah, O., et al. (2002). Molecular characterization of three estrogen receptor forms in zebrafish: binding characteristics, transactivation properties, and tissue distributions. Biol. Reprod. 66, 1881-1892. doi: 10.1095/biolreprod66.6.1881

Menuet, A., Pellegrini, E., Brion, F., Gueguen, M. M., Anglade, I., Pakdel, F., et al. (2005). Expression and estrogen-dependent regulation of the zebrafish brain aromatase gene. J. Comp. Neurol. 485, 304-320. doi: 10.1002/cne.20497

Mhaouty-Kodja, S. (2017). Role of the androgen receptor in the central nervous system. Mol. Cell. Endocrinol. doi: 10.1016/j.mce.2017.08.001

Micevych, P. E., Chaban, V., Ogi, J., Dewing, P., Lu, J. K., and Sinchak, K. (2007). Estradiol stimulates progesterone synthesis in hypothalamic astrocyte cultures. Endocrinology 148, 782-789. doi: 10.1210/en.2006-0774
Micevych, P., and Sinchak, K. (2008a). Synthesis and function of hypothalamic neuroprogesterone in reproduction. Endocrinology 149, 2739-2742. doi: 10.1210/en.2008-0011

Micevych, P., and Sinchak, K. (2008b). Estradiol regulation of progesterone synthesis in the brain. Mol. Cell. Endocrinol. 290, 44-50. doi: $10.1016 /$ j.mce.2008.04.016

Micevych, P., Sinchak, K., Mills, R. H., Tao, L., LaPolt, P., and Lu, J. K. (2003). The luteinizing hormone surge is preceded by an estrogen-induced increase of hypothalamic progesterone in ovariectomized and adrenalectomized rats. Neuroendocrinology 78, 29-35. doi: 10.1159/000071703

Mitani, Y., Kanda, S., Akazome, Y., Zempo, B., and Oka, Y. (2010). Hypothalamic Kiss1 but not Kiss2 neurons are involved in estrogen feedback in medaka (Oryzias latipes). Endocrinology 151, 1751-1759. doi: 10.1210/en.2009-1174

Mitra, S. W., Hoskin, E., Yudkovitz, J., Pear, L., Wilkinson, H. A., Hayashi, S., et al. (2003). Immunolocalization of estrogen receptor beta in the mouse brain: comparison with estrogen receptor alpha. Endocrinology 144, 2055-2067. doi: 10.1210/en.2002-221069

Morali, G., Larsson, K., and Beyer, C. (1977). Inhibition of testosterone-induced sexual behavior in the castrated male rat by aromatase blockers. Horm. Behav. 9, 203-213. doi: 10.1016/0018-506X(77)90056-3

Morini, M., Peñaranda, D. S., Vílchez, M. C., Nourizadeh-Lillabadi, R., Lafont, A. G., Dufour, S., et al. (2017). Nuclear and membrane progestin receptors in the European eel: characterization and expression in vivo through spermatogenesis. Comp. Biochem. Physiol. Part A Mol. Integr. Physiol. 207, 79-92. doi: 10.1016/j.cbpa.2017.02.009

Mouriec, K., Lareyre, J. J., Tong, S. K., Le Page, Y., Vaillant, C., Pellegrini, E., et al. (2009). Early regulation of brain aromatase (cyp19a1b) by estrogen receptors during zebrafish development. Dev. Dyn. 238, 2641-2651. doi: 10.1002/dvdy.22069

Mouriec, K., Pellegrini, E., Anglade, I., Menuet, A., Adrio, F., Thieulant, M. L., et al. (2008). Synthesis of estrogens in progenitor cells of adult fish brain: evolutive novelty or exaggeration of a more general mechanism implicating estrogens in neurogenesis? Brain Res. Bull. 75, 274-280. doi: 10.1016/j.brainresbull.2007.10.030

Mourot, B., Nguyen, T., Fostier, A., and Bobe, J. (2006). Two unrelated putative membrane-bound progestin receptors, progesterone membrane receptor component 1 (PGMRC1) and membrane progestin receptor (mPR) beta, are expressed in the rainbow trout oocyte and exhibit similar ovarian expression patterns. Reprod. Biol. Endocrinol. 4:6. doi: 10.1186/1477-7827-4-6

Mukai, H., Kimoto, T., Hojo, Y., Kawato, S., Murakami, G., Higo, S., et al. (2010). Modulation of synaptic plasticity by brain estrogen in the hippocampus. Biochim. Biophys. Acta 1800, 1030-1044. doi: 10.1016/j.bbagen.2009.11.002

Muñoz-Cueto, J. A., Burzawa-Gérard, E., Kah, O., Valotaire, Y., and Pakdel, F. (1999). Cloning and sequencing of the gilthead sea bream estrogen receptor cDNA. DNA Seq. 10, 75-84.

Murashov, A. K., Pak, E. S., Hendricks, W. A., and Tatko, L. M. (2004). 17beta-Estradiol enhances neuronal differentiation of mouse embryonic stem cells. FEBS Lett. 569, 165-168. doi: 10.1016/j.febslet.2004.0 5.042

Na, W., Lee, J. Y., Kim, W. S., Yune, T. Y., and Ju, B. G. (2015). 17beta-estradiol ameliorates tight junction disruption via repression of MMP transcription. Mol. Endocrinol. 29, 1347-1361. doi: 10.1210/ME.2015-1124

Nagler, J. J., Cavileer, T., Sullivan, J., Cyr, D. G., and Rexroad, C. III. (2007). The complete nuclear estrogen receptor family in the rainbow trout: discovery of the novel ERalpha2 and both ERbeta isoforms. Gene 392, 164-173. doi: 10.1016/j.gene.2006.12.030

Navas, J. M., Anglade, I., Bailhache, T., Pakdel, F., Breton, B., Jego, P., et al. (1995). Do gonadotrophin-releasing hormone neurons express estrogen receptors in the rainbow trout? A double immunohistochemical study. J. Comp. Neurol. 363, 461-474. doi: 10.1002/cne.903630309

Nico, B., Frigeri, A., Nicchia, G. P., Quondamatteo, F., Herken, R., Errede, M., et al. (2001). Role of aquaporin-4 water channel in the development and integrity of the blood-brain barrier. J. Cell Sci. 114, 1297-1307.

Noctor, S. C., Flint, A. C., Weissman, T. A., Dammerman, R. S., and Kriegstein, A. R. (2001). Neurons derived from radial glial cells establish radial units in neocortex. Nature 409, 714-720. doi: 10.1038/350 55553 
Okada, M., Makino, A., Nakajima, M., Okuyama, S., Furukawa, S., and Furukawa, Y. (2010). Estrogen stimulates proliferation and differentiation of neural stem/progenitor cells through different signal transduction pathways. Int. J. Mol. Sci. 11, 4114-4123. doi: 10.3390/ijms11104114

Olsson, P. E., Berg, A. H., von Hofsten, J., Grahn, B., Hellqvist, A., Larsson, A., et al. (2005). Molecular cloning and characterization of a nuclear androgen receptor activated by 11-ketotestosterone. Reprod. Biol. Endocrinol. 3:37. doi: 10.1186/1477-7827-3-37

Ormerod, B. K., and Galea, L. A. (2001). Reproductive status influences cell proliferation and cell survival in the dentate gyrus of adult female meadow voles: a possible regulatory role for estradiol. Neuroscience 102, 369-379. doi: 10.1016/S0306-4522(00)00474-7

Ormerod, B. K., and Galea, L. A. (2003). Reproductive status influences the survival of new cells in the dentate gyrus of adult male meadow voles. Neurosci. Lett. 346, 25-28. doi: 10.1016/S0304-3940(03)00546-9

Ortiz-Muñoz, G., Couret, D., Lapergue, B., Bruckert, E., Meseguer, E., Amarenco, P., et al. (2016). Dysfunctional HDL in acute stroke. Atherosclerosis 253, 75-80. doi: 10.1016/j.atherosclerosis.2016.08.035

Pakdel, F., Le Gac, F., Le Goff, P., and Valotaire, Y. (1990). Full-length sequence and in vitro expression of rainbow trout estrogen receptor cDN. Mol. Cell. Endocrinol. 71, 195-204. doi: 10.1016/0303-7207(90)90025-4

Pang, Y., and Thomas, P. (2009). Involvement of estradiol-17beta and its membrane receptor, $G$ protein coupled receptor 30 (GPR30) in regulation of oocyte maturation in zebrafish, Danio rario. Gen. Comp. Endocrinol. 161, 58-61. doi: 10.1016/j.ygcen.2008.10.003

Pang, Y., Dong, J., and Thomas, P. (2008). Estrogen signaling characteristics of Atlantic croaker G protein-coupled receptor 30 (GPR30) and evidence it is involved in maintenance of oocyte meiotic arrest. Endocrinology 149, 3410-3426. doi: 10.1210/en.2007-1663

Pang, Y., Dong, J., and Thomas, P. (2013). Characterization, neurosteroid binding and brain distribution of human membrane progesterone receptors delta and \{epsilon\} (mPRdelta and mPR\{epsilon\}) and mPRdelta involvement in neurosteroid inhibition of apoptosis. Endocrinology 154, 283-295. doi: 10.1210/en.2012-1772

Panzica, G. C., Castagna, C., Viglietti-Panzica, C., Russo, C., Tlemcani, O., and Balthazart, J. (1998). Organizational effects of estrogens on brain vasotocin and sexual behavior in quail. J. Neurobiol. 37, 684-699. doi: 10.1002/(SICI)10974695(199812)37:4<684::AID-NEU15>3.0.CO;2-U

Pardridge, W. M., and Mietus, L. J. (1979). Transport of steroid hormones through the rat blood-brain barrier. Primary role of albumin-bound hormone. J. Clin. Investig. 64, 145-154. doi: 10.1172/JCI109433

Parimisetty, A., Dorsemans, A. C., Awada, R., Ravanan, P., Diotel, N., and Lefebvre d'Hellencourt, C. (2016). Secret talk between adipose tissue and central nervous system via secreted factors-an emerging frontier in the neurodegenerative research. J. Neuroinflammation 13, 67. doi: 10.1186/s12974-0160530-x

Pasmanik, M., and Callard, G. V. (1985). Aromatase and 5 alpha-reductase in the teleost brain, spinal cord, and pituitary gland. Gen. Comp. Endocrinol. 60, 244-251. doi: 10.1016/0016-6480(85)90320-X

Pasmanik, M., and Callard, G. V. (1988). Changes in brain aromatase and 5 alpha-reductase activities correlate significantly with seasonal reproductive cycles in goldfish (Carassius auratus). Endocrinology 122, 1349-1356. doi: 10.1210/endo-122-4-1349

Pawlisch, B. A., and Remage-Healey, L. (2015). Neuroestrogen signaling in the songbird auditory cortex propagates into a sensorimotor network via an 'interface' nucleus. Neuroscience 284, 522-535. doi: 10.1016/j.neuroscience.2014.10.023

Pellegrini, E., Coumailleau, P., Kah, O., and Diotel, N. (2015). “Aromatase and estrogens: involvement in constitutive and regenerative neurogenesis in adult zebrafish," inEstrogen Effects on Traumatic Brain Injury - Mechanisms of Neuroprotection and Repair, ed A. Duncan Kelli (Amsterdam: Academic Press Elsevier), 51-71.

Pellegrini, E., Menuet, A., Lethimonier, C., Adrio, F., Gueguen, M. M., Tascon, C., et al. (2005). Relationships between aromatase and estrogen receptors in the brain of teleost fish. Gen. Comp. Endocrinol. 142, 60-66. doi: 10.1016/j.ygcen.2004.12.003

Pellegrini, E., Mouriec, K., Anglade, I., Menuet, A., Le Page, Y., Gueguen, M. M., et al. (2007). Identification of aromatase-positive radial glial cells as progenitor cells in the ventricular layer of the forebrain in zebrafish. J. Comp. Neurol. 501, 150-167. doi: 10.1002/cne.21222

Pellegrini, E., Vaillant, C., Diotel, N., Benquet, P., Brion, F., and Kah, O. (2013). "Expression, regulation and potential functions of aromatase in radial glial cells of the fish brain," in Brain Aromatase, Estrogens, and Behavior, eds Balthazart, J. Ball, and F.Gregory (Oxford; New York, NY: University Press), 2013.

Pelletier, G. (2010). Steroidogenic enzymes in the brain: morphological aspects. Prog. Brain Res. 181, 193-207. doi: 10.1016/S0079-6123(08)81011-4

Perkins, A., and Roselli, C. E. (2007). The ram as a model for behavioral neuroendocrinology. Horm. Behav. 52, 70-77. doi: 10.1016/j.yhbeh.2007. 03.016

Petersen, S. L., Intlekofer, K. A., Moura-Conlon, P. J., Brewer, D. N., Del Pino Sans, J., and Lopez, J. A. (2013). Novel progesterone receptors: neural localization and possible functions. Front. Neurosci. 7:164. doi: 10.3389/fnins.2013.00164

Peterson, R. S., Lee, D. W., Fernando, G., and Schlinger, B. A. (2004). Radial glia express aromatase in the injured zebra finch brain. J. Comp. Neurol. 475, 261-269. doi: 10.1002/cne.20157

Peterson, R. S., Saldanha, C. J., and Schlinger, B. A. (2001). Rapid upregulation of aromatase mRNA and protein following neural injury in the zebra finch (Taeniopygia guttata). J. Neuroendocrinol. 13, 317-323. doi: 10.1046/j.1365-2826.2001.00647.x

Peterson, R. S., Yarram, L., Schlinger, B. A., and Saldanha, C. J. (2005). Aromatase is pre-synaptic and sexually dimorphic in the adult zebra finch brain. Proc. Biol. Sci. 272, 2089-2096. doi: 10.1098/rspb.2005.3181

Petralia, S. M., and Frye, C. A. (2005). In the ventral tegmental area picrotoxin blocks FGIN 1-27-induced increases in sexual behavior of rats and hamsters. Psychopharmacology 178, 174-182. doi: 10.1007/s00213-004-2001-9

Petrone, A. B., Rudy, C. C., Barr, T. L., Simpkins, J. W., and Reed, M. N. (2015). "Neuroprotective effects of estrogen following neural injury," in Estrogen Effects on Traumatic Brain Injury - Mechanisms of Neuroprotection and Repair,ed A. Duncan Kelli (Amsterdam: Academic Press Elsevier), 91-111.

Phan, A., Gabor, C. S., Favaro, K. J., Kaschack, S., Armstrong, J. N., MacLusky, N. J., et al. (2012). Low doses of 17beta-estradiol rapidly improve learning and increase hippocampal dendritic spines. Neuropsychopharmacology 37, 2299-2309. doi: 10.1038/npp.2012.82

Pouso, P., Quintana, L., Bolatto, C., and Silva, A. C. (2010). Brain androgen receptor expression correlates with seasonal changes in the behavior of a weakly electric fish, Brachyhypopomus gauderio. Horm. Behav. 58, 729-736. doi: 10.1016/j.yhbeh.2010.07.005

Putnam, C. D., Brann, D. W., and Mahesh, V. B. (1991). Acute activation of the adrenocorticotropin-adrenal axis: effect on gonadotropin and prolactin secretion in the female rat. Endocrinology 128, 2558-2566. doi: 10.1210/endo-128-5-2558

Quan, G., Xie, C., Dietschy, J. M., and Turley, S. D. (2003). Ontogenesis and regulation of cholesterol metabolism in the central nervous system of the mouse. Brain Res. Dev. Brain Res. 146, 87-98. doi: 10.1016/j.devbrainres.2003.09.015

Ravi, V., and Venkatesh, B. (2008). Rapidly evolving fish genomes and teleost diversity. Curr. Opin. Genet. Dev. 18, 544-550. doi: 10.1016/j.gde.2008.11.001

Roncali, L., Nico, B., Ribatti, D., Bertossi, M., and Mancini, L. (1986). Microscopical and ultrastructural investigations on the development of the blood-brain barrier in the chick embryo optic tectum. Acta Neuropathol. 70, 193-201. doi: 10.1007/BF00686072

Roof, R. L., and Hall, E. D. (2000). Gender differences in acute CNS trauma and stroke: neuroprotective effects of estrogen and progesterone. J. Neurotrauma 17, 367-388. doi: 10.1089/neu.2000.17.367

Roselli, C. E., Cross, E., Poonyagariyagorn, H. K., and Stadelman, H. L. (2003). Role of aromatization in anticipatory and consummatory aspects of sexual behavior in male rats. Horm. Behav. 44, 146-151. doi: 10.1016/S0018-506X(03)00123-5

Roselli, C. F. (2007). Brain aromatase: roles in reproduction and neuroprotection. J. Steroid Biochem. Mol. Biol. 106, 143-150. doi: 10.1016/j.jsbmb.2007.05.014

Rosner, W. (2015). Free estradiol and sex hormone-binding globulin. Steroids 99, 113-116. doi: 10.1016/j.steroids.2014.08.005

Rossetti, M. F., Cambiasso, M. J., Holschbach, M. A., and Cabrera, R. (2016). Oestrogens and progestagens: synthesis and action in the brain. J. Neuroendocrinol. 28. doi: 10.1111/jne.12402

Rothenaigner, I., Krecsmarik, M., Hayes, J. A., Bahn, B., Lepier, A., Fortin, G., et al. (2011). Clonal analysis by distinct viral vectors identifies bona fide neural 
stem cells in the adult zebrafish telencephalon and characterizes their division properties and fate. Development 138, 1459-1469. doi: 10.1242/dev.058156

Roy, S. R., Wang, J., Rana, M. R., Nakashima, M., and Tokumoto, T. (2017). Characterization of membrane progestin receptor alpha (mPRalpha) of the medaka and role in the induction of oocyte maturation. Biomed. Res. 38, 79-87. doi: 10.2220/biomedres.38.79

Sabo-Attwood, T., Kroll, K. J., and Denslow, N. D. (2004). Differential expression of largemouth bass (Micropterus salmoides) estrogen receptor isotypes alpha, beta, and gamma by estradiol. Mol. Cell. Endocrinol. 218, 107-118. doi: $10.1016 /$ j.mce.2003.12.007

Sager, T., Kashon, M., and Krajnak, K. (2017). Estrogen and environmental enrichment differentially affect neurogenesis, dendritic spine immunolabeling and synaptogenesis in the hippocampus of young and reproductively senescent female rats. Neuroendocrinology. doi: 10.1159/000479699

Sakamoto, H., Ukena, K., and Tsutsui, K. (2001a). Activity and localization of 3beta-hydroxysteroid dehydrogenase/ Delta5-Delta4-isomerase in the zebrafish central nervous system. J. Comp. Neurol. 439, 291-305. doi: 10.1002/cne.1351

Sakamoto, H., Ukena, K., and Tsutsui, K. (2001b). Effects of progesterone synthesized de novo in the developing Purkinje cell on its dendritic growth and synaptogenesis. J. Neurosci. 21, 6221-6232.

Sakamoto, H., Ukena, K., and Tsutsui, K. (2002). Dendritic spine formation in response to progesterone synthesized de novo in the developing Purkinje cell in rats. Neurosci. Lett. 322, 111-115. doi: 10.1016/S0304-3940(02)00077-0

Salbert, G., Bonnec, G., Le Goff, P., Boujard, D., Valotaire, Y., and Jego, P. (1991). Localization of the estradiol receptor mRNA in the forebrain of the rainbow trout. Mol. Cell. Endocrinol. 76, 173-180. doi: 10.1016/0303-7207(91)90271-S

Saldanha, C. J., Remage-Healey, L., and Schlinger, B. A. (2011). Synaptocrine signaling: steroid synthesis and action at the synapse. Endocr. Rev. 32, 532-549. doi: 10.1210/er.2011-0004

Sar, M., Lubahn, D. B., French, F. S., and Wilson, E. M. (1990). Immunohistochemical localization of the androgen receptor in rat and human tissues. Endocrinology 127, 3180-3186. doi: 10.1210/endo-127-6-3180

Sasano, H., Takashashi, K., Satoh, F., Nagura, H., and Harada, N. (1998). Aromatase in the human central nervous system. Clin. Endocrinol. 48, 325-329. doi: 10.1046/j.1365-2265.1998.00390.x

Schlinger, B. A. (1997). The activity and expression of aromatase in songbirds. Brain Res. Bull. 44, 359-364. doi: 10.1016/S0361-9230(97)00215-3

Schlinger, B. A., and Remage-Healey, L. (2012). Neurosteroidogenesis: insights from studies of songbirds. J. Neuroendocrinol. 24, 16-21. doi: 10.1111/j.1365-2826.2011.02150.x

Schlinger, B. A., Pradhan, D. S., and Soma, K. K. (2008). 3beta-HSD activates DHEA in the songbird brain. Neurochem. Int. 52, 611-620. doi: 10.1016/j.neuint.2007.05.003

Schlinger, B. A., Soma, K. K., and London, S. E. (2001). Neurosteroids and brain sexual differentiation. Trends Neurosci. 24, 429-431. doi: 10.1016/S0166-2236(00)01855-5

Schmidt, K. L., Pradhan, D. S., Shah, A. H., Charlier, T. D., Chin, E. H., and Soma, K. K. (2008). Neurosteroids, immunosteroids, and the Balkanization of endocrinology. Gen. Comp. Endocrinol. 157, 266-274. doi: 10.1016/j.ygcen.2008.03.025

Schumacher, M., Guennoun, R., Stein, D. G., and De Nicola, A. F. (2007). Progesterone: therapeutic opportunities for neuroprotection and myelin repair. Pharmacol. Ther. 116, 77-106. doi: 10.1016/j.pharmthera.2007.06.001

Scordalakes, E. M., Imwalle, D. B., and Rissman, E. F. (2002). Oestrogen's masculine side: mediation of mating in male mice. Reproduction 124, 331-338. doi: 10.1530/rep.0.1240331

Sellers, K. J., Erli, F., Raval, P., Watson, I. A., Chen, D., and Srivastava, D. P. (2015). Rapid modulation of synaptogenesis and spinogenesis by 17beta-estradiol in primary cortical neurons. Front. Cell. Neurosci. 9:137. doi: $10.3389 /$ fncel.2015.00137

Seredynski, A. L., Balthazart, J., Ball, G. F., and Cornil, C. A. (2015). Estrogen receptor beta activation rapidly modulates male sexual motivation through the transactivation of metabotropic glutamate receptor 1a. J. Neurosci. 35, 13110-13123. doi: 10.1523/JNEUROSCI.2056-15.2015

Seredynski, A. L., Balthazart, J., Christophe, V. J., Ball, G. F., and Cornil, C. A. (2013). Neuroestrogens rapidly regulate sexual motivation but not performance. J. Neurosci. 33, 164-174. doi: 10.1523/JNEUROSCI.2557-12.2013
Shah, A. H., Chin, E. H., Schmidt, K. L., and Soma, K. K. (2011). DHEA and estradiol levels in brain, gonads, adrenal glands, and plasma of developing male and female European starlings. J. Comp. Physiol. A Neuroethol. Sens. Neural Behav. Physiol. 197, 949-958. doi: 10.1007/s00359-011-0655-4

Shahrokhi, N., Haddad, M. K., Joukar, S., Shabani, M., Keshavarzi, Z., and Shahozehi, B. (2012). Neuroprotective antioxidant effect of sex steroid hormones in traumatic brain injury. Pak. J. Pharm. Sci. 25, 219-225.

Shi, Y., Liu, X., Zhu, P., Li, J., Sham, K. W., Cheng, S. H., et al. (2013). G-proteincoupled estrogen receptor 1 is involved in brain development during zebrafish (Danio rerio) embryogenesis. Biochem. Biophys. Res. Commun. 435, 21-27. doi: 10.1016/j.bbrc.2013.03.130

Shughrue, P. J., Lane, M. V., and Merchenthaler, I. (1997). Comparative distribution of estrogen receptor-alpha and -beta mRNA in the rat central nervous system. J. Comp. Neurol. 388, 507-525. doi: 10.1002/(SICI)10969861(19971201)388:4<507::AID-CNE1>3.0.CO;2-6

Si, D., Li, J., Liu, J., Wang, X., Wei, Z., Tian, Q., et al. (2014). Progesterone protects blood-brain barrier function and improves neurological outcome following traumatic brain injury in rats. Exp. Ther. Med. 8, 1010-1014. doi: $10.3892 /$ etm.2014.1840

Sinchak, K., Mills, R. H., Tao, L., LaPolt, P., Lu, J. K., and Micevych, P. (2003). Estrogen induces de novo progesterone synthesis in astrocytes. Dev. Neurosci. 25, 343-348. doi: 10.1159/000073511

Slewa-Younan, S., Green, A. M., Baguley, I. J., Gurka, J. A., and Marosszeky, J. E. (2004). Sex differences in injury severity and outcome measures after traumatic brain injury. Arch. Phys. Med. Rehabil. 85, 376-379. doi: 10.1016/j.apmr.2003.05.007

Socorro, S., Power, D. M., Olsson, P. E., and Canario, A. V. (2000). Two estrogen receptors expressed in the teleost fish, Sparus aurata: cDNA cloning, characterization and tissue distribution. J. Endocrinol. 166, 293-306. doi: 10.1677 /joe. 0.1660293

Södersten, P. (2013). "A historical and personal perspective on the aromatization revolution," in Brain Aromatase, Estrogens, and Behavior, eds J. Balthazart and G. F. Ball (New York, NY; Oxford UP), 281-314.

Sohrabji, F. (2015). "Cerebrovascular stroke: sex differences and the impact of Estrogens," in Estrogen Effects on Traumatic Brain Injury - Mechanisms of Neuroprotection and Repair, ed A. Duncan Kelli (Amsterdam: Academic Press Elsevier), 125-141.

Soma, K. K., Alday, N. A., Hau, M., and Schlinger, B. A. (2004). Dehydroepiandrosterone metabolism by 3beta-hydroxysteroid dehydrogenase/Delta5-Delta4 isomerase in adult zebra finch brain: sex difference and rapid effect of stress. Endocrinology 145, 1668-1677. doi: 10.1210/en.2003-0883

Soma, K. K., Sinchak, K., Lakhter, A., Schlinger, B. A., and Micevych, P. E. (2005). Neurosteroids and female reproduction: estrogen increases 3betaHSD mRNA and activity in rat hypothalamus. Endocrinology 146, 4386-4390. doi: 10.1210/en.2005-0569

Sperry, T. S., and Thomas, P. (1999a). Characterization of two nuclear androgen receptors in Atlantic croaker: comparison of their biochemical properties and binding specificities. Endocrinology 140, 1602-1611. doi: $10.1210 /$ endo.140.4.6631

Sperry, T. S., and Thomas, P. (1999b). Identification of two nuclear androgen receptors in kelp bass (Paralabrax clathratus) and their binding affinities for xenobiotics: comparison with Atlantic croaker (Micropogonias undulatus) androgen receptors. Biol. Reprod. 61, 1152-1161. doi: 10.1095/biolreprod61.4.1152

Spritzer, M. D., and Galea, L. A. (2007). Testosterone and dihydrotestosterone, but not estradiol, enhance survival of new hippocampal neurons in adult male rats. Dev. Neurobiol. 67, 1321-1333. doi: 10.1002/dneu.20457

Stephens, S. B., Tolson, K. P., Rouse, M. L. Jr., Poling, M. C., HashimotoPartyka, M. K., Mellon, P. L., et al. (2015). Absent progesterone signaling in kisspeptin neurons disrupts the LH surge and impairs fertility in female mice. Endocrinology 156, 3091-3097. doi: 10.1210/en.2015-1300

Sterling, R. J., Gasc, J. M., Sharp, P. J., Renoir, J. M., Tuohimaa, P., and Baulieu, E. E. (1987). The distribution of nuclear progesterone receptor in the hypothalamus and forebrain of the domestic hen. Cell Tissue Res. 248, 201-205. doi: $10.1007 / \mathrm{BF} 01239981$ 
Stewart, P. A., and Wiley, M. J. (1981). Structural and histochemical features of the avian blood-brain barrier. J. Comp. Neurol. 202, 157-167. doi: $10.1002 /$ cne. 902020203

Stone, D. J., Rozovsky, I., Morgan, T. E., Anderson, C. P., Hajian, H., and Finch, C. E. (1997). Astrocytes and microglia respond to estrogen with increased apoE mRNA in vivo and in vitro. Exp. Neurol. 143, 313-318. doi: 10.1006/exnr.1996.6360

Strobl-Mazzulla, P. H., Lethimonier, C., Gueguen, M. M., Karube, M., Fernandino, J. I., Yoshizaki, G., et al. (2008). Brain aromatase (Cyp19A2) and estrogen receptors, in larvae and adult pejerrey fish Odontesthes bonariensis: neuroanatomical and functional relations. Gen. Comp. Endocrinol. 158, 191-201. doi: 10.1016/j.ygcen.2008.07.006

Strobl-Mazzulla, P. H., Moncaut, N. P., López, G. C., Miranda, L. A., Canario, A. V., and Somoza, G. M. (2005). Brain aromatase from pejerrey fish (Odontesthes bonariensis): cDNA cloning, tissue expression, and immunohistochemical localization. Gen. Comp. Endocrinol. 143, 21-32. doi: 10.1016/j.ygcen.2005.02.026

Strobl-Mazzulla, P. H., Nuñez, A., Pellegrini, E., Gueguen, M. M., Kah, O., and Somoza, G. M. (2010). Progenitor radial cells and neurogenesis in pejerrey fish forebrain. Brain Behav. Evol. 76, 20-31. doi: 10.1159/000316022

Strömstedt, M., and Waterman, M. R. (1995). Messenger RNAs encoding steroidogenic enzymes are expressed in rodent brain. Brain Res. Mol. Brain Res. 34, 75-88. doi: 10.1016/0169-328X(95)00140-N

Sugiyama, D., Kusuhara, H., Shitara, Y., Abe, T., Meier, P. J., Sekine, T., et al. (2001). Characterization of the efflux transport of 17beta-estradiol-D-17betaglucuronide from the brain across the blood-brain barrier. J. Pharmacol. Exp. Ther. 298, 316-322.

Sugiyama, N., Andersson, S., Lathe, R., Fan, X., Alonso-Magdalena, P., Schwend, T., et al. (2009). Spatiotemporal dynamics of the expression of estrogen receptors in the postnatal mouse brain. Mol. Psychiatry 14, 223-232. doi: $10.1038 / \mathrm{mp} .2008 .118$

Suzuki, S., Gerhold, L. M., Böttner, M., Rau, S. W., Dela Cruz, C., Yang, E., et al. (2007). Estradiol enhances neurogenesis following ischemic stroke through estrogen receptors alpha and beta. J. Comp. Neurol. 500, 1064-1075. doi: $10.1002 /$ cne. 21240

Takeo, J., and Yamashita, S. (1999). Two distinct isoforms of cDNA encoding rainbow trout androgen receptors. J. Biol. Chem. 274, 5674-5680.

Takeo, J., and Yamashita, S. (2000). Rainbow trout androgen receptor-alpha fails to distinguish between any of the natural androgens tested in transactivation assay, not just 11-ketotestosterone and testosterone. Gen. Comp. Endocrinol. 117, 200-206. doi: 10.1006/gcen.1999.7398

Tan, N. S., Lam, T. J., and Ding, J. L. (1995). The hormone-binding domain of Oreochromis aureus estrogen receptor gene: homology comparison with other steroid binding receptors. DNA Seq. 5, 371-379.

Tanapat, P., Hastings, N. B., and Gould, E. (2005). Ovarian steroids influence cell proliferation in the dentate gyrus of the adult female rat in a dose- and timedependent manner. J. Comp. Neurol. 481, 252-265. doi: 10.1002/cne.20385

Tanapat, P., Hastings, N. B., Reeves, A. J., and Gould, E. (1999). Estrogen stimulates a transient increase in the number of new neurons in the dentate gyrus of the adult female rat. J. Neurosci. 19, 5792-5801.

Tang, H., Liu, Y., Li, J., Yin, Y., Li, G., Chen, Y., et al. (2016). Gene knockout of nuclear progesterone receptor provides insights into the regulation of ovulation by LH signaling in zebrafish. Sci. Rep. 6:28545. doi: 10.1038/srep28545

Taziaux, M., Keller, M., Bakker, J., and Balthazart, J. (2007). Sexual behavior activity tracks rapid changes in brain estrogen concentrations. J. Neurosci. 27, 6563-6572. doi: 10.1523/JNEUROSCI.1797-07.2007

Tchoudakova, A., Pathak, S., and Callard, G. V. (1999). Molecular cloning of an estrogen receptor beta subtype from the goldfish, Carassius auratus. Gen. Comp. Endocrinol. 113, 388-400. doi: 10.1006/gcen.1998.7217

Thomas, P. (2008). Characteristics of membrane progestin receptor alpha (mPRalpha) and progesterone membrane receptor component 1 (PGMRC1) and their roles in mediating rapid progestin actions. Front. Neuroendocrinol. 29, 292-312. doi: 10.1016/j.yfrne.2008.01.001

Thompson, R. R., George, K., Dempsey, J., and Walton, J. C. (2004). Visual sex discrimination in goldfish: seasonal, sexual, and androgenic influences. Horm. Behav. 46, 646-654. doi: 10.1016/j.yhbeh.2004.06.008

Thornton, J. W. (2001). Evolution of vertebrate steroid receptors from an ancestral estrogen receptor by ligand exploitation and serial genome expansions. Proc. Natl. Acad. Sci. U.S.A. 98, 5671-5676. doi: 10.1073/pnas.091 553298

Tikkanen, M. J., Vihma, V., Jauhiainen, M., Höckerstedt, A., Helisten, H., and Kaamanen, M. (2002). Lipoprotein-associated estrogens. Cardiovasc. Res. 56, 184-188. doi: 10.1016/S0008-6363(02)00535-7

Timmers, R. J., and Lambert, J. G. (1987). Measurement of aromatase activity in the brain of the African catfish, Clarias gariepinus-a comparison of two assay methods. Comp. Biochem. Physiol. B Comp. Biochem. 88, 453-456. doi: 10.1016/0305-0491(87)90325-7

Tokumoto, M., Nagahama, Y., Thomas, P., and Tokumoto, T. (2006). Cloning and identification of a membrane progestin receptor in goldfish ovaries and evidence it is an intermediary in oocyte meiotic maturation. Gen. Comp. Endocrinol. 145, 101-108. doi: 10.1016/j.ygcen.2005.07.002

Tokumoto, T., Tokumoto, M., Oshima, T., Shimizuguchi, K., Fukuda, T., Sugita, E., et al. (2012). Characterization of multiple membrane progestin receptor (mPR) subtypes from the goldfish ovary and their roles in the induction of oocyte maturation. Gen. Comp. Endocrinol. 177, 168-176. doi: 10.1016/j.ygcen.2012.03.005

Tomy, S., Wu, G. C., Huang, H. R., Dufour, S., and Chang, C. F. (2007). Developmental expression of key steroidogenic enzymes in the brain of protandrous black porgy fish, Acanthopagrus schlegeli. J. Neuroendocrinol. 19, 643-655. doi: 10.1111/j.1365-2826.2007.01572.x

Tong, S. K., Mouriec, K., Kuo, M. W., Pellegrini, E., Gueguen, M. M., Brion, F., et al. (2009). A cyp19alb-gfp (aromatase B) transgenic zebrafish line that expresses GFP in radial glial cells. Genesis 47, 67-73. doi: 10.1002/dvg. 20459

Toran-Allerand, C. D. (2005). Estrogen and the brain: beyond ER-alpha, ER-beta, and 17beta-estradiol. Ann. N. Y. Acad. Sci. 1052, 136-144. doi: 10.1196/annals.1347.009

Toran-Allerand, C. D., Guan, X., MacLusky, N. J., Horvath, T. L., Diano, S., Singh, M., et al. (2002). ER-X: a novel, plasma membrane-associated, putative estrogen receptor that is regulated during development and after ischemic brain injury. J. Neurosci. 22, 8391-8401.

Tramontin, A. D., Wingfield, J. C., and Brenowitz, E. A. (2003). Androgens and estrogens induce seasonal-like growth of song nuclei in the adult songbird brain. J. Neurobiol. 57, 130-140. doi: 10.1002/neu.10263

Tran-Dinh, A., Diallo, D., Delbosc, S., Varela-Perez, L. M., Dang, Q. B., Lapergue, B., et al. (2013). HDL and endothelial protection. Br. J. Pharmacol. 169, 493-511. doi: 10.1111/bph.12174

Tsutsui, K. (2008). Progesterone biosynthesis and action in the developing neuron. Endocrinology 149, 2757-2761. doi: 10.1210/en.2007-1592

Tsutsui, K. (2011). Neurosteroid biosynthesis and function in the brain of domestic birds. Front. Endocrinol. 2:37. doi: 10.3389/fendo.2011.00037

Tsutsui, K., and Ukena, K. (1999). Neurosteroids in the cerebellar Purkinje neuron and their actions (review). Int. J. Mol. Med. 4, 49-56. doi: 10.3892/ijmm.4.1.49

Tsutsui, K., and Yamazaki, T. (1995). Avian neurosteroids. I. Pregnenolone biosynthesis in the quail brain. Brain Res. 678, 1-9. doi: 10.1016/0006-8993(95)00116-8

Tsutsui, K., Haraguchi, S., Inoue, K., Miyabara, H., Suzuki, S., Ogura, Y., et al. (2009). Identification, biosynthesis, and function of 7alphahydroxypregnenolone, a new key neurosteroid controlling locomotor activity, in nonmammalian vertebrates. Ann. N. Y. Acad. Sci. 1163, 308-315. doi: 10.1111/j.1749-6632.2009.04426.x

Tsutsui, K., Matsunaga, M., Miyabara, H., and Ukena, K. (2006). Neurosteroid biosynthesis in the quail brain: a review. J. Exp. Zool. A Comp. Exp. Biol. 305, 733-742. doi: 10.1002/jez.a.302

Tsutsui, K., Ukena, K., Takase, M., Kohchi, C., and Lea, R. W. (1999). Neurosteroid biosynthesis in vertebrate brains. Comp. Biochem. Physiol. C Pharmacol. Toxicol. Endocrinol. 124, 121-129. doi: 10.1016/S0742-8413(99)00065-1

Ukena, K., Honda, Y., Inai, Y., Kohchi, C., Lea, R. W., and Tsutsui, K. (1999). Expression and activity of 3beta-hydroxysteroid dehydrogenase/Delta5Delta4-isomerase in different regions of the avian brain. Brain Res. 818, 536-542. doi: 10.1016/S0006-8993(98)01296-7

Vance, J. E., and Hayashi, H. (2010). Formation and function of apolipoprotein E-containing lipoproteins in the nervous system. Biochim. Biophys. Acta 1801, 806-818. doi: 10.1016/j.bbalip.2010.02.007

Vitali, C., Wellington, C. L., and Calabresi, L. (2014). HDL and cholesterol handling in the brain. Cardiovasc. Res. 103, 405-413. doi: 10.1093/cvr/cvul48 
Wakai, S., and Hirokawa, N. (1978). Development of the blood-brain barrier to horseradish peroxidase in the chick embryo. Cell Tissue Res. 195, 195-203. doi: 10.1007/BF00236719

Wang, C., Liu, D., Chen, W., Ge, W., Hong, W., Zhu, Y., et al. (2016). Progestin increases the expression of gonadotropins in pituitaries of male zebrafish. J. Endocrinol. 230, 143-156. doi: 10.1530/JOE-16-0073

Wang, L., Andersson, S., Warner, M., and Gustafsson, J. A. (2003). Estrogen receptor (ER)beta knockout mice reveal a role for ERbeta in migration of cortical neurons in the developing brain. Proc. Natl. Acad. Sci. U.S.A. 100, 703-708. doi: 10.1073/pnas.242735799

Waters, E. M., Thompson, L. I., Patel, P., Gonzales, A. D., Ye, H. Z., Filardo, E. J., et al. (2015). G-protein-coupled estrogen receptor 1 is anatomically positioned to modulate synaptic plasticity in the mouse hippocampus. J. Neurosci. 35, 2384-2397. doi: 10.1523/JNEUROSCI.1298-14.2015

Watson, J. T., and Adkins-Regan, E. (1989a). Testosterone implanted in the preoptic area of male Japanese quail must be aromatized to activate copulation. Horm. Behav. 23, 432-447. doi: 10.1016/0018-506X(89)90055-X

Watson, J. T., and Adkins-Regan, E. (1989b). Activation of sexual behavior by implantation of testosterone propionate and estradiol benzoate into the preoptic area of the male Japanese quail (Coturnix japonica). Horm. Behav. 23, 251-268. doi: 10.1016/0018-506X(89)90065-2

Weger, M., Diotel, N., Weger, B. D., Beil, T., Zaucker, A., Eachus, H. L., et al. (accepted). Expression profiling of the steroidogenic enzymes of glucocorticoid biosynthesis and the fdx1 co-factors in zebrafish. J. Neuroendocrinol.

Weidenfeld, J., Siegel, R. A., and Chowers, I. (1980). In vitro conversion of pregnenolone to progesterone by discrete brain areas of the male rat. J. Steroid Biochem. 13, 961-963. doi: 10.1016/0022-4731(80)90171-5

Weissman, T., Noctor, S. C., Clinton, B. K., Honig, L. S., and Kriegstein, A. R. (2003). Neurogenic radial glial cells in reptile, rodent and human: from mitosis to migration. Cereb. Cortex 13, 550-559. doi: 10.1093/cercor/13.6.550

Witt, K. A., and Sandoval, K. E. (2014). Steroids and the blood-brain barrier: therapeutic implications. Adv. Pharmacol. 71, 361-390. doi: 10.1016/bs.apha.2014.06.018

Xia, Z., Patiño, R., Gale, W. L., Maule, A. G., and Densmore, L. D. (1999). Cloning, in vitro expression, and novel phylogenetic classification of a channel catfish estrogen receptor. Gen. Comp. Endocrinol. 113, 360-368. doi: 10.1006/gcen.1999.7196

Xiao, H., Deng, M., Yang, B., Hu, Z., and Tang, J. (2017). Pre-treatment of 17betaestradiol Attenuates cerebral-ischemia-induced blood-brain barrier disruption in aged rats: involvement of antioxidant signaling. Neuroendocrinology. doi: $10.1159 / 000455866$

Xing, L., Esau, C., and Trudeau, V. L. (2015). Direct regulation of aromatase B expression by 17beta-estradiol and dopamine D1 receptor agonist in adult radial glial cells. Front. Neurosci. 9:504. doi: 10.3389/fnins.2015.00310

Xing, L., Goswami, M., and Trudeau, V. L. (2014). Radial glial cell: critical functions and new perspective as a steroid synthetic cell. Gen. Comp. Endocrinol. 203, 181-185. doi: 10.1016/j.ygcen.2014.03.010

Xing, L., Martyniuk, C. J., Esau, C., Da Fonte, D. F., and Trudeau, V. L. (2016). Proteomic profiling reveals dopaminergic regulation of progenitor cell functions of goldfish radial glial cells in vitro. J. Proteomics 144, 123-132. doi: 10.1016/j.jprot.2016.05.003

Yague, J. G., Muñoz, A., de Monasterio-Schrader, P., Defelipe, J. Garcia-Segura, L. M., and Azcoitia, I. (2006). Aromatase expression in the human temporal cortex. Neuroscience 138, 389-401. doi: 10.1016/j.neuroscience.2005.11.054
Yu, L., Romero, D. G., Gomez-Sanchez, C. E., and Gomez-Sanchez, E. P. (2002). Steroidogenic enzyme gene expression in the human brain. Mol. Cell. Endocrinol. 190, 9-17. doi: 10.1016/S0303-7207(02)00041-2

Zempo, B., Kanda, S., Okubo, K., Akazome, Y., and Oka, Y. (2013). Anatomical distribution of sex steroid hormone receptors in the brain of female medaka. J. Comp. Neurol. 521, 1760-1780. doi: 10.1002/cne.23255

Zhang, J., and Liu, Q. (2015). Cholesterol metabolism and homeostasis in the brain. Protein Cell 6, 254-264. doi: 10.1007/s13238-014-0131-3

Zhang, P., Xie, M. Q., Ding, Y. Q., Liao, M., Qi, S. S., Chen, S. X., et al. (2015). Allopregnanolone enhances the neurogenesis of midbrain dopaminergic neurons in APPswe/PSEN1 mice. Neuroscience 290, 214-226. doi: 10.1016/j.neuroscience.2015.01.019

Zhang, W., Cheng, J., Vagnerova, K., Ivashkova, Y., Young, J., Cornea, A., et al. (2014). Effects of androgens on early post-ischemic neurogenesis in mice. Transl. Stroke Res. 5, 301-311. doi: 10.1007/s12975-013-0298-6

Zhang, Y., Wang, H., Qin, F., Liu, S., Wu, T., Li, M., et al. (2012). Molecular characterization of estrogen receptor genes in loach Paramisgurnus dabryanus and their expression upon 17alpha-ethinylestradiol exposure in juveniles. Gen. Comp. Endocrinol. 178, 194-205. doi: 10.1016/j.ygcen.2012. 06.004

Zhang, Z., Yang, R., Zhou, R., Li, L., Sokabe, M., and Chen, L. (2010). Progesterone promotes the survival of newborn neurons in the dentate gyrus of adult male mice. Hippocampus 20, 402-412. doi: 10.1002/hipo.20642

Zhao, Y., Wang, J., Liu, C., Jiang, C., Zhao, C., and Zhu, Z. (2011). Progesterone influences postischemic synaptogenesis in the CA1 region of the hippocampus in rats. Synapse 65, 880-891. doi: 10.1002/syn.20915

Zhu, Y., Bond, J., and Thomas, P. (2003). Identification, classification, and partial characterization of genes in humans and other vertebrates homologous to a fish membrane progestin receptor. Proc. Natl. Acad. Sci. U.S.A. 100, 2237-2242. doi: 10.1073/pnas.0436133100

Zhu, Y., Liu, D., Shaner, Z. C., Chen, S., Hong, W., and Stellwag, E. J. (2015). Nuclear progestin receptor (pgr) knockouts in zebrafish demonstrate role for pgr in ovulation but not in rapid non-genomic steroid mediated meiosis resumption. Front. Endocrinol. 6:37. doi: 10.3389/fendo.2015. 00037

Zuloaga, D. G., Yahn, S. L., Pang, Y., Quihuis, A. M., Oyola, M. G., Reyna, A., et al. (2012). Distribution and estrogen regulation of membrane progesterone receptor-beta in the female rat brain. Endocrinology 153, 4432-4443. doi: 10.1210/en.2012-1469

Zwain, I. H., and Yen, S. S. (1999). Neurosteroidogenesis in astrocytes, oligodendrocytes, and neurons of cerebral cortex of rat brain. Endocrinology 140, 3843-3852. doi: 10.1210/endo.140.8.6907

Conflict of Interest Statement: The authors declare that the research was conducted in the absence of any commercial or financial relationships that could be construed as a potential conflict of interest.

Copyright (c) 2018 Diotel, Charlier, Lefebvre d'Hellencourt, Couret, Trudeau, Nicolau, Meilhac, Kah and Pellegrini. This is an open-access article distributed under the terms of the Creative Commons Attribution License (CC BY). The use, distribution or reproduction in other forums is permitted, provided the original author(s) and the copyright owner are credited and that the original publication in this journal is cited, in accordance with accepted academic practice. No use, distribution or reproduction is permitted which does not comply with these terms. 